Universidade De SÃo PaUlo

Faculdade de Filosofia, Ciências e letras de Ribeirão Preto Pós-GraduaÇÃo em Física Aplicada à Medicina e Biologia

\title{
Reconhecimento de Padrões Usando uma Rede Neural Pulsada Inspirada no Bulbo Olfatório
}

Versão Corrigida

Lucas Baggio Figueira

Ribeirão Preto - SP

2011 


\section{LUCAS BAGGIO FIGUEIRA}

\section{Reconhecimento de Padrões Usando uma Rede Neural Pulsada Inspirada no Bulbo Olfatório}

Tese apresentada à Faculdade de Filosofia, Ciências e Letras de Ribeirão Preto da Universidade de São Paulo, como parte das exigências para a obtenção do título de Doutor em Ciências

Área de Concentração:

Física Aplicada à Medicina e Biologia

Orientador:

Prof. Dr. Antonio Carlos Roque da Silva Filho

Ribeirão Preto - SP 
AUTORIZO A REPRODUÇÃO E DIVULGAÇÃO TOTAL OU PARCIAL DESTE TRABALHO, POR QUALQUER MEIO CONVENCIONAL OU ELETRÔNICO, PARA FINS DE ESTUdo E PESQUiSA, DESDE QUE CITADA A FONTE.

Figueira, Lucas Baggio.

Reconhecimento de Padrões Usando uma Rede Neural Pulsada Inspirada no Bulbo Olfatório/ Lucas Baggio Figueira; orientador Prof. Dr. Antonio Carlos Roque da Silva Filho. Ribeirão Preto, 2011. 146 p.

Tese (Doutorado - Programa de Pós-Graduação em Física Aplicada à Medicina e Biologia) - Faculdade de Filosofia, Ciências e Letras de Ribeirão Preto da Universidade de São Paulo.

1. Bulbo Olfatório, 2. Redes Neurais Pulsadas, 3. Aprendizado de Máquina, 4. Reconhecimento de Padrões 
Nome: Figueira, Lucas Baggio

Título: Reconhecimento de Padrões Usando uma Rede Neural Pulsada Inspirada no Bulbo Olfatório

Tese apresentada à Faculdade de Filosofia, Ciências e Letras de Ribeirão Preto da Universidade de São Paulo, como parte das exigências para a obtenção do título de Doutor em Ciências.

Aprovado em:

\section{Banca Examinadora}

Prof. Dr. :

Julgamento:

Prof. Dr. :

Julgamento:

Prof. Dr. :

Julgamento:

Prof. Dr. :

Julgamento:

Prof. Dr. :

Julgamento:
Instituição:

Assinatura:

Instituição:

Assinatura:

Instituição:

Assinatura:

Instituição:

Assinatura:

Instituição:

Assinatura: 
À minha amada Junia Figueira. 


\section{AGRADECIMENTOS}

Agradeço primeiramente à Deus, que me deu força, inteligência e sabedoria.

Ao meu orientador, Prof. Dr. Antonio Carlos Roque, não apenas pela orientação, mas pela amizade e sobretudo pela paciência que demostrou ter, não sendo apenas um orientador, mas um educador.

À Junia, minha esposa, que esteve, e está, sempre ao meu lado me amando. Não preciso dizer mais nada, só ela sabe as todas as delícias e dores que passei até aqui.

Aos meus pais, Washington e Conceição, pela certeza que sempre tiveram em seus corações de que eu chegaria aqui, por isso não pouparam esforços de qualquer natureza para me apoiar, eu amo vocês.

Ao meu irmão, Rodrigo (Brou), que mesmo estando um pouco longe sempre torceu por mim, e, nos momentos difíceis me ligava dizendo: Brou, isso vai passar, você vai conseguir, força.

Aos meus sobrinhos Beatriz e Miguel, que mesmo não entendendo ainda o que é uma tese de doutorado, já fizeram diferença por alegrar a vida do tio aqui.

Aos demais familiares da minha parte e da parte da minha esposa pela convivência amável e pacífica.

Aos meus amiguinhos, Pedro e Milena, Roger e Priscila, pela amizade que se iniciou de maneira despretenciosa na banda, e se tornou algo pra sempre no meu coração. Obrigado pelo apoio, fé e incentivo.

Aos meus amigos de laboratório Diogo, Denise, Julian, Misael, Rafael e André, pela convivência agradável, e pela ajuda dispensada quando precisei.

Aos meus chefes Prof. Edson e Prof. Guilherme pela paciência e compreensão nos momentos críticos para o término dessa tese.

À todos os meu amigos que não cito nominalmente aqui, mas fizeram parte da minha trajetória e de quem eu sou. 
Ao Programa de Pós-graduação em Física Aplicada à Medicina e Biologia. 
"Então um dia você se dá conta que se passaram dez anos ..."

Time

(Mason, Waters, Wright, Gilmour)

Dark Side of The Moon - 1973 


\section{RESUMO}

FIGUEIRA, L. B. Reconhecimento de Padrões Usando uma Rede Neural Pulsada Inspirada no Bulbo Olfatório. 146 p. Tese (Doutorado) - Faculdade de Filosofia, Ciências e Letras de Ribeirão Preto, Universidade de São Paulo, Ribeirão Preto, 2011.

O sistema olfatório é notável por sua capacidade de discriminar odores muito similares, mesmo que estejam misturados. Essa capacidade de discriminação é, em parte, devida a padrões de atividade espaço-temporais gerados nas células mitrais, as células principais do bulbo olfatório, durante a apresentação de um odor. Tais padrões dinâmicos decorrem de interações sinápticas recíprocas entre as células mitrais e interneurônios inibitórios do bulbo olfatório, por exemplo, as células granulares. Nesta tese, apresenta-se um modelo do bulbo olfatório baseado em modelos pulsados das células mitrais e granulares e avalia-se o seu desempenho como sistema reconhecedor de padrões usando-se bases de dados de padrões artificiais e reais. Os resultados dos testes mostram que o modelo possui a capacidade de separar padrões em diferentes classes. Essa capacidade pode ser explorada na construção de sistemas reconhecedores de padrões. Apresenta-se também a ferramenta denominada Nemos, desenvolvida para a implementação do modelo, que é uma plataforma para simulação de neurônios e redes de neurônios pulsados com interface gráfica amigável com o usuário.

Palavras-chave: 1. Bulbo Olfatório, 2. Redes Neurais Pulsadas, 3. Aprendizado de Máquina, 4. Reconhecimento de Padrões 


\section{ABSTRACT}

FIGUEIRA, L. B. Pattern Reconigtion Using Spiking Neuron Networks Inspired on Olfactory Bulb. 146 p. Thesis (Ph.D.) - Faculdade de Filosofia, Ciências e Letras de Ribeirão Preto, Universidade de São Paulo, Ribeirão Preto, 2011.

The olfactory system is a remarkable system capable of discriminating very similar odorant mixtures. This is in part achieved via spatio-temporal activity patterns generated in mitral cells, the principal cells of the olfactory bulb, during odor presentation. Here, we present a spiking neural network model of the olfactory bulb and evaluate its performance as a pattern recognition system with datasets taken from both artificial and real pattern databases. Our results show that the dynamic activity patterns produced in the mitral cells of the olfactory bulb model by pattern attributes presented to it have a pattern separation capability. This capability can be explored in the construction of high-performance pattern recognition systems. Besides, we proposed Nemos a framework for simulation spiking neural networks through graphical user interface and has extensible models for neurons, synapses and networks.

Key-words: 1. Olfactory Bulb, 2. Spiking Neuron Networks, 3. Machine Learning, 4. Pattern Recongnition 


\section{LISTA DE FIGURAS}

2.1 Esquema genérico de um neurônio, composto por dendritos, soma e axonio, realizando sinapses químicas com seus pares. . . . . . . . 10

2.2 Principais abordagens utilizadas na modelagem de neurônios. A figura da esquerda ilustra a modelagem iônica, de maior correpondência biofísica e a figura da direita ilustra a modelagem simplificada, de menor custo computacional. . . . . . . . . . . . . . . 12

2.3 Circuito Elétrico Equivalente à Membrana para o Modelo de HodgkinHuxley. . . . . . . . . . . . . . . . . . . . . 13

2.4 (a) Simulação de um potencial de ação gerado pela injeção de uma densidade de corrente externa constante de $5 \mathrm{nA} / \mathrm{cm}^{2}$. (b) Comportamento ao longo do tempo das variáveis $m, n$ e $h . \ldots 16$

2.5 Modelo Integra-e-Dispara, (a) Circuito RC correspondente à equação do modelo IF. (b) Comportamento temporal da voltagem para o modelo integra-e-dispara. Se o voltímetro indicar o potencial $V t h \mathrm{um}$ disparo ocorre e a voltagem é retornada a $V_{r} \ldots \ldots \ldots$

2.6 Resposta do modelo de FitzHugh-Nagumo, (a) e (c), a dois valores de estímulos, e suas respectivas trajetórias no espaço de fases do modelo, (b) e (d) . . . . . . . . . . . . . . . . . . . 21

2.7 Quatro tipos de bifurcação, a saber: (a) nó-sela, (b) nó-sela sobre ciclo invariante, (c) Hopf subcrítica e (d) Hopf supercrítica. . . . . . . 22

2.8 Espaço de fases do modelo de Izhikevich (a) e uma aproximação visual (b) do destaque em amarelo. . . . . . . . . . . . . . . . 24

2.9 Diferentes tipos de comportamento de disparo do modelo de Izhikevich obtidos por alteração dos parâmetros do modelo. . . . . . . . . 25

2.10 Funções $\alpha$ para os receptores sinápticos GABA, AMPA e NMDA. . 27 
2.11 Esquema do padrão de conexões entre o epitélio olfatório e o bulbo olfatório. O epitélio é dividido em quatro zonas (I, II, III e IV) e os tipos de neurônios receptores que estão em uma zona não são encontrados em outras zonas. Os neurônios receptores de uma dada zona do epitélio enviam projeções para glomérulos da zona correspondente (I, II, III e IV) no bulbo olfatório. Os axônios dos neurônios receptores que expressam o mesmo receptor de características moleculares (em preto ou cinza na figura) convergem para um único glomérulo específico no bulbo olfatório. Figura baseada na Figura 2 de [Mori, Nagao e Yoshihara 1999].

2.12 Esquema do padrão de conexões sinápticas no bulbo olfatório. Os dendritos primários dos neurônios mitrais (M) e tufosos ( $\mathrm{T}$ ) recebem sinapses excitatórias (indicadas por setas brancas) dos axônios dos neurônios receptores olfatórios nos glomérulos (GL). Existem dois tipos de interneurônios que fazem sinapses inibitórias (setas escuras) nos neurônios m/t - os neurônios periglomerulares (PG) e os neurônios granulares (Gr). Os primeiros fazem sinapses com os dendritos primários dos neurônios $\mathrm{m} / \mathrm{t}$ e os segundos fazem sinapses com os dendritos secundários desses neurônios, que se estendem horizontalmente por longas distancias. Os neurônios de saída do bulbo são os neurônios $\mathrm{m} / \mathrm{t} . \ldots \ldots \ldots$. . . . . . . . . . . . . 30

3.1 Pseudo-código de uma Simulação Síncrona. . . . . . . . . . . . . . . . 35

3.2 Pacotes nos quais se dividem os principais itens do Nemos de acordo com sua funcionalidade. . . . . . . . . . . . . . . . . 36

3.3 Diagrama de classes representando o kernel do Nemos. . . . . . . . . 37

3.4 Diagrama de classes representando as funções matemáticas disponíveis no Nemos, bem como as classes contendo as técnicas de integração para as equações diferenciais. . . . . . . . . . . . . . . . 39 
3.5 Diagrama de classes representando os modelos de neurônios disponíveis no Nemos. Os modelos seguem uma hierarquia, onde os modelos mais altos são mais gerais e servem de base para os modelos com propósitos mais específicos. . . . . . . . . . . . . . . . . . . . . . . . 40

3.6 Espaco euclidiano 3D utilizado pelo Nemos, onde as esferas indicam os neurônios.

3.7 Resultado da simulação do Algoritmo 3.1. A primeira janela é a parte de interação visual do Nemos, a segunda representa os estímulos de corrente e a terceira mostra as respostas dos neurônios aos estímulos. A cor em ambas as janelas faz o par estímulo-potencial. . . . . . . . . . 44

3.8 Resultado da simulação do Algoritmo 3.2. (a) Estímulos de corrente. (b) Respostas de dois neurônios de Izhikevich aos estímulos em (a). A mesma cor é usada para um estímulo e a resposta do neurônio que o recebe. (c) Correntes sinápticas referentes a sinapses excitatórias feitas pelos neurônios em (b) em um terceiro neurônio de Izhikevich. (d) Resposta do neurônio de Izhikevich que recebe as entradas sinápticas mostradas em (c) . . . . . . . . . . . . . . . . . . . 46

3.9 Resultado da simulação do Algoritmo 3.3. A janela superior mostra a disposição tridimensional dos neurônios e a janela inferior mostra o rasterplot da rede simulada. . . . . . . . . . . . . . . . . . . 48

3.10 Desempenho do Nemos em relação ao Nest para simulações de quatro modelos de neurônios. Valores positivos indicam que o Nemos apresentou melhor desempenho. . . . . . . . . . . . . . 50

3.11 Desempenho do Nemos em relação ao Nest em simulações onde variase a quantidade de sinapses conectadas ao modelo de Izhikevich. . . . 51

3.12 Desempenho do Nemos em relação ao Nest para simulações de redes com número variável de neurônios de Izhikevich. . . . . . . . . . . . . 52

4.1 Arquitetura básica do sistema computacional desenvolvido nesta tese, onde $i(\cdot)$ corresponde à entrada para o bulbo olfatório, que produz um fluxo contínuo de informação $x(t)$ que é lido e identificado pelo leitor de saída gerando assim uma saída $y(t) \ldots \ldots . . . . . . .54$ 
4.2 Potenciais de membrana do modelo de célula mitral bi-estável em resposta a diferentes tipos de estímulos. (a) Transição entre os estados de respouso downstate e upstate. (b) Comportamento de ressonador do estado upstate quando excitado de forma sublimiar. (c) Geração de potencial de ação a partir do estado upstate. (d) Geração de potenciais de ação a partir do estado downstate. . . . . . . . . . . . . 57

4.3 Diagrama do espaço de fases do modelo de célula mitral bi-estável das equações 4.1, mostrando diversas trajetórias possíveis. Os pontos escuros indicam os pontos fixos estáveis e os pontos claros indicam a os pontos fixos instáveis. . . . . . . . . . . . . . . . . . 58

4.4 Diagrama do espaço de fases referente ao modelo da célula mitral não bi-estável. Os pontos escuros indicam os pontos fixos estáveis e os pontos claros indicam a os pontos fixos instáveis. . . . . . . . . . 58

4.5 Potenciais de membrana do modelo não bi-estável em resposta a diferentes tipos de estímulos. (a) Geração de um potencial seguida de uma inibição por estímulo direto. (b) Comportamento sublimiar de tipo ressonador exibido pelo modelo não-biestável. (c) Geração de potenciais de ação a partir de dois estímulos diferentes em duração e intensidade. (d) Geração de uma sequência de potenciais de ação. . 59

4.6 Curva FI do modelo compartimental de [Migliore e Shepherd 2008] para a célula granular. . . . . . . . . . . . . . . . 6 61

4.7 Potencial de membrana do modelo compartimental de [Migliore e Shepherd 2008] para a célula granular em resposta a diferentes estímulos $(0.05,0.07$, $0.09,0.11 \mathrm{nA}$ ). A coluna da esquerda mostra os resultados para o modelo com canais de $K D R$ e a coluna da direita mostra os resultados para o modelo sem canais de KDR . . . . . . . . . . . . . . 62

4.8 Potencial de membrana (coluna da esquerda) e seu respectivo espaço de fases (coluna da direita) do modelo simplificado de célula granular em resposta a diferentes valores de corrente injetada: (a) $I=27 p A$, (b) $I=32 p A$ (reobase) e (C) $I=45 p A \ldots \ldots$. . . . . . . 63 
4.9 Padrão de disparos do modelo compartimental de [Migliore e Shepherd 2008] (coluna da esquerda) e do modelo simplificado (coluna direita) para diferentes estímulos (correntes injetadas). . . . . . . . . . . . . . 64

4.10 Valores do parâmetro $a$ do modelo simplificado da célula granular ajustados para diferentes valores de corrente injetada (pontos). A curva contínua corresponde a um ajuste cúbico para os pontos. . . . . 65

4.11 Curvas FI dos modelos compartimental de [Migliore e Shepherd 2008] e simplificado para a célula granular.

4.12 Disposição espacial das células mitrais e granulares no modelo simplificado do bulbo olfatório. A conectividade entre mitrais e granulares é determinada pela equação 4.3 usando a distância euclidiana $D(m, g)$ entre mitrais e granulares. . . . . . . . . . . . . . . . . . 66

4.13 Efeitos da equação 4.4 na sinapse. (a) Depressão sináptica e (b) facilitação sináptica, ambos em resposta a disparos regulares. . . . . . 68

4.14 Sequência de disparos geradas pelo algoritmo 4.1 a partir do vetor indicado no título do gráfico. Cada valor está também indicado ao lado do eixo-y de sua respectiva sequência e o eixo-x representa o tempo em ms. . . . . . . . . . . . . . . . . . . . . . 70

5.1 Resposta do modelo do bulbo, para diferentes combinações dos parâmetros $\lambda$ e $A$, a estímulos poissonianos co diferentes frequências $(5 \mathrm{~Hz}$, $25 \mathrm{~Hz}$ e $50 \mathrm{~Hz}$ ), na presença de sinapses dinâmicas (linha superior) e na ausência de sinapses dinâmicas (linha inferior). . . . . . . . . . 78

5.2 Separabilidade das células (a) mitrais e (b) granulares isoladas para pares de entradas com diferentes graus de correlação. . . . . . . . . . 80

5.3 Gráficos de distância entre os estados $x_{a}(t)$ e $x_{b}(t)$ gerados por modelos de bulbos com diferentes valores dos parâmetros $A$ e $\lambda$ (mostrados nos cabeçalhos de cada gráfico) em resposta a pares de padrões $a$ e $b$ com diferentes graus de correlação entre eles (mostrados no retângulo superior direito (inset e codificados por cores diferentes) . . . . . . . . 81 
5.4 Rasterplot do modelo bulbo com parâmetros $\lambda=2,0, W A=2,0$, mostrando atividade oscilatória. Os índices de 0 a 100 representam as células mitrais e os índices acima de 100 representam as células granulares. . . . . . . . . . . . . . . . . . . 82

5.5 Gráficos de distância entre os estados $x_{a}(t)$ e $x_{b}(t)$ gerados por modelos de bulbos com diferentes valores dos parâmetros $A$ e $\lambda$ (mostrados nos cabeçalhos de cada gráfico) em resposta a pares de padrões $a$ e $b$ constantes com diferentes graus de correlação entre eles (mostrados no retângulo superior direito (inset e codificados por cores diferentes). 83

5.6 Nova entrada gerada a partir da combinação de segmentos dos templates 1 e 2 (ver texto para maiores detalhes). . . . . . . . . . . . . . 84

5.7 Desempenho apresentado pelos leitores de saída na identificação de cada um dos segmentos, gráficos de (a) a (d). As cores representam os diferentes valores de $A$, e o eixo-x especifica os valores de $\lambda$. . . . 85

5.8 Desempenho do sistema computacional (vermelho) e do perceptron paralelo isolado (cinza) para os domínios de conhecimento indicados no eixo-x. . . . . . . . . . . . . . . . . . 87

5.9 Desempenho do sistema computacional para entradas de cinco difrentes domínios codificadas na forma de trens de disparo. As barras vermelhas indicam o caso sem pré-entrada ruidosa e as barras verdes indicam o caso com pré-entrada ruidosa. . . . . . . . . . . . . . 88

5.10 Esquema de treinamento e teste para o problema de classificação de imagens usando análise de componentes principais e o sistema computacional proposto. Os componentes principais selecionados podem ou não ser transformados em sequências (trens) de disparo. . . . . . . 89

5.11 Desempenho de classificação para o domínio Faces. A primeira barra indica o desempenho do perceptron paralelo isolado e as outras três apresentam o desempenho do sistema com diferentes formas de codificação de entradas. . . . . . . . . . . . . . . . . . . . . . . . 90 90

5.12 Desempenho do sistema computacional na classificação de instâncias com $40 \%$ de atributos ausentes. . . . . . . . . . . . . . . . . 91 


\section{LISTA DE TABELAS}

2.1 Parâmetros para as variáveis $n, m$ e $h \ldots \ldots \ldots$

2.2 Parâmetros $g$ e $E$ para Na, K e vaz. . . . . . . . . . . . . . . 15

4.1 Parâmetros do modelo simplificado da célula granular. . . . . . . . . 64

5.1 Distribuição de Classes - Domínio Iris . . . . . . . . . . . . . . . 74

5.2 Distribuição de Classes - Domínio Breast Cancer . . . . . . . . . . . 74

5.3 Distribuição de Classes - Domínio Heart Disease . . . . . . . . . . . . 75

5.4 Distribuição de Classes - Domínio Parkinson Disease . . . . . . . . . 75

5.5 Distribuição de Classes - Domínio Faces . . . . . . . . . . . . . . . . 75

5.6 Distribuição de Classes - Domínios A e B . . . . . . . . . . . 76

5.7 Parâmetros sinápticos usados entre as células mitrais (m) e granulares (g), onde a seta indica o sentido da sinapse. . . . . . . . . . . 76 


\section{SUMÁRIO}

Lista de Figuras $\quad$ x

Lista de Tabelas $\quad$ xvi

1 Introdução 3

1.1 Introdução . . . . . . . . . . . . . . . . . . . . 3

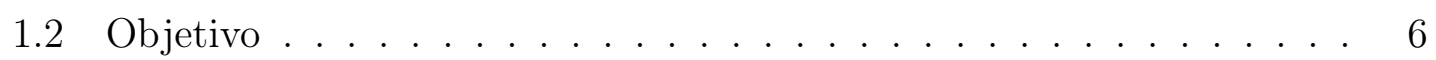

1.3 Organização do Trabalho . . . . . . . . . . . . . . . . 6

2 Revisão Bibliográfica $\quad 8$

2.1 Considerações Iniciais . . . . . . . . . . . . . . . . . . . 8

2.2 Neurônios e Sinapses . . . . . . . . . . . . . . . . . . . . 8

2.3 Modelagem de Neurônios Pulsados e Sinapses . . . . . . . . . . . . . 10

2.3 .1 Modelagem Iônica . . . . . . . . . . . . . . . 12

2.3.2 Modelagem Simplificada . . . . . . . . . . . . . 17

2.3.3 Modelagem de Sinapses . . . . . . . . . . . . . . . . . . 24

2.4 Redes Neurais Pulsadas . . . . . . . . . . . . . . . 26

2.5 Bulbo Olfatório . . . . . . . . . . . . . . . . . . . . . 28

2.6 Consideraçõs Finais . . . . . . . . . . . . . . . . . . . . . . 32

3 Nemos: Neuron Models Simulation System 33

3.1 Considerações Iniciais . . . . . . . . . . . . . . . . . . . . . . 33

3.2 Estratégias de Simulação . . . . . . . . . . . . . . . . . . . 34

3.3 Arquitetura Básica do Nemos . . . . . . . . . . . . . . . 35

3.3 .1 Métodos de Integração . . . . . . . . . . . . . . . . . 38

3.4 Modelos de Neurônios e Sinapses . . . . . . . . . . . . . . . . . 38 
3.5 Redes de Neurônios . . . . . . . . . . . . . . . . . . . . . . . . . . . . 40

3.6 Usando o Nemos . . . . . . . . . . . . . . . . . . . . . . . . . . . 41

3.7 Testes e Comparações . . . . . . . . . . . . . . . . . . 47

3.8 Considerações Finais . . . . . . . . . . . . . . . . . . . . . . 50

4 Sistema Computacional Inspirado no Bulbo Olfatório 53

4.1 Considerações Iniciais . . . . . . . . . . . . . . . . . . . 53

4.2 Arquitetura do Sistema . . . . . . . . . . . . . . . . . 53

4.3 Modelagem do Bulbo Olfatório . . . . . . . . . . . . . . 54

4.3.1 Modelo da Célula Mitral . . . . . . . . . . . . . . 56

4.3 .2 Célula Granular . . . . . . . . . . . . . . . . . . . . . . . 59

4.3 .3 Conectividade . . . . . . . . . . . . . . 63

4.4 Codificação das Entradas . . . . . . . . . . . . . . . . . . . . . 68

4.5 Parallel Perceptron como Leitor de Saída . . . . . . . . . . . . . . . . 69

4.6 Considerações Finais . . . . . . . . . . . . . . . . . . . . . . 72

5 Experimentos e Testes $\quad 73$

5.1 Considerações Iniciais . . . . . . . . . . . . . . . . . . . 73

5.2 Metodologia e Protocolos . . . . . . . . . . . . . . . . 73

5.2.1 Bases de Dados . . . . . . . . . . . . . . . 73

5.2.2 Pararâmetros Default . . . . . . . . . . . . 76

5.2.3 Metodologia de Testes e Experimentos . . . . . . . . . . . 77

5.3 Análise de Comportamento de Frequência . . . . . . . . . . . . . . . 77

5.4 Separabilidade do Sistema . . . . . . . . . . . . . . . . . 78

5.5 Memória do Modelo . . . . . . . . . . . . . . . . . . . . . . . . . 82

5.6 Reconhecimento de Padrões . . . . . . . . . . . . . . . . . . 86

5.7 Considerações Finais . . . . . . . . . . . . . . . . . . . . . . . . . . . 90

6 Conclusão $\quad 92$

$\begin{array}{ll}\text { Referências Bibliográficas } & 96\end{array}$

$\begin{array}{ll}\text { A Código do Modelo do Bulbo no Nemos } & 107\end{array}$ 


\section{CAPÍtulo}

1

\section{INTRODUÇÃO}

\subsection{Introdução}

O desenvolvimento de sistemas computacionais envolvendo técnicas de aprendizado de máquina (AM) para reconhecimento e classificação de padrões tem sido muito importante para a evolução de diversas áreas (medicina, engenharia, finanças, etc). Uma das principais razões para a utilização de AM é a de que vários domínios de aplicação possuem natureza incerta, imprecisa e dinâmica, como, por exemplo, o conhecimento médico [Meunier e Bouchon 2000]. Nas suas aplicações, e em domínios desses tipos, tais técnicas devem apresentar capacidade de representar, codificar e processar diversos elementos que possam auxiliar na tomada de decisões.

Várias técnicas foram desenvolvidas e apresentadas para ser usadas em sistemas de cognição dinâmica, entre elas, podemos citar, regras de produção, indução de árvores de decisão [Quinlan 1986], raciocínio baseado em casos, redes neurais [Haykin 1998, Principe, CurtLefebvre e Euliano 2000], algoritmos genéticos [Mitchell 1998], lógica nebulosa [Zadeh 1965], entre outros. A partir dessas técnicas, vários sistemas para reconhecimento de padrões e auxílio a tomada de decisões foram desenvolvidos incluindo desde sistemas de amplo escopo até sistemas voltados para domínios específicos (apenas para ficar nas aplicações em medicina pode-se consultar, por exemplo, as referências citadas em [Adlassnig et al. 1985, Szolovits 1982, Miller et al. 1986],[Barnett et al. 1987, David, Krivine e Simmons 1993, Miller e Geissbuhler 1999], e

[Silva 2000, Musen, Shahar e Shortliffe 2001]).

A principal motivação para o uso de redes neurais artificiais para o desenvolvi- 
mento de sistemas de cognição dinâmica vem do fato de que elas procuram capturar alguns elementos do funcionamento do cérebro. O cérebro é um sistema altamente complexo e não-linear que possui capacidades notáveis de processamento de informação. O maior objetivo da computação neural é entender a organização interna do cérebro e os princípios funcionais por meio dos quais ele executa tarefas de processamento de informação, tendo assim em vista desenvolver sistemas neurais artificiais capazes de desempenhos semelhantes [Marr 1982].

A promessa implícita na abordagem da computação neural é a de que ela seria particularmente apropriada para a execução de atividades nas quais os seres vivos se destacam, como interagir satisfatoriamente com o ambiente. Não há como negar, a biologia já resolveu alguns dos desafios para os quais os engenheiros e cientistas ainda não ofereceram solução. Por causa disso pode ser vantajoso estudar os princípios utilizados pelos sistemas biológicos para construir sistemas artificiais [Dreyfus e Dreyfus 1986, Principe, CurtLefebvre e Euliano 2000]. A biologia encontrou um conjunto de princípios indutivos [Principe, CurtLefebvre e Euliano 2000] que são particularmente bem sintonizados para a interação com um ambiente complexo e imprevisível.

Esses princípios não são conhecidos de forma explícita, mas têm sido gradualmente desvendados pelos estudos em biologia e neurociência computacional [Koch e Segev 1999, Kandel, Schwartz e Jessell 2000, Dayan e Abbott 2001]. Eles envolvem a extração de características (informação) do mundo exterior a partir dos receptores sensoriais, a criação de representações dessa informação, a combinação e a composição de novos dados com informação armazenada de diferentes naturezas, o aprendizado a partir de dados e a tomada de decisão em situações de incerteza.

Os princípios enunciados acima devem estar presentes em todas as atividades humanas que envolvem cognição e tomadas de decisão. Inspirados e motivados por essa crença, diversos sistemas para reconhecimento de padrões baseados em redes neurais artificiais têm sido propostos [Bishop 1995, Duda e Hart 2000]. A maior parte dos modelos de redes neurais artificiais utilizados por esses sistemas são variantes do perceptron e sua extensão de multicamadas - o perceptron de multicamadas - e do mapa de auto-organização de Kohonen [Haykin 1998, Principe, CurtLefebvre e Euliano 2000]. Um dos motivos para isso, além do bom 
desempenho apresentado por essas redes neurais artificiais em aplicações, decorre do fato de que esses modelos de redes neurais artificiais podem ser contextualizados em termos da teoria estatística de reconhecimento e classificação de padrões [Bishop 1995, Duda e Hart 2000].

Apesar de bem sucedidos e teoricamente sedimentados em termos estatísticos, modelos tradicionais de redes neurais artificiais - tais como os supra citados - ainda estão distantes de concretizar o seu objetivo inspirador de reproduzir funções cerebrais de processamento de informação vinda de um ambiente incerto e variável no espaço e no tempo. Em virtude disso, diversos pesquisadores têm se voltado novamente para o cérebro em busca de novas idéias para o desenvolvimento de sistemas processadores de informação [Fujii et al. 1996, Buonomano e Merzenich 1999, Diesmann, Gewaltig e Aertsen 1999, Tsuda 2001, Maass, Natschläger e Markram 2002, Principe, Euliano e Garani 2002, Knüsel et al. 2004, Huerta et al. 2004, Ferrández e Mira 2009].

Dos vários sistemas processadores de informação existentes no cérebro, um dos mais interessantes é o sistema olfatório. O sistema olfatório é utilizado pelo cérebro para perceber misturas complexas de diferentes moléculas voláteis presentes no ar como entidades singulares, os odores, muitas vezes com fortes associações com memórias e emoções adquiridas ao longo da vida do indivíduo. Isso é feito de maneira distinta, única, em comparação com a maneira como os demais sistemas sensoriais processam estímulos. Em termos mais concretos, as saídas dos neurônios receptores olfatórios não passam pelo tálamo para chegar ao córtex, como ocorre com os demais sistemas sensoriais, mas vão diretamente para o bulbo olfatório, que é uma estrutura cortical [Kratskin e Belluzzi 2005].

Um padrão genérico pode ser representado por um conjunto de dados de diferentes naturezas, contínuos, discretos, nominais, categóricos, e a tarefa de um sistema de reconhecimento de padrões é atribuir ao padrão algum rótulo, ou valor de saída, único quando o padrão é apresentado em sua entrada, segundo algum tipo de processamento. Pode-se então pensar numa analogia entre o reconhecimento de padrões a partir de seus atributos e características (dados) e o reconhecimento (percepção) de um odor a partir das componentes físico-químicas de moléculas dispersas no ar. A tentativa de explorar essa analogia, ainda que de maneira preliminar, constitui a 
principal contribuição desta tese.

\subsection{Objetivo}

O objetivo desta tese foi construir um sistema computacional para reconhecimento de padrões inspirado no funcionamento do sistema olfatório. Em particular, a arquitetura do sistema foi baseada na arquitetura do bulbo olfatório que é considerado, do ponto de vista da neurobiologia, um sistema chave no processamento das informações olfatórias [Shepherd 2004]. Além da arquitetura, levou-se em consideração também as propriedades fisiológicas dos neurônios do bulbo olfatório. Isto foi feito usando (1) modelos pulsados para os neurônios considerados capazes de capturar as suas propriedades de disparo conforme registradas experimentalmente e (2) modelos de sinapses capazes de capturar propriedades dinâmicas de curta duração presentes nas sinapses biológicas.

\subsection{Organização do Trabalho}

A presente tese está organizada da seguinte maneira:

- no Capítulo 2 faremos uma revisão bibliográfica com o intuito de contextualizar os principais conceitos utilizados nessa tese, tais como: modelagem de neurônios e sinapses a partir da abordagem iônica e dos sistemas dinâmicos, seguido pelas redes neurais pulsadas, finalizando com uma apresentação sucinta sobre o funcionamento do bulbo olfatório.

- no Capítulo 3 apresentamos o Nemos como um framework para espeficicação de simulações neurais e desenvolvimento de modelos de neurônios e sinapses a partir do paradigma orientado à objetos. Além disso, mostramos suas funcionalidades e os resultados das comparações com outro framework conhecido.

- no Capítulo 4 mostramos os elementos necessários para a especificação do sistema computacional de reconhecimento de padrões, bem como o modo com que tais elementos foram usados na construção de tal sistema. 
- no Capítulo 5 executamos experimentos e testes com intuito de verificar a viabilidade do sistema computacional, ou seja, qual o nível de aplicabilidade que o mesmo apresenta, sendo assim testamos o sistema computacional em diversas situações que requerem classificação de instâncias nos mais variados domínios.

- no Capítulo 6 apresentamos os principais pontos que merecem destaque nessa tese, e comentamos os desdobramentos e trabalhos futuros. 


\section{Capítulo}

\section{REVISÃo BIBLIOGRÁFICA}

\subsection{Considerações Iniciais}

Com o intuito de contextualizar o leitor, faremos, neste capítulo, uma revisão dos principais conceitos envolvidos nesse trabalho. A revisão cobrirá os seguintes tópicos: elementos de anatomia e fisiologia de neurônios e sinapses; principais abordagens para a modelagem computacional de neurônios e sinapses; breve apresentação das redes neurais pulsadas; e, por último, descrição sucinta do bulbo olfatório de mamíferos.

\subsection{Neurônios e Sinapses}

O sistema nervoso é composto por diferentes tipos de células, mas aquelas consideradas como básicas do ponto de vista funcional são os neurônios. De maneira geral, neurônios são compostos por três partes principais, a saber: dendritos, soma, e axônio. A Figura 2.1 mostra essas partes, assim como a visão canônica sobre seus respectivos papéis no processamento neuronal: os dendritos são a principal fonte de entrada de sinais vindos de outros neurônios, o soma é o responsável por integrar sinais recebidos pelos dendritos e, caso o valor integrado desses sinais seja suficientemente intenso, um sinal elétrico é emitido na região de contato entre o soma e o axônio e se propaga por este último tendo como destino outros neurônios. Esses sinais elétricos gerados pelos neurônios são chamados de potenciais de ação, disparos, ou spikes e são a unidade de informação básica usada pela maioria dos neurônios para se comunicar. 
O mecanismo de geração e propagação de potenciais de ação em um determinado neurônio depende das características elétricas e químicas da sua membrana. A membrana neuronal é uma bi-camada lipídica que possui uma série de estruturas protéicas que permitem a passagem de íons, tanto para dentro como para fora do neurônio. Em geral, tais estruturas, chamadas de canais iônicos, são sensíveis apenas a um tipo de íon, sendo que a condutância de um canal iônico varia dependendo das concentrações do íon dentro e fora do neurônio e da diferença de potencial elétrico entre o interior e o exterior do neurônio (chamada de potencial de membrana) [Kandel, Schwartz e Jessell 2000]. O efeito combinado dos fluxos (entrando ou saindo da célula) dos diversos tipos de íons pelos canais iônicos da membrana de um neurônio determina o valor instantâneo do seu potencial de membrana. Quando o neurônio está em repouso, o valor do seu potencial de membrana é chamado de potencial de repouso. Quando o neurônio é estimulado de maneira a fazer o seu potencial de membrana crescer em relação ao potencial de repouso dizemos que o neurônio está despolarizado. Por outro lado, quando o estímulo aplicado ao neurônio faz o seu potencial de membrana diminuir em relação ao potencial de repouso, dizemos que o neurônio está hiperpolarizado.

O valor do potencial de membrana também afeta as condutâncias iônicas. Quando o neurônio é despolarizado de modo que o seu potencial de membrana ultrapasse certo valor limiar, o efeito sobre as condutâncias iônicas dá-se no sentido de provocar uma despolarização ainda maior do potencial de membrana. Esse mecanismo de realimentação positiva está na base da geração de um potencial de ação.

É importante ressaltar que, anatomicamente, os neurônios diferem bastante entre si, ou seja, o neurônio apresentado na Figura 2.1 é apenas uma representação abstrata genérica.

A região onde acontece a comunicação entre dois neurônios é chamada de sinapse, sendo que o neurônio que envia o potencial de ação é chamado de neurônio pré-sináptico e o neurônio que recebe o potencial de ação é chamado de neurônio pós-sináptico. As sinapses podem ser natureza química ou elétrica, sendo que as químicas são consideradas como as mais importantes em vertebrados. Somente sinapses químicas são consideradas nesta tese. Em uma sinapse química não há 


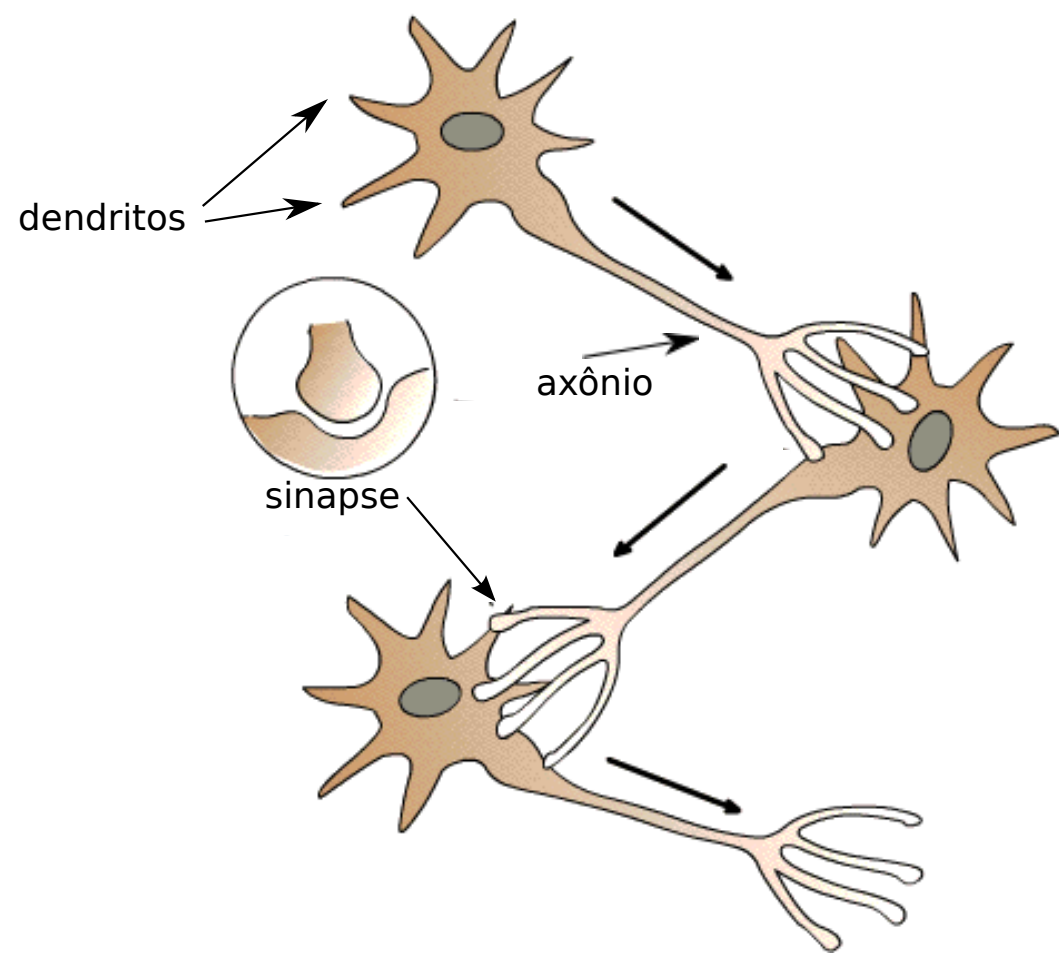

Figura 2.1: Esquema genérico de um neurônio, composto por dendritos, soma e axonio, realizando sinapses químicas com seus pares.

um verdadeiro contato entre os neurônios, existindo uma pequena separação entre eles denominada fenda sináptica (ver Figura 2.1). Quando um potencial de ação chega à extremidade do axônio do neurônio pré-sináptico, uma série de eventos bioquímicos provoca a liberação de neurotransmissores na fenda sináptica que se difundem até o neurônio pós-sináptico e se ligam a proteínas na sua membrana. Essa ligação pode ter efeito excitatório ou inibitório sobre o neurônio pós-sináptico, ou seja, o neurônio pré-sináptico pode contribuir para facilitar a geração de um potencial de ação no neurônio pós-sináptico ou pode contribuir para dificultar a geração de um potencial de ação no neurônio pós-sináptico. Em geral, as sinapses químicas são exclusivamente excitatórias ou exclusivamente inibitórias (lei de Dale) [Kandel, Schwartz e Jessell 2000].

\subsection{Modelagem de Neurônios Pulsados e Sinapses}

Nesta seção apresentaremos algumas das principais formas de modelagem de neurônios pulsados e de sinapses. Elas diferem, basicamente, em termos de com- 
plexidade, comportamento, plausibilidade biológica e custo computacional. Vale ressaltar que dependendo da hipótese que se deseja testar ou do fenômeno que se deseja modelar, alguns tipos de modelagem são mais adequados que outros.

Com relação à modelagem de neurônios pulsados, podemos ressaltar que as várias estratégias e diferentes abordagens existentes têm como foco principal modelar a geração do potencial de ação, assim como o comportamento do potencial de membrana entre disparos sucessivos (chamado de comportamento sublimiar) [Izhikevich 2007].

Na Figura 2.2 apresentamos um esquema mostrando as duas principais abordagens para a modelagem de neurônios pulsados. Elas podem ser divididas em dois grupos, a saber: modelagem baseada em condutâncias iônicas (ou simplesmente modelagem iônica) e modelagem simplificada [Izhikevich 2007]. É possível ver que na primeira há uma correspondência entre a membrana neuronal, com os diferentes fluxos iônicos através dela, e um circuito RC com várias condutâncias em paralelo (uma para cada tipo de canal iônico). As equações que regem a dinâmica das condutâncias iônicas dependendem do potencial de membrana e a equação que rege o comportamento do potencial de membrana depende das condutâncias iônicas. Essa abordagem torna possível modelar a geração de potenciais de ação completos, ou seja, com as fases de subida (upstroke), de descida (downstroke) e de hiperpolarização (ver Figura 2.2) [Lytton 2002].

Já na modelagem simplificada, modela-se o comportamento do potencial de membrana de um neurônio a partir de duas perspectivas [Izhikevich 2007]: (1) redução drástica do modelo baseado no circuito $\mathrm{RC}$, resultando na família de modelos denominados integra-e-dispara. Os modelos desta família modelam apenas um comportamento sublimiar, sendo que o limiar para um disparo é definido manualmente e o potencial de ação é reduzido a um evento sem estrutura ocorrendo num determinado instante de tempo (uma linha vertical como mostrado na Figura 2.2). (2) A outra perspectiva vem da teoria dos sistemas dinâmicos baseada na análise de sistemas de duas ou três variáveis no espaço de fases [Strogatz 1994]. Neste caso, a partir do ajuste dos parâmetros do modelo é possível modelar de maneira aproximada tanto a forma do disparo de um neurônio como o comportamento sublimiar do seu potencial de membrana. 


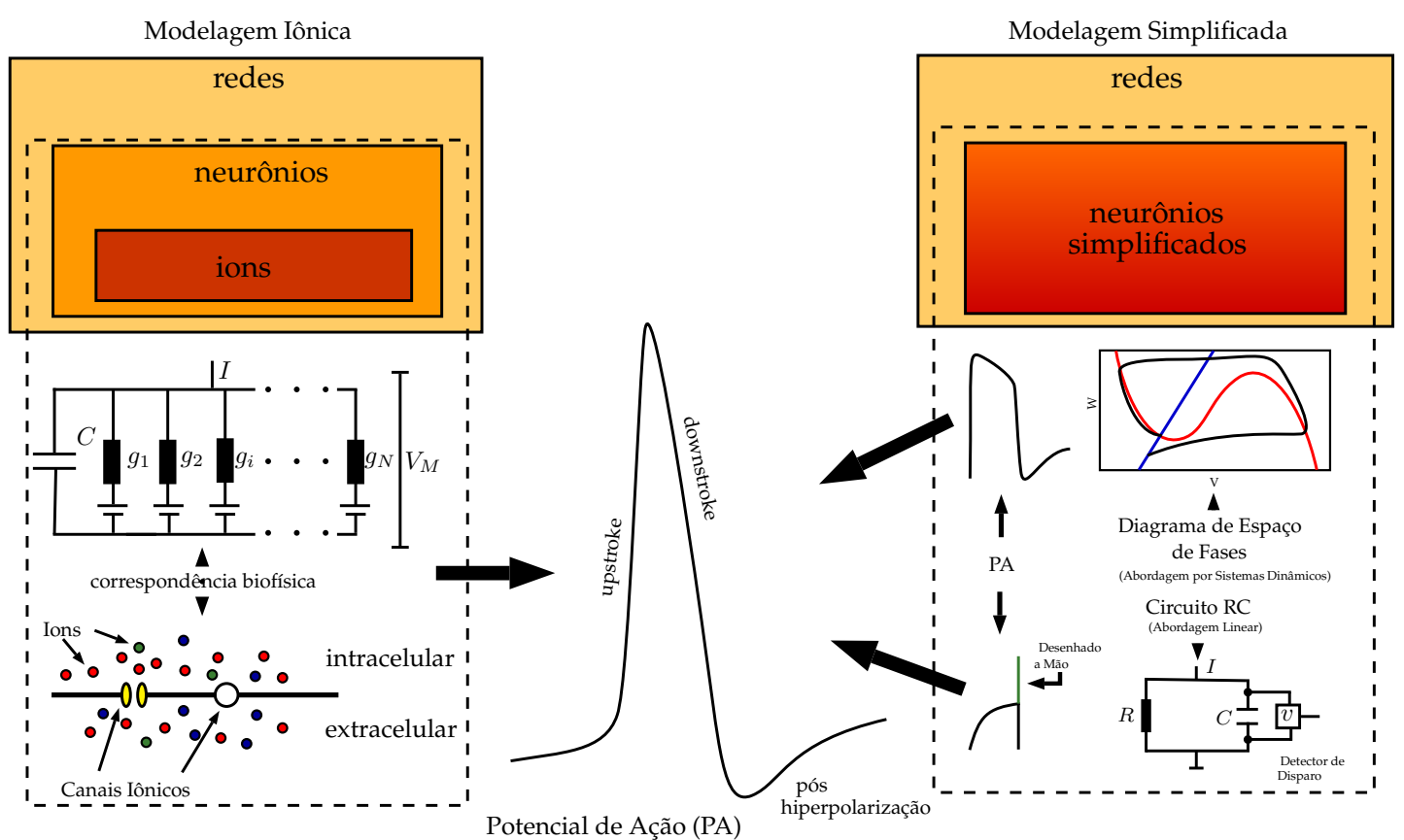

Figura 2.2: Principais abordagens utilizadas na modelagem de neurônios. A figura da esquerda ilustra a modelagem iônica, de maior correpondência biofísica e a figura da direita ilustra a modelagem simplificada, de menor custo computacional.

\subsubsection{Modelagem Iônica}

Em 1952 Hodgkin e Huxley (HH) propuseram o primeiro modelo baseado em condutâncias [Hodgkin e Huxley 1952] e isso deu origem à abordagem de modelagem iônica de neurônios. Experimentos realizados no axônio gigante de lula, denominados grampeamento espacial e grampeamento de voltagem, possibilitaram o estudo do comportamento temporal das condutâncias iônicas presentes no axônio em função de diferentes valores do potencial de membrana, resultando em um circuito elétrico equivalente (ver Figura 2.3). Nesse circuito, as condutâncias iônicas do sódio e do potássio variam no tempo de acordo com equações diferenciais determinadas por HH.

A partir da análise da Figura 2.3 podemos ver que a corrente de membrana $\left(I_{m}(t)\right)$ é composta pela soma das correntes capacitiva $\left(C_{m} \frac{d V_{m}(t)}{d t}\right)$, de sódio $\left(I_{N a}\right)$, de potássio $\left(I_{K}\right)$ e de vazamento (ou fuga) $\left(I_{v a z}\right)$. Portanto, 


$$
I_{m}(t)=C_{m} \frac{d V_{m}(t)}{d t}+I_{N a}(t)+I_{K}(t)+I_{v a z}(t)
$$

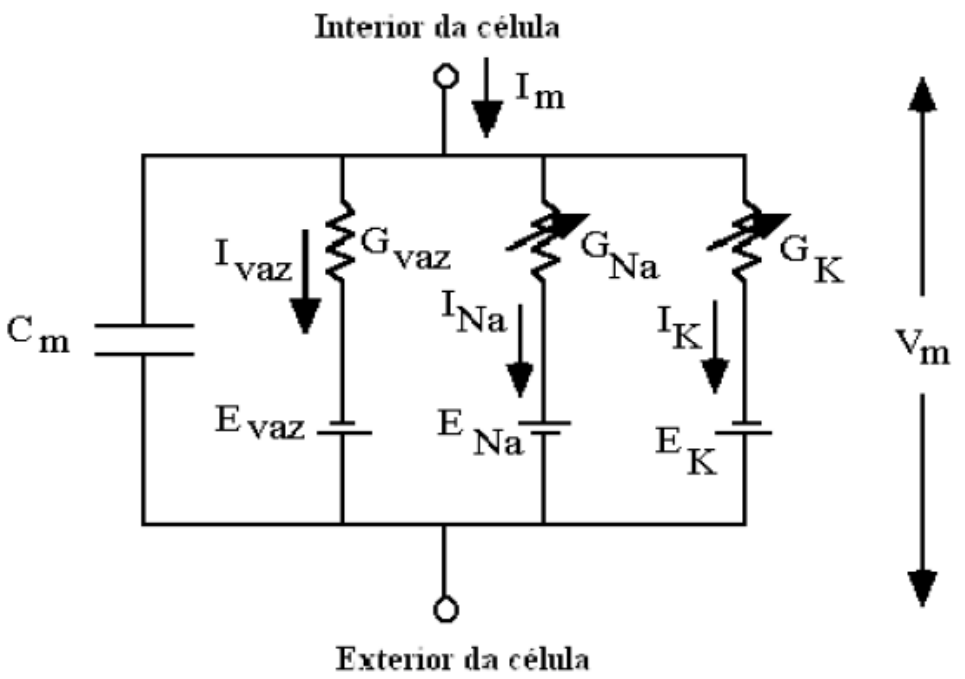

Figura 2.3: Circuito Elétrico Equivalente à Membrana para o Modelo de HodgkinHuxley.

As correntes $I_{N a}, I_{K}$ e $I_{v a z}$ são representadas por condutâncias $(G)$ conectadas em série com baterias $E$, sendo que cada bateria indica o valor de equilíbrio do potêncial de membrana caso apenas o íon correspondente fluisse pela membrana (chamado de potencial de Nernst). O comportamento dinâmico das condutâncias do sódio e do potássio é determinado pelas chamadas variáveis de ativação e de inativação. Uma variável de ativação pode ser imaginada como associada a portões no interior dos canais iônicos que se abrem, permitindo a passagem de íons, quando o potencial de membrana aumenta e se fecham, impedindo a passagem de íons, quando o potencial diminui. Uma variável de inativação pode ser imaginada como associada a portões que possuem comportamento oposto, se fechando quando o potencial aumenta e se abrindo quando o potencial diminui. Cada tipo de condutância iônica pode ter mais de uma cópia de um portão de ativação e mais de uma cópia de um portão de inativação. O produto das variáveis de ativação e inativação de uma condutância iônica, cada uma elevada a um número inteiro que indica quantas cópias dos portões correspondentes existem para a condutância, ou seja, a fração dos canais iônicos associados à condutância abertos em dado instante. Multiplicando-se esta fração pela condutância iônica máxima da membrana, que dá a condutância da membrana 
quando todos os seus canais iônicos para um dado tipo de íon estão abertos, tem-se finalmente a condutância iônica instantânea da membrana ao íon correspondente.

No modelo de $\mathrm{HH}$, a condutância do sódio depende de uma variável de ativação $(m)$ associada a três portões e de uma variável de inativação $(h)$ associada a um único portão. A condutância do potássio depende de apenas uma variável de ativação $(n)$ associada a quatro portões. A equação diferencial para o potencial de membrana do modelo de $\mathrm{HH}$ pode ser escrita como

$$
C_{m} \frac{d V_{m}}{d t}=I_{i n j}-\left(g_{N a} m^{3} h\left(V_{m}-E_{N a}\right)+g_{K} n^{4}\left(V_{m}-E_{K}\right)+g_{v a z}\left(V_{m}-E_{v a z}\right)\right) .
$$

Esta equação está escrita, como é mais costumeiro na literatura sobre modelos iônicos, em termos das densidades de condutâncias iônicas, indicadas por letras minúsculas $(g)$, ao invés das condutâncias absolutas, indicadas por maísculas $(G)$ [Izhikevich 2007]. A variável $I_{i n j}$ representa alguma densidade de corrente externa injetada no neurônio.

As variáveis de ativação e inativação do sódio e do potássio obedecem a equações idênticas, apenas com parâmetros diferentes. Uma maneira padronizada de escrever essas três equações é dada por 2.3. As variáveis $\tau_{x}$ e $x_{\infty}$ indicam o tempo característico e o valor de estado estacionário respectivamente, lembrando que elas dependem da voltagem, ou seja, para as equações abaixo $V=u$. Os valores dos parâmetros $\alpha$ e $\beta$ que aparecem na equação 2.3, assim como os valores dos demais parâmetros do modelo de HH, podem ser vistos nas Tabelas 2.1 e 2.2, respectivamente.

$$
\begin{aligned}
& \frac{d x}{d t}=-\frac{1}{\tau_{x}(u)}\left[x-x_{0}(u)\right] \\
& x_{\infty}(u)=\frac{\alpha_{x}(u)}{\left[\alpha_{x}(u)+\beta_{x}(u)\right]} \\
& \tau_{x}(u)=\left[\alpha_{x}(u)+\beta_{x}(u)\right]^{-1}
\end{aligned}
$$

A Figura 2.4 (a) mostra o resultado da simulação das equações acima quando se injeta uma densidade de corrente despolarizante constante igual a $5 \mathrm{nA} / \mathrm{cm}^{2}$ entre os instantes $t=10 \mathrm{~ms}$ e $t=15 \mathrm{~ms}$. Pode-se ver claramente as três principais fases de um potencial de ação: subida, descida e hiperpolarização. 
Tabela 2.1: Parâmetros para as variáveis $n, m$ e $h$.

\begin{tabular}{ccc}
\hline$x$ & $\alpha_{x}(u / m V)$ & $\beta_{x}(u / m V)$ \\
\hline$n$ & $(0.1-0.01 u) /[\exp (1-0.1 u)-1]$ & $0.125 \exp (-u / 80)$ \\
$m$ & $(2.5-0.1 u) /[\exp (2.5-0.1 u)-1]$ & $4 \exp (-u / 18)$ \\
$h$ & $0.07 \exp (-u / 20)$ & $1 /[\exp (3-0.1 u)+1]$ \\
\hline
\end{tabular}

Tabela 2.2: Parâmetros $g$ e $E$ para $\mathrm{Na}, \mathrm{K}$ e vaz.

\begin{tabular}{ccc}
$x$ & $g_{x}$ & $E_{x}$ \\
\hline$N a$ & $120 m S / \mathrm{cm}^{2}$ & $115 m V$ \\
$K$ & $36 m S / \mathrm{cm}^{2}$ & $-12 m V$ \\
$v a z$ & $0.3 m S / \mathrm{cm}^{2}$ & $10.6 m V$ \\
\hline
\end{tabular}

A Figura 2.4 (b) mostra os comportamentos das variáveis de ativação e inativação do $N a$ e do $K$ durante o potencial de ação. Uma análise dos comportamentos dessas três variáveis permite entender como as condutâncias iônicas controlam o potencial de ação. No repouso, pode-se ver que $m$ possui um valor baixo, $h$ um valor bem mais alto e $n$ um valor intermediário. O resultado é que no repouso a condutância da membrana ao $K\left(\propto n^{4}\right)$ é bem maior que a condutância da membrana ao $N a$ $\left(\propto m^{3} h\right)$. Isso implica que o fluxo de $K$ através da membrana no repouso é bem maior que o fluxo de $\mathrm{Na}$. Como o potencial de Nernst do $K$ é negativo (ver tabela 2.2), o domínio do fluxo pelo $K$ faz com que o potencial de repouso seja negativo. O valor do potencial de repouso fica um pouco acima do potencial de Nernst do $K$ por causa do pequeno fluxo de $N a$ pela membrana, que tende a elevar o potencial de membrana (o potencial de Nernst do $N a$ é positivo). Quando ocorre a despolarização da membrana pela injeção de corrente, $m$ cresce quase que instantaneamente para o seu valor máximo enquanto que $h$ e $n$ variam mais lentamente, a primeira decaindo e a segunda crescendo. O resultado é que por um breve instante de tempo o produto $m^{3} h$ torna-se maior que $n^{4}$, fazendo com que durante este breve instante o fluxo dominante pela membrana seja o de $N a$. O domínio do fluxo de $N a$ despolariza ainda mais a membrana, pois o potencial de Nernst do $\mathrm{Na}$ é positivo, e este é o mecanismo de retroalimentação positiva que causa a fase de subida do potencial de 
membrana em direção ao pico. À medida que o potencial de membrana cresce cada vez mais, porém, a variável $h$ tende a zero, de maneira que por maior que seja $m$ o produto $m^{3} h$ torna-se praticamente nulo. Por outro lado, $n$ cresce continuamente levando o fluxo de $K$ a ser novamente dominante. O valor do potencial de membrana começa então a cair em direção ao potencial de Nernst do $K$. Essa é a fase de descida. Como o fluxo de $\mathrm{Na}$ permanece praticamente nulo por um tempo relativamente longo, a descida do potencial de membrana o leva a cair abaixo do potencial de repouso, atingindo um valor muito próximo do potencial de Nernst do $K$. Essa é a fase de hiperpolarização. Após o término da injeção de corrente os valores de $m, h$ e $n$ retornam gradualmente aos seus valores de repouso.
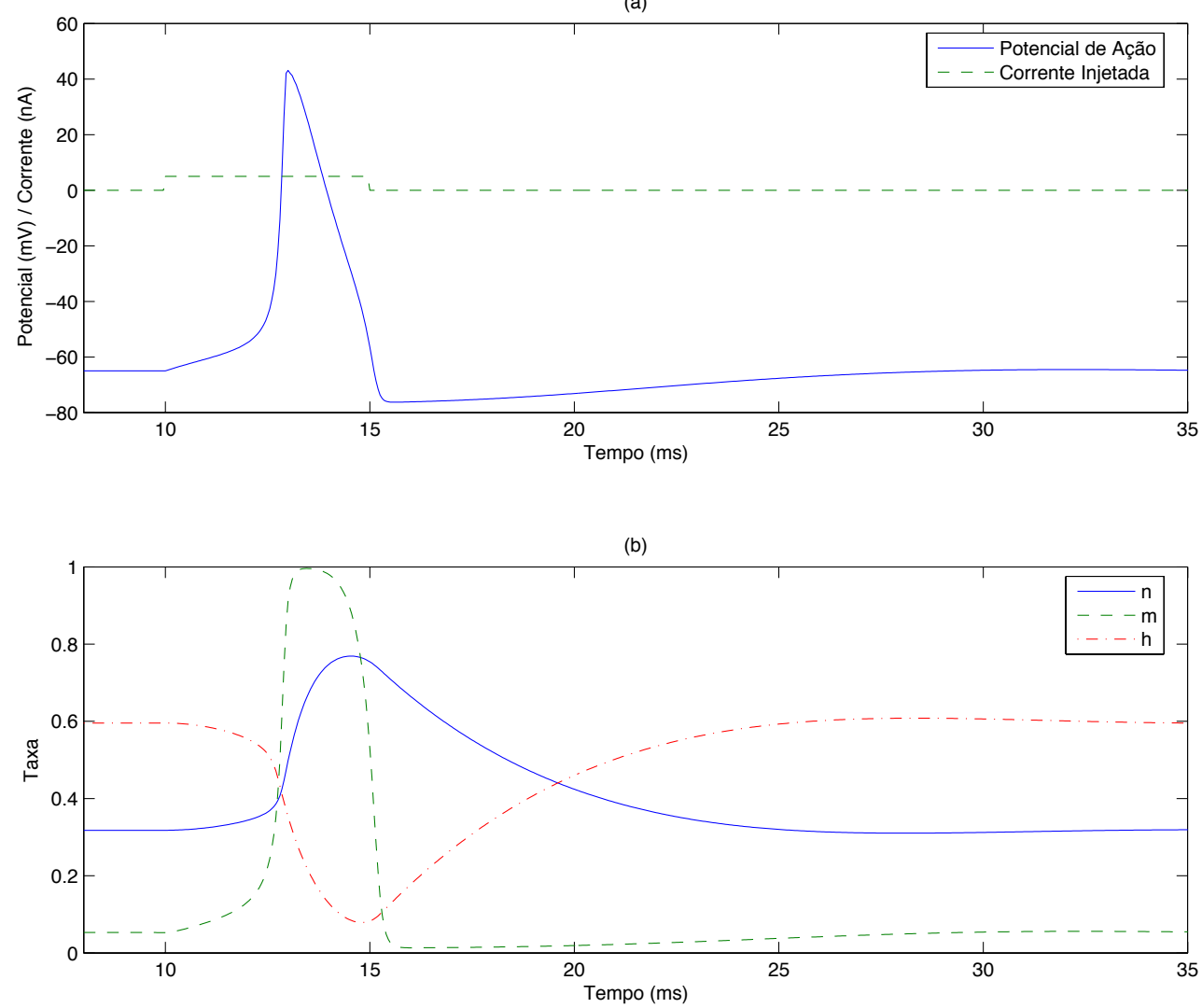

Figura 2.4: (a) Simulação de um potencial de ação gerado pela injeção de uma densidade de corrente externa constante de $5 \mathrm{nA} / \mathrm{cm}^{2}$. (b) Comportamento ao longo do tempo das variáveis $m, n$ e $h$. 
A abordagem do modelo de $\mathrm{HH}$ pode ser usada para modelar qualquer outra condutância iônica presente nas membranas de neurônios, dando origem assim à modelagem iônica. Segundo a modelagem iônica, uma corrente iônica genérica pode ser descrita como

$$
I=\bar{g} p(u-E)
$$

onde $\bar{g}$ é a densidade de condutância máxima, $E$ é o potencial de reversão da corrente iônica (este nome é dado porque quando o valor do potencial de membrana passa por $E$ a corrente muda de sentido) e $p$ é a fração de canais abertos. Esta última pode ser expressa em termos de uma variável de ativação $m$ e de uma variável de inativação $h$ como $p=m^{a} h^{b}$. De maneira genérica, a equação para o potencial de membrana de um neurônio segundo a modelagem iônica é

$$
C_{m} \frac{d V_{m}}{d t}=I_{i n j}-\sum_{i=1}^{N} \bar{g}_{i} p_{i}\left(V_{m}-E_{i}\right)
$$

onde $N$ é a quantidade de correntes iônicas consideradas pelo modelo, em geral obtidas após estudos experimentais com o neurônio em questão. Existem diversas correntes iônicas descritas na literatura [Parri e Crunelli 1999, Kay, Sugimori e Llinas 1998, Geiger e Jonas 2000, Korngreen e Sakmann 1998], o que permite a construção de uma enorme variedade de modelos iônicos. Apesar do seu elevado grau de fidelidade biofísica, tais modelos apresentam alto custo computacional devido ao grande número de equações diferenciais que precisam ser resolvidas.

\subsubsection{Modelagem Simplificada}

Para os casos em que se quer modelar redes formadas por grandes quantidades de neurônios o custo computacional se torna um importante fator a ser observado. É justamente para esse cenário que a modelagem simplificada torna-se útil, pois os modelos simplificados apresentam custo computacional muito mais baixo que os dos modelos iônicos.

Como comentado acima, os modelos simplificados podem ser divididos em dois grupos. O primeiro é composto pelos modelos do tipo integra-e-dispara. Estes são os 
modelos mais simples existentes, contendo apenas uma equação diferencial e tendo por isso o menor custo computacional possível. Basicamente, um modelo integra-edispara é descrito por um circuito RC e pode ser representado pela equação abaixo,

$$
\begin{aligned}
& \tau \frac{d V}{d t}=-V+R I \\
& V \leftarrow V_{r} \text { se } V=V_{t h}
\end{aligned}
$$

onde os parâmtros constantes $R$, e $\tau$ podem ser alterados com o intuito de alterar a frequência de disparos para uma dada corrente $I$. Na Figura 2.5 podemos ver (a) o circuito $R C$ do modelo integra-e-dispara e (b) o gráfico dando o comportamento $(V \times t)$ para o modelo. Pode-se ver que, ao estimularmos o modelo com uma corrente constante $I$, o capacitor é carregado com tempo característico $\tau$ e que, quando o valor limiar $V_{t h}$ é atingido o potencial é colocado forçadamente no valor de repouso $V_{r}$.

(a)

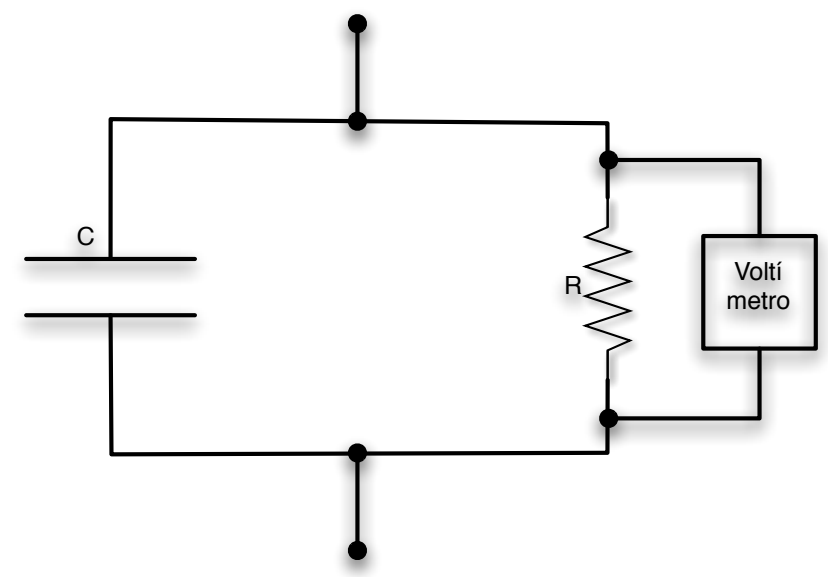

(b)

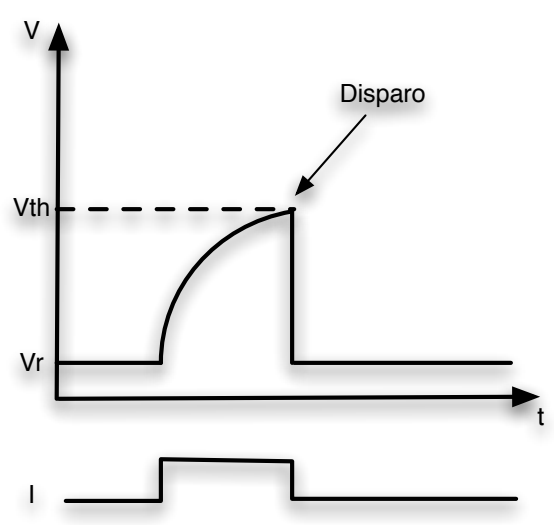

Figura 2.5: Modelo Integra-e-Dispara, (a) Circuito RC correspondente à equação do modelo IF. (b) Comportamento temporal da voltagem para o modelo integra-edispara. Se o voltímetro indicar o potencial $V t h$ um disparo ocorre e a voltagem é retornada a $V_{r}$.

Os modelos integra-e-dispara apresentam apenas um tipo característico de gráfico de disparos contra tempo quando estimulados por uma corrente constante, ou seja, possuem baixa variabilidade em contraste com experimentos realizados com neurô- 
nios biológicos, os quais mostram que os neurônios biológicos possuem padrões de disparo bem distintos entre si.

Outra possibilidade para se contruir modelos simplificados é desenvolver modelos de duas ou mais variáveis que obedeçam a equações diferenciais e possam ser analisados pela teoria dos sistemas dinâmicos. Não é nosso objetivo aqui fazer uma revisão sobre sistemas dinâmicos, entretanto algumas considerações precisam ser feitas, pois serão úteis mais adiante.

Um sistema dinâmico pode ser visto como um conjunto de variáveis que descrevem seu estado e regras que descrevem a evolução dessas variáveis no tempo, ou seja, como o estado do sistema muda do instante atual para o próximo instante de tempo [Strogatz 1994]. Por exemplo, o modelo de HH (Hodgkin-Huxley) pode ser visto como um sistema de quatro variáveis $(u, n, m$ e $h$ ), com quatro equações diferenciais que determinam a evolução do sistema.

Um importante método de análise qualitativa que se pode fazer em sistemas dinâmicos é a análise no espaço de fases. O espaço de fases de um sistema dinâmico é um sistema de eixos coordenados onde cada eixo representa uma variável e o tempo é um parâmetro. Um sistema de duas variáveis pode, portanto, ser visualizado em um espaço de fase bidimensional e um de três variáveis pode ser visualizado em um espaço de fases tri-dimensional. A análise no espaço de fases pode ser usada para indicar características importantes de uma sistema dinâmico, tais como pontos estáveis, instáveis e bifurcações [Strogatz 1994].

Para introduzir os conceitos acima citados, apresentaremos o modelo de FitzHugh-Nagumo [FitzHugh 1961, Nagumo, Arimoto e Yoshizawa 1962]. O modelo de FitzHugh-Nagumo consiste de uma redução para duas dimensões do modelo de HH. Essa redução é feita da seguinte maneira: (1) a variável $m$ do modelo de $\mathrm{HH}$ varia no tempo de maneira muito mais rápida do que as demais variáveis do modelo de $\mathrm{HH}$ e, por isso, assume-se que o seu valor é congelado em $m_{\infty} ;(2)$ as variáveis $n$ e $h$ do modelo de $\mathrm{HH}$ se comportam de forma aproximadamente simétrica (uma como reflexão especular da outra) satisfazendo uma relação do tipo $(b-h) \approx a$ an com $a$ e $b$ constantes que ajustam essa relação. Por causa disso pode-se usar uma única variável $w=b-h=$ an no lugar de $n$ e $h$. Em consequência dessas duas observações, o modelo genérico de FitzHugh-Nagumo pode ser escrito como: 


$$
\begin{gathered}
\frac{d u}{d t}=\frac{1}{\tau}[F(u, w)+R I] \\
\frac{d w}{d t}=\frac{1}{\tau_{w}} G(u, w)
\end{gathered}
$$

onde $R=g_{\text {vaz }}^{-1}, \tau=R C, F$ e $G$ são funções que devem ser especificadas para o modelo reduzido que se deseja obter. No caso da redução do modelo de HH [FitzHugh 1961, Nagumo, Arimoto e Yoshizawa 1962], as funções $F$ e $G$ são definidas como

$$
\begin{gathered}
F(u, w)=u-\frac{1}{3} u^{3}-w \\
G(u, w)=a(u+b-c * w)
\end{gathered}
$$

Podemos ver, na Figura 2.6 (a), a resposta do modelo de FitzHugh-Nagumo para um estímulo que altera o comportamento do potencial de membrana (representado pela variável $u$ ) ao longo do tempo, mas não causa nenhum potencial de ação, ou seja, só provoca alterações sublimiares no modelo. Por outro lado, na Figura 2.6 (b) é possível ver, em vermelho, a trajetória do modelo no espaço de fases, bem como as chamadas isóclinas-nulas das duas variáveis do modelo, $u$ e $w$. As isóclinas-nulas representam os pontos do espaço de fase onde as derivadas temporais das variáveis do sistema dinâmico são zero [Strogatz 1994, Izhikevich 2007]. Além disso, é possível perceber que a trajetória do modelo tende ao ponto de intersecção entre as duas isóclinas nulas que, neste caso, é um ponto de equilíbrio estável ou atrator, pois a trajetória do sistema, ao alcançar esse ponto, permanecerá ali indefinidamente.

Outra situação corresponde ao caso mostrado na Figura 2.6 (c). Neste caso o comportamento temporal da variável $u$ possui uma série de potenciais de ação e o ponto de intersecção entre as isóclinas nulas (Figura 2.6 (d)) torna-se um ponto de equilíbrio instável ou repulsor. Neste caso, como o ponto de intersecção entre as duas isóclinas nulas se tornou instável a trajetória do sistema não converge mais para ele, mas para uma órbita estável em torno dele (ciclo limite). Cada volta completa em torno do ponto instável corresponde a um potencial de ação.

A mudança de comportamento observada nas Figuras 2.6 (c) e (d) ocorreu devido ao deslocamento da isóclina-nula de $u$ para cima. Tal deslocamento foi consequência do aumento do estímulo aplicado ao sistema. Por causa disso o ponto que antes 

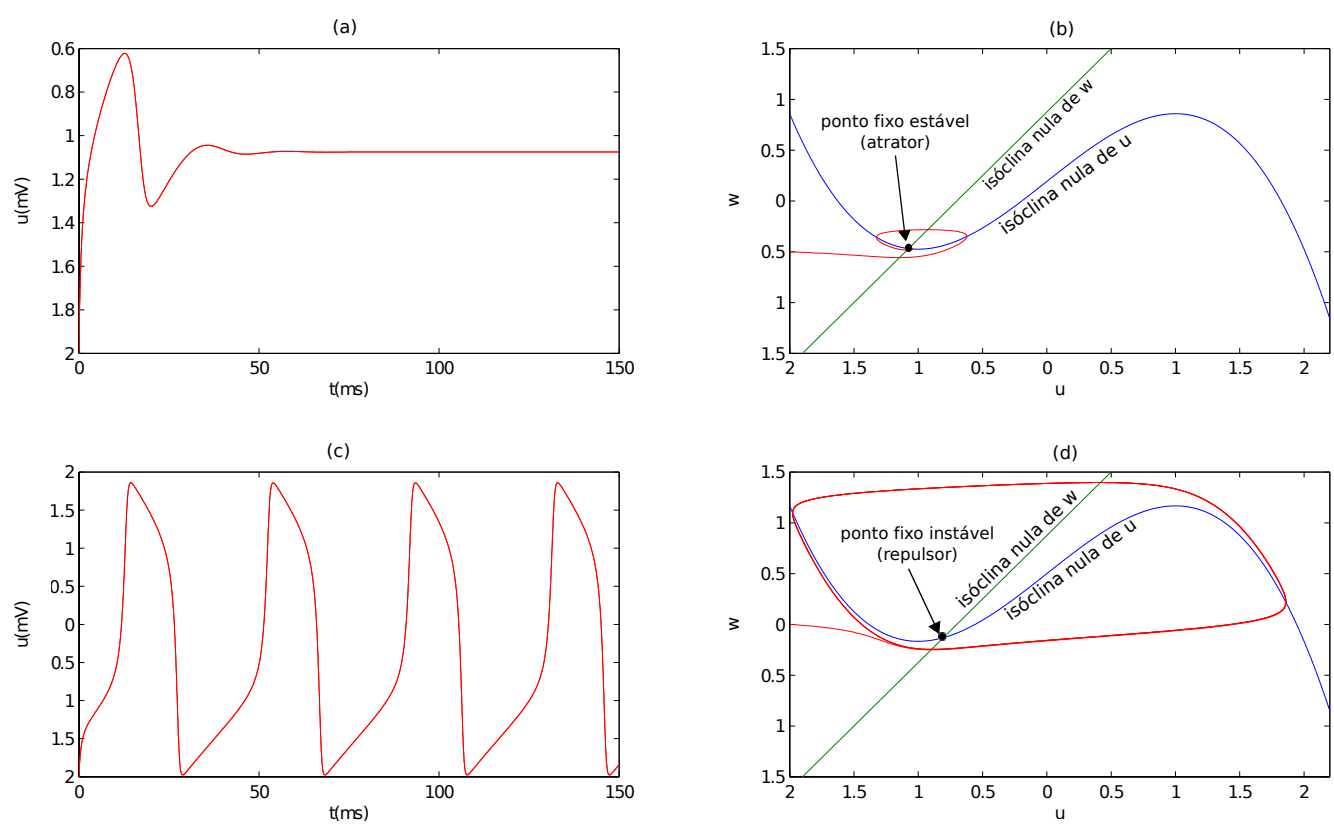

Figura 2.6: Resposta do modelo de FitzHugh-Nagumo, (a) e (c), a dois valores de estímulos, e suas respectivas trajetórias no espaço de fases do modelo, (b) e (d).

era estável se tornou instável, propiciando a geração de potenciais de ação. Tal mudança de comportamento no espaço de fases é chamada bifurcação do sistema. Há quatro tipos importantes de bifurcações para modelos bi-dimensionais de neurônios [Izhikevich 2000, Izhikevich 2007]:

- Bifurcação Nó-Sela: a medida que a corrente é injetada no neurônio o ponto de equilíbrio estável (circulo preto na Figura 2.7 (a)), que corresponde ao repouso da membrana, se aproxima do ponto de equilíbrio instável (circulo vazio na Figura 2.7 (a)) até que eles colidem e se aniquilam (segunda trajetória da Figura 2.7 (a)) indicando a não existência de repouso, restanto apenas o ciclo limite que corresponde a disparos periódicos (terceira trajetória da Figura $2.7(\mathrm{a}))$.

- Bifurcação Nó-Sela sobre Circulo Invariante: similar à bifurcação anterior, entretanto possui um ciclo invariante que se torna um atrator após o aniquilamento dos pontos (Figura 2.7 (b)). 

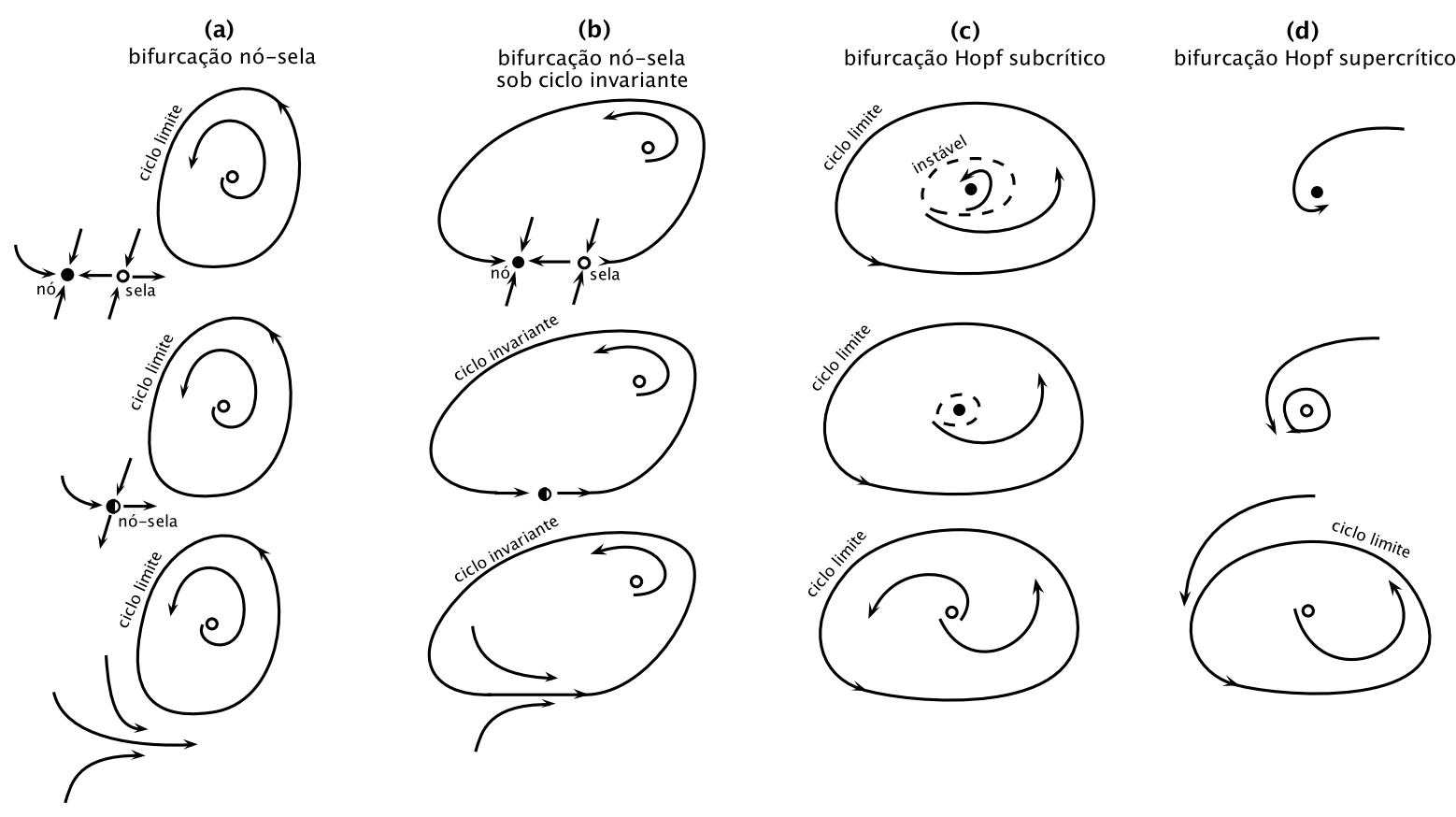

Figura 2.7: Quatro tipos de bifurcação, a saber: (a) nó-sela, (b) nó-sela sobre ciclo invariante, (c) Hopf subcrítica e (d) Hopf supercrítica.

- Bifurcação de Hopf Subcrítica: a Figura 2.7 (c) indica que tal bifurcação ocorre quando um pequeno ciclo limite instável diminui convergindo para um ponto fixo estável e, por fim, ambos se aniquilam dando origem a um ponto fixo instável no interior de um ciclo limite.

- Bifurcação de Hopf Supercrítica: o ponto fixo perde estabilidade e dá lugar a um ciclo limite estável. À medida que a magnitude da corrente injetada aumenta, a amplitude do ciclo limite aumenta tornando-se uma trajetória de potencial de ação (Figura $2.7(\mathrm{~d})$ ).

No caso do modelo de FitzHugh-Nagumo a bifurcação é do tipo Hopf supercrítica. A seguir, veremos o modelo simplificado usado nesta tese e como ele se encaixa na teoria dos sistemas dinâmicos.

\section{Modelo de Izhikevich}

O modelo de Izhikevich usa a teoria dos sistemas dinâmicos para a construção de modelos simplificados combinando uma variável rápida, que descreve o potencial 
de membrana $(V)$, e uma variável lenta, que governa a recuperação do sistema $(u)$. O espaço de fases para o modelo de Izhikevich está mostrado na Figura 2.8. A região em destaque nesta figura, ampliada na Figura 2.8 (b), mostra a intersecção entre as isóclinas nulas de $V$ e $u$. É quando o estado do sistema está nessa região que ocorre a geração ou não de um potencial de ação. Todo o resto da trajetória do sistema pelo espaço de fase (região fora do destaque) modela apenas o pico do potencial de ação e a sua descida em direção ao repouso. Portanto, para modelar o comportamento sublimiar do potencial de ação e a sua geração basta apenas considerar a região próxima da intersecção entre as duas isóclinas nulas (Figura 2.8 (b)). Não é necessário, no espírito de simplificar o modelo, ter equações para descrever a subida do potencial até o pico do potencial de ação e nem para descrever a repolarização do potencial; isso pode ser feito à mão, recolocando o potencial num valor de reinício (reset) após o pico. As equações do modelo de Izhikevich modelam apenas o comportamento do sistema na região em destaque na Figura 2.8. Elas são [Izhikevich 2007]:

$$
\begin{aligned}
& C \frac{d v}{d t}=k\left(v-v_{r}\right)\left(v-v_{t}\right)-u+I \\
& \frac{d u}{d t}=a\left\{b\left(v-v_{r}\right)-u\right\} \\
& \text { se } v \geq v_{\text {peak }} \text { ento } v \leftarrow c, u \leftarrow u+d
\end{aligned}
$$

Nestas equações, $v$ é o potencial de membrana, $u$ é a variável de recuperação, $C$ é a capacitância da membrana, $v_{r}$ é o potencial de repouso da célula, $v_{t}$ é o limiar de disparo, $v_{\text {peak }}$ é o pico do potencial de ação, $a$ é a constante de tempo de recuperação, $c$ é o valor de reset da variável $v$, ou seja, tal constante determina o valor da variável $v$ logo após um potencial de ação, e $d$ descreve a influência da variável de recuperação do sistema após a ocorrência de um potencial de ação.

Os parâmetros $v_{r}, v_{t}, v_{\text {peak }}$ e $C$ podem ser determinados experimentalmente para o neurônio que se deseja modelar, ou mesmo a partir de modelos detalhados baseados no formalismo de Hodgkin-Huxley. O outros parâmetros, $k, a, b, c$ e $d$, podem ser encontrados empiricamente no intuito de fazer com que o modelo resultante seja compatível com a célula real em questão. Na Figura 2.9 é possível ver os diferentes tipos de comportamentos de disparos do modelo obtidos apenas com a alteração dos 


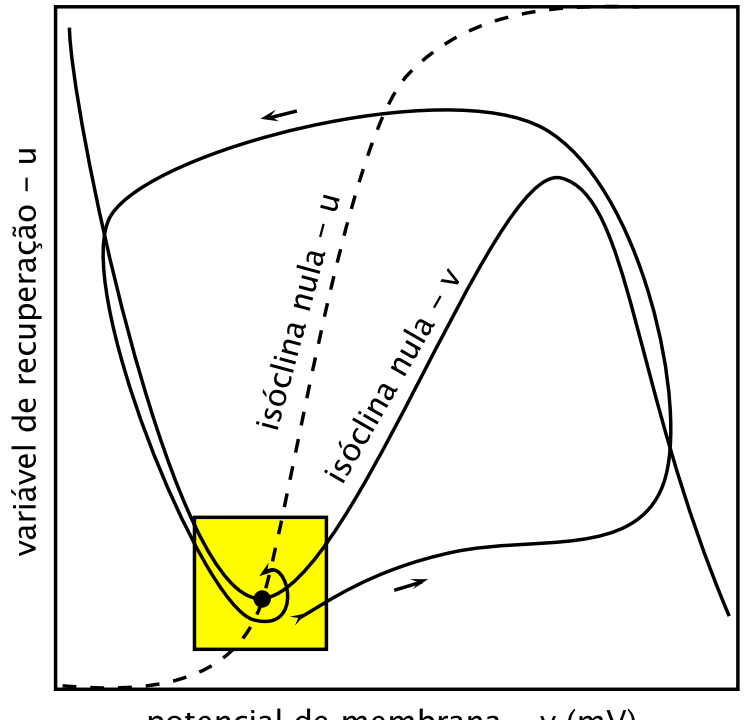

potencial de membrana $-\mathrm{v}(\mathrm{mV})$

(a)

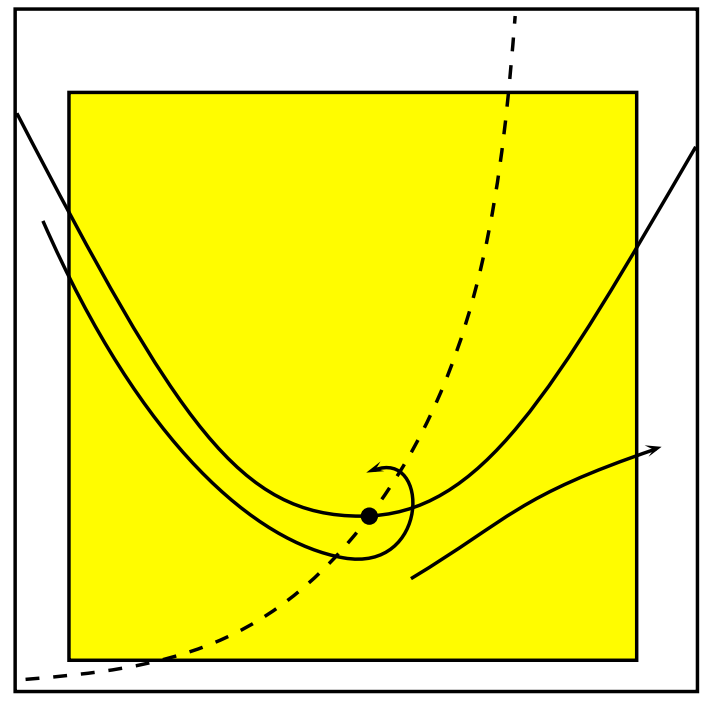

potencial de membrana $-\mathrm{v}(\mathrm{mV})$

(b)

Figura 2.8: Espaço de fases do modelo de Izhikevich (a) e uma aproximação visual (b) do destaque em amarelo.

seus parâmetros.

Por causa da diversidade de comportamentos capturados pelo modelo de Izhikevich, aliada à sua simplicitade, este foi o modelo escolhido para a implementação dos modelos de neurônios desta tese. É importante ressaltar, no entanto, que existem muitos outros modelos simplificados de neurônios que poderiam ser utilizados em um trabalho como o desta tese [FitzHugh 1955, Nagumo, Arimoto e Yoshizawa 1962, Gerstner e Kistler 2002].

\subsubsection{Modelagem de Sinapses}

As sinapses representam o meio pelo qual os neurônios se comunicam. O processo sináptico tem início quando um neurônio pré-sináptico ativado libera neurotransmissores na fenda sináptica. Esses neurotransmissores se difundem pela fenda sináptica até o outro lado, onde ativam receptores localizados na membrana do neurônio pós-sináptico. A ativação dos receptores pós-sinápticos resulta na abertura de certos canais iônicos, gerando assim uma corrente pós-sináptica excitatória (excitatory post-synaptic current, EPSC) ou inibitória (inhibitory post-synaptic current, IPSC).

Esse fenômeno poderia ser modelado por equações matemáticas que descreves- 


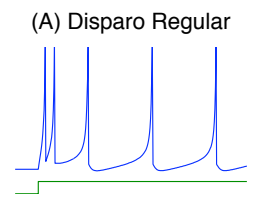

(E) Modo misto

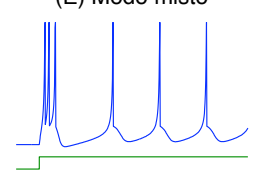

(I) Latência

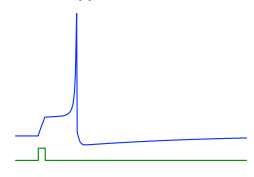

(M) Disparo por rebote

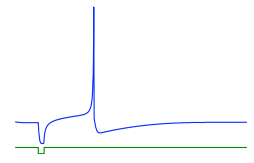

(Q) Despolarização pós disparo

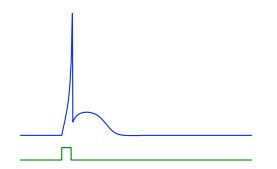

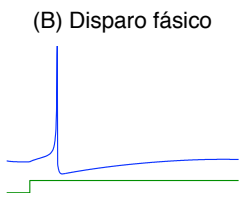

(F) Adaptação de disparos

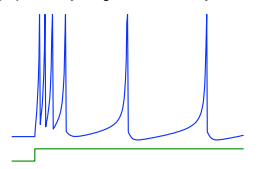

(J) Oscilações sublimiares

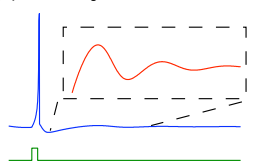

(N) Rajada por rebote

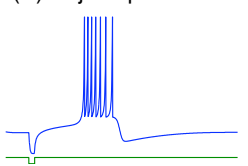

(R) Acomodação

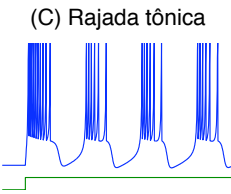

(G) Classe 1

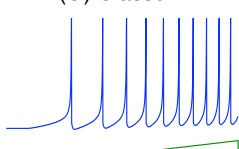

(K) Ressoador

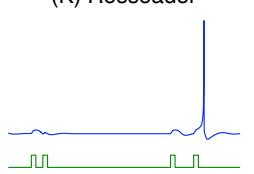

(O) Variabilidade de limiar de disparo

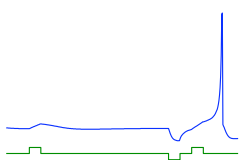

(S) inib. pré disparo

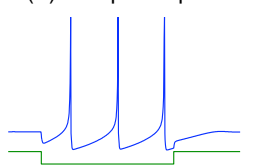

(D) Rajada fásica

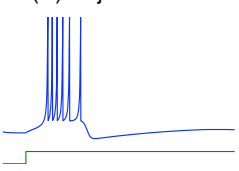

(H) Classe 2

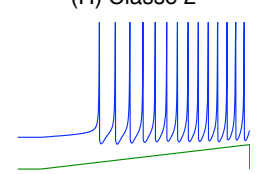

(L) Integrador

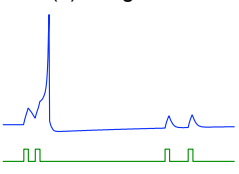

(P) Biestabilidade

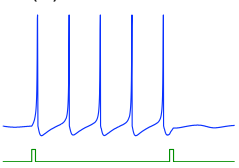

(T) inib. pré rajada

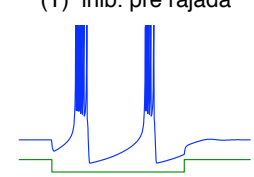

Figura 2.9: Diferentes tipos de comportamento de disparo do modelo de Izhikevich obtidos por alteração dos parâmetros do modelo.

sem os processos de liberação de neurotransmissores, difusão dos mesmos pela fenda sináptica e ativação dos canais iônicos do neurônio pós-sináptico. É possível perceber o custo computacional de tal modelo, sobretudo em redes com uma grande quantidade de neurônios. Para evitar isso é comum usar o que se chama de função $\alpha$ para modelar uma condutância sináptica [Gerstner e Kistler 2002, Lytton 2002]. Segundo essa abordagem simplificada, uma corrente pós-sináptica pode ser modelada usando uma função padronizada para a variação temporal da condutância, $g_{\text {syn }}(t)$, chamada de função $\alpha$, que é ativada toda vez que um potencial de ação pré-sinaptico ocorrer. A corrente que passa através da membrana do neurônio pós- 
sináptico depende do potencial de reversão $E_{s y n}$ e do potencial de membrana $(u)$ como no modelo para uma corrente iônica do modelo de $\mathrm{HH}$ :

$$
I_{\text {syn }}(t)=g_{\text {syn }}(t)\left(u-E_{\text {syn }}\right) .
$$

Nesta equação, o parâmetro $E_{\text {syn }}$ pode ser ajustado para produzir pontenciais póssinápticos inibitórios $\left(E_{\text {syn }} \approx-75 \mathrm{mV}\right)$ ou excitatórios $\left(E_{\text {syn }} \approx 0 \mathrm{mV}\right)$. A forma escolhida para a variação temporal de $g_{s y n}$ pode ser usada para representar potenciais pós-sinápticos produzidos por diferentes receptores sinápticos. Por exemplo, os receptores inibitórios GABA (ácido gama- amino-butírico) e os excitatórios AMPA (ácido $\alpha$-amino-3-hidroxi-5-metilisoxazole-propriônico), podem ser modelados pela seguinte função $\alpha$ :

$$
g_{\text {syn }}(t)=\overline{g_{\text {syn }}} B\left(e^{\frac{-t}{\tau_{1}}}-e^{\frac{-t}{\tau_{2}}}\right),
$$

onde $B$ é uma constante de normalização dada por:

$$
B=\left(\left(\frac{\tau_{2}}{\tau_{1}}\right)^{\tau_{\text {raise }} / \tau_{1}}-\left(\frac{\tau_{2}}{\tau_{1}}\right)^{\tau_{\text {raise }} / \tau_{2}}\right)^{-1},
$$

com o tempo de crescimento definido por $\tau_{\text {raise }}=\tau_{1} \tau_{2} /\left(\tau_{1}-\tau_{2}\right)$ e o tempo de decaimento por $\tau_{1}$.

O comportamento da condutância sináptica associada a outro receptor excitatório, chamado de NMDA (N-metil-D-aspartato), pode ser descrito pela seguinte função $\alpha$ :

$$
g_{N M D A}(t, u)=g_{\text {syn }}(t)\left(1+\frac{\left[M g^{2+}\right]}{3.57 m M} e^{u / 16.13 m V}\right)^{-1},
$$

onde $g_{s y n}$ é dado pela equação 2.11. A resposta desse receptor é dependente do potencial de membrana pós-sináptico $(u)$ e da concentração de magnésio $([\mathrm{Mg}])$. A Figura 2.10 mostra as funções $\alpha$ para os três receptores sinápticos supra-citados, usando seus respectivos parâmetros encontrados na literatura [Izhikevich 2007].

\subsection{Redes Neurais Pulsadas}

Em [Maass e Ruf 1996] há uma especificação formal de uma rede neural pulsada (spiking neuron network). Segundo esta definição, uma rede neural pulsada $N$ é 


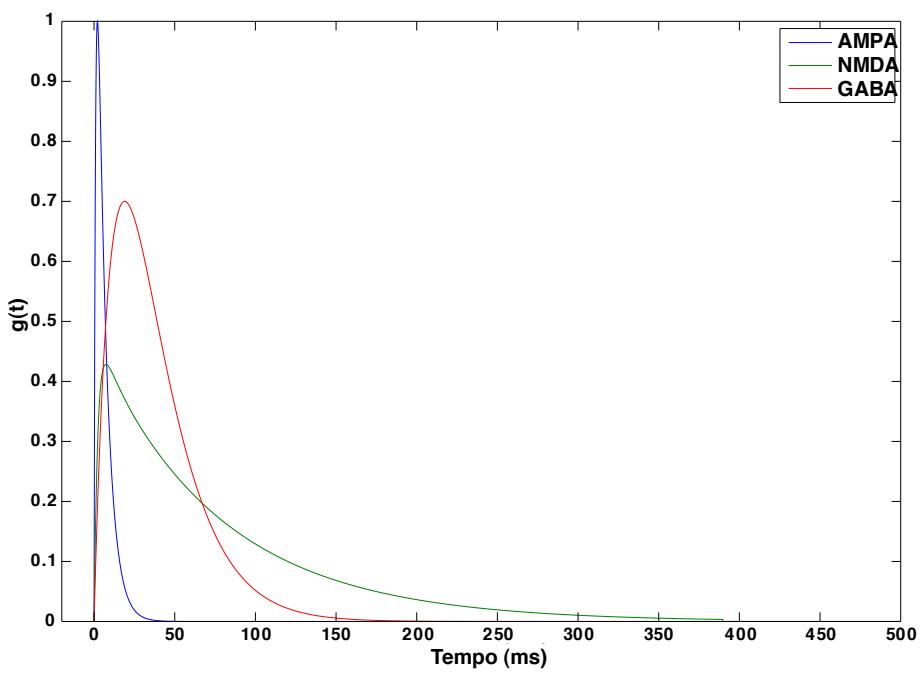

Figura 2.10: Funções $\alpha$ para os receptores sinápticos GABA, AMPA e NMDA.

formada por:

- um grafo finito $\langle V, E\rangle$, onde $V$ é o conjunto dos neurônios e $E$ é o conjunto das sinapses.

- um subconjunto $V_{i n} \subseteq V$ de neurônios de entrada.

- um subconjunto $V_{\text {out }} \subseteq V$ de neurônios de saída.

- para cada neurônio $n \in V-V_{\text {in }}$ existe uma função de limiar (threshold function) $\Theta_{v}: R^{+} \rightarrow R \cup\{\infty\}$ (onde $R^{+} \leftarrow\{x \in R: x \geq 0\}$ ).

- para cada sinapse $\langle u, v\rangle \in E$ existe uma função de resposta $\varepsilon_{u, v}: R^{+} \rightarrow R$ e um peso $w_{u, v} \in R^{+}$.

O padrão de disparos apresentado pelos neurônios $V_{i n}$ é determinado fora da rede $N$, ou seja, os conjuntos $F_{v} \subseteq R^{+}$que representam os tempos de disparo (spike times) dos neurônios $v \in V_{\text {in }}$ são dados como entradas da rede $N$.

Dado um neurônio $v \in V-v_{i n}$, seu conjunto de tempos de disparo $F_{v}$ pode ser definido recursivamente, onde o primeiro elemento de $F_{v}$ é inf $\left\{t \in R^{+}: P_{v}(t) \geq\right.$ $\left.\Theta_{v}(0)\right\}$, e para qualquer subsequente $s \in F_{v}$ é definido como inf $\left\{t \in R^{+}: t>\right.$ $\left.s, P_{v}(t) \geq \Theta_{v}(t-s)\right\}$, onde $P_{v}(t)$ é a função potencial $P_{v}: R^{+} \rightarrow R$ definida por:

$$
P_{v}(t) \leftarrow 0+\sum_{u:\langle u, v\rangle \in E} \sum_{s \in F_{u}: s<t} w_{u, v} \cdot \varepsilon_{u, v}(t-s)
$$


O termo 0 garante que $P_{v}(t)$ é bem definida mesmo se $F_{u}=\emptyset$ para todo $u$ com $\langle u, v\rangle \in E$. Os tempos de disparos dos neurônios de saída $v \in V_{\text {out }}$ dados pelo respectivo conjunto $F_{v}$ podem ser interpretados como a saída da rede $N$.

\subsection{Bulbo Olfatório}

O principal problema da neurobiologia do olfato é determinar como o cérebro discrimina um odor de outro [Wilson e Stevenson 2003]. Diversos trabalhos nas últimas décadas levaram a uma visão mais ou menos consensual sobre alguns aspectos da representação e do processamento de odores pelo sistema olfatório [Buck 1996, Mori, Nagao e Yoshihara 1999]. O reconhecimento da importância desses trabalhos foi feito recentemente com a atribuição do Prêmio Nobel de Fisiologia e Medicina de 2004 a Richard Axel e Linda B. Buck pelo seu trabalho de descoberta dos genes codificadores das proteínas dos receptores de odores no epitélio olfatório [Buck e Axel 1991].

Nos mamíferos, o ar inalado entra pelas narinas e segue até a sua parte mais dorsal onde está localizado o epitélio olfatório, uma fina camada de células sensíveis às moléculas dos odores [Kandel, Schwartz e Jessell 2000]. O epitélio olfatório contém da ordem de $10^{6}$ a $10^{7}$ neurônios sensoriais (neurônios receptores olfatórios).

Acredita-se que cada um desses neurônios receptores olfatórios expresse nas suas membranas celulares um único receptor molecular selecionado de um repertório de aproximadamente 1000 receptores (a maior super-família de genes do genoma dos mamíferos). Um receptor molecular olfatório não reconhece moléculas inteiras, mas características físico-químicas específicas das moléculas odorantes [Araneda, Firestein e Kini 2000]. Isto sugere que um dado neurônio receptor olfatório responde a umas poucas moléculas odorantes - aquelas que possuem as características específicas para se ligar ao receptor molecular expresso pelo neurônio.

No epitélio, os neurônios receptores olfatórios que expressam um dado receptor têm sua distribuição espacial restrita a uma de quatro zonas distintas (Figura 2.11), sendo que dentro da sua zona correspondente os neurônios receptores estão amplamente dispersos e misturados com outros neurônios receptores que expressam receptores diferentes. Isto implica que moléculas odorantes diferentes são codifica- 


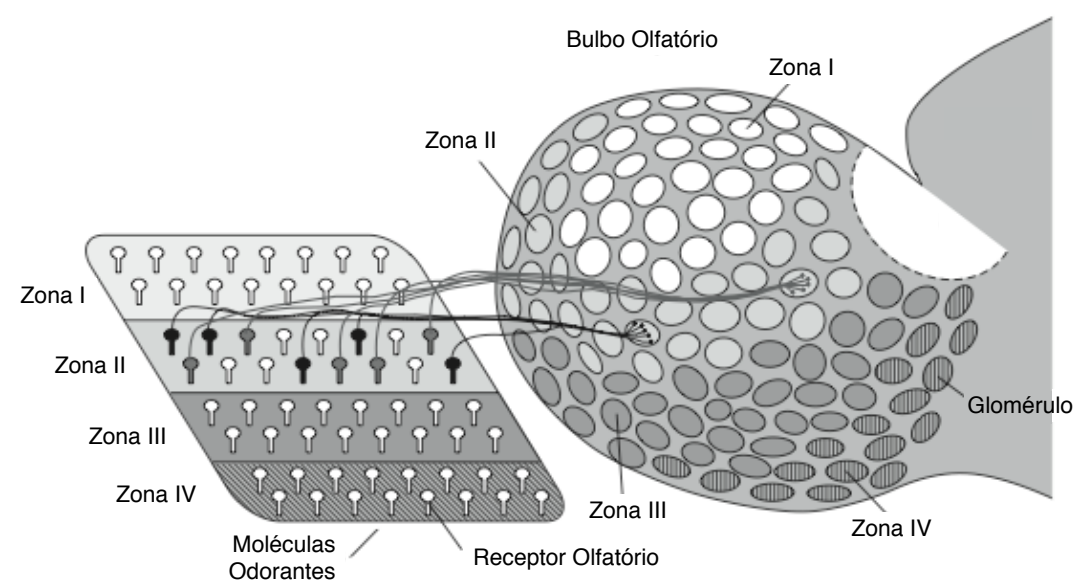

Figura 2.11: Esquema do padrão de conexões entre o epitélio olfatório e o bulbo olfatório. O epitélio é dividido em quatro zonas (I, II, III e IV) e os tipos de neurônios receptores que estão em uma zona não são encontrados em outras zonas. Os neurônios receptores de uma dada zona do epitélio enviam projeções para glomérulos da zona correspondente (I, II, III e IV) no bulbo olfatório. Os axônios dos neurônios receptores que expressam o mesmo receptor de características moleculares (em preto ou cinza na figura) convergem para um único glomérulo específico no bulbo olfatório. Figura baseada na Figura 2 de [Mori, Nagao e Yoshihara 1999].

das no epitélio olfatório por diferentes combinações espaciais - com sobreposição de neurônios receptores olfatórios [Malnic et al. 1999]. O ponto importante a ser notado aqui é que esse esquema combinatorial de codificação implica em uma representação temporalmente invariante de odores no epitélio olfatório [Laurent 1997].

Na projeção da informação do epitélio olfatório para o bulbo olfatório ocorre uma convergência notavelmente precisa dos axônios dos neurônios receptores olfatórios sobre estruturas denominadas glomérulos (Figura 2.11). Os glomérulos são estruturas aproximadamente esféricas dentro das quais os axônios vindos dos neurônios receptores olfatórios do epitélio fazem sinapses excitatórias com dendritos de neurônios mitrais e tufosos (que serão denominados aqui como neurônios $\mathrm{m} / \mathrm{t}$ para simplificar), que são os neurônios de saída do bulbo olfatório(Figura 2.12).

O padrão de conexões entre o epitélio e o bulbo é tal que todos os neurônios receptores olfatórios que expressam um dado receptor convergem seus axônios para um pequeno número de glomérulos - talvez para apenas um na maioria dos casos [Mori, Nagao e Yoshihara 1999]. Essa convergência provoca uma redução brutal (por um fator de redução da ordem de 10000:1) na dimensionalidade da representa- 


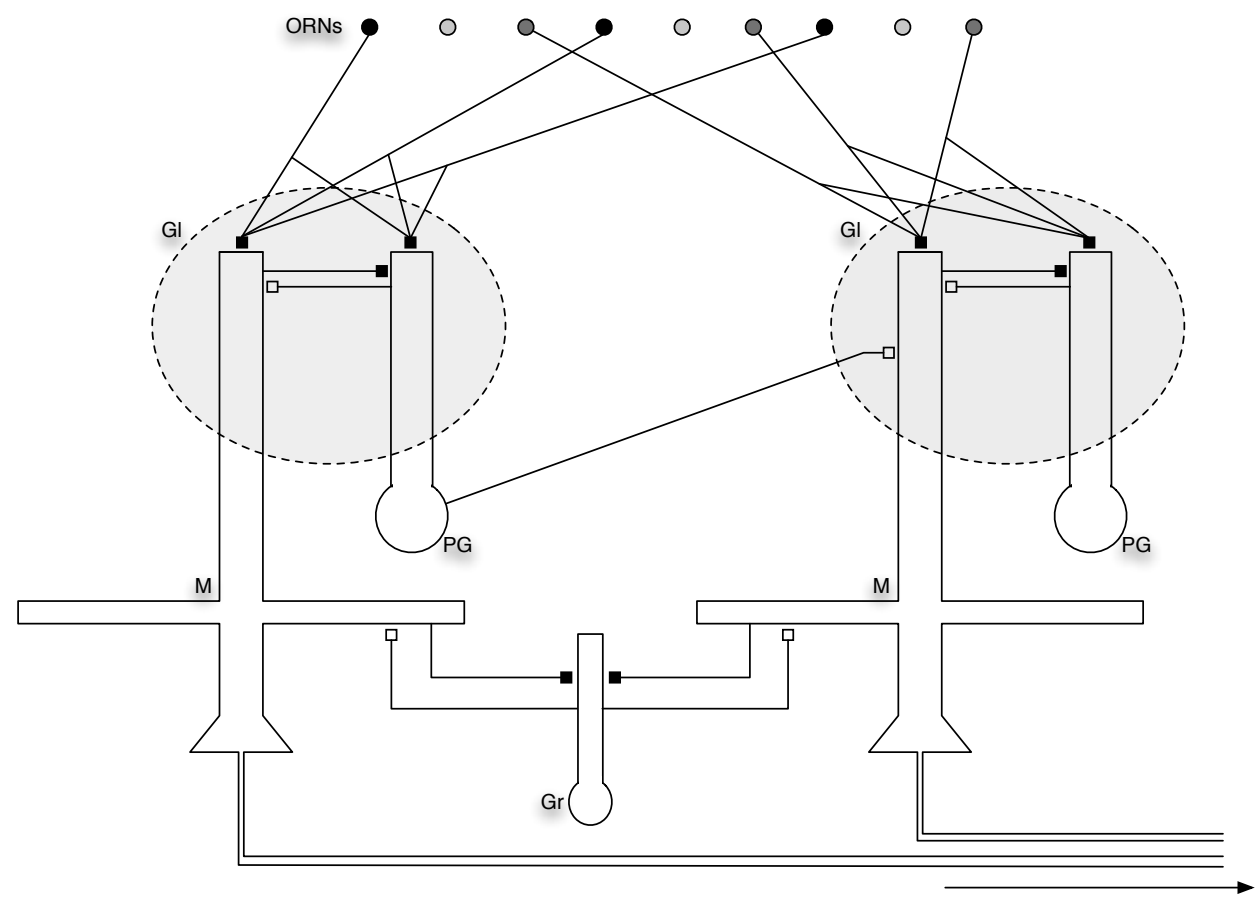

Figura 2.12: Esquema do padrão de conexões sinápticas no bulbo olfatório. Os dendritos primários dos neurônios mitrais (M) e tufosos (T) recebem sinapses excitatórias (indicadas por setas brancas) dos axônios dos neurônios receptores olfatórios nos glomérulos (GL). Existem dois tipos de interneurônios que fazem sinapses inibitórias (setas escuras) nos neurônios $\mathrm{m} / \mathrm{t}$ - os neurônios periglomerulares (PG) e os neurônios granulares $(\mathrm{Gr})$. Os primeiros fazem sinapses com os dendritos primários dos neurônios $\mathrm{m} / \mathrm{t}$ e os segundos fazem sinapses com os dendritos secundários desses neurônios, que se estendem horizontalmente por longas distancias. Os neurônios de saída do bulbo são os neurônios m/t. 
ção espacial das características de uma molécula odorante. Desta forma, na camada glomerular do bulbo olfativo existe uma nova representação espacial das características dos odores em que cada um dos 1000 tipos de receptor é codificado por um pequeno número de glomérulos.

Estudos de imageamento metabólico e óptico sobre a resposta dos glomérulos do bulbo olfatório a moléculas odorantes [Rubin e Katz 1999] permitiram determinar que a projeção do epitélio olfatório para o bulbo olfatório é topográfica: neurônios receptores sensíveis a características moleculares parecidas convergem seus axônios para glomérulos vizinhos. Desta forma, tanto no nível do epitélio olfatório como no da camada glomerular na entrada do bulbo olfatório há uma representação espacial de moléculas odorantes em que elas são decompostas em características que ativam diferentes combinações espaciais de neurônios receptores olfatórios ou glomérulos.

Este último achado implica que cada molécula odorante produz um padrão espacial de ativação específico - um mapa do odorante - na camada glomerular do bulbo. Esse padrão espacial é transformado pelo bulbo, devido à sua conectividade intrínseca (Figura 2.12), em um padrão espaço-temporal [Laurent et al. 2001, Spors e Grinvald 2002] refletido nos padrõees de disparo das suas células de saída - as células m/t - que transmitem os resultados das computações feitas pelo bulbo aos centros corticais olfatórios superiores. Portanto, características essenciais de um odor, por exemplo sua identidade e concentração (intensidade), parecem ser representadas dinamicamente pelo padrão de atividade espaço-temporal induzido pelo odor nas células $\mathrm{m} / \mathrm{t}$ do bulbo olfatório [Laurent et al. 2001, Stopfer, Jayaraman e Laurent 2003].

O entendimento dos mecanismos pelos quais a circuitaria interna do bulbo olfatório produz e mantém esses padrões de atividade, bem como do papel que tais padrões espaço-temporais teriam no processamento da informação olfatória, é uma questão ainda em aberto na neurobiologia contemporânea [Friedrich 2002, Korsching 2002, Wilson e Stevenson 2003, Souza e Roque 2004]. A maneira pela qual os centros corticais olfatórios extraem informação dos padrões espaço-temporais do bulbo para reconhecer um odor também é pouco conhecida e objeto de intenso debate [Haberly 2001, Laurent et al. 2001, Wilson e Stevenson 2003].

Como o objetivo deste trabalho não é estudar o sistema olfatório, mas utilizar 
alguns dos seus princípios de funcionamento para obter inspiração para o desenvolvimento de um sistema artificial de reconhecimento de padrões, o que foi descrito acima sobre o bulbo olfatório é suficiente para o trabalho aqui apresentado.

\subsection{Consideraçõs Finais}

Fizemos neste capítulo a revisão bibliográfica básica para o trabalho descrito nesta tese. Iniciamos pelas abordagens básicas para a modelagem computacional de neurônios e sinapses e terminamos com uma revisão sucinta sobre a anatomia e o funcionamento do bulbo olfatório, sobre o qual a rede pulsada deste trabalho está fortemente inspirada. No próximo capítulo apresentaremos o framework para modelagem e simulação de redes neurais pulsadas desenvolvido durante a execução desta tese. 


\section{CAPÍtUlo}

\section{Nemos: Neuron Models SiMUlation SYSTEM}

\subsection{Considerações Iniciais}

Para a realização deste trabalho desenvolvemos um framework, chamado Nemos (Neural Models Simulation System), que é uma plataforma computacional feita em Java voltada para as áreas de aprendizado de máquina, redes neurais e neurociência computacional. Apesar da existência de algumas ferramentas para simulação de redes neurais e de modelos de neurônios detalhados ou simplificados, como, por exemplo, Genesis [Bower e Beeman 1998], Neuron [Carnevale e Hines 2006], Nest [Gewaltig e Diesmann 2007], CSim [Pecevski, Natschläger e Schuch 2009], entre outras, optamos pelo desenvolvimento do Nemos pelas seguintes razões:

1. Para termos maior controle e conhecimento da estrutura básica (núcleo ou kernel) da ferramenta, uma vez que em sistemas de terceiros estaríamos limitados pela documentação e capacidade estrutural do mesmo.

2. Para termos um sistema em uma ferramenta multiplataforma, ou seja, que possa ser executada na maioria dos sistemas operacionais. Neste caso estamos usando linguagem Java.

3. Pela coesão da plataforma, uma vez que, algumas das plataformas disponíveis estão escritas em diferentes ferramentas, por exemplo em C e Matlab.

4. Para obtermos know how no desenvolvimento de ferramentas que simulam sistemas dinâmicos, mais espeficicamente redes neurais pulsadas, e analisam 
os dados obtidos em tais simulações. Esse item tem como objetivo provocar uma interação com desenvolvedores de outras ferramentas, compartilhando informações úteis para a otimização, capacidade, usabilidade e divulgação do framework.

Nas próximas subseções iremos apresentar alguns conceitos sobre simulação e como tais conceitos foram usados para implementarmos o framework Nemos. Na subseção final mostraremos alguns resultados de simulações e testes comparativos feitos com o Nemos.

\subsection{Estratégias de Simulação}

Uma das partes mais importantes em uma plataforma de desenvolvimento de redes neurais é a estratégia de simulação, que compõe o núcleo da plataforma. Ela diz respeito à forma da evolução temporal dos modelos de neurônios, sinapses e outras entidades auxiliares da rede neural. Podemos citar, basicamente, duas estratégias de simulação para redes neurais e, de modo geral, para sistemas dinâmicos:

1. Simulação Síncrona: também chamada de algoritmo clock-driven, onde todas as entidades ${ }^{1}$ do sistema são atualizadas a cada passo de tempo, ou seja, as variáveis de estado das entidades são atualizadas a cada $d t, X(t) \rightarrow X(t+d t)$. Um exemplo de simulação síncrona de redes neurais pode ser visto no pseudocódigo dado na Figura 3.1.

2. Simulação Assíncrona: também chamada de algoritmo event-driven, onde as variáveis de estado são atualizadas nos instantes de ocorrência de eventos temporais determinados estatisticamente; logo, as entidades possuem filas que armazenam tais eventos a fim de serem processados.

Para a construção do Nemos foi adotada a estratégia de simulação síncrona, pois ela oferece algumas vantagens tais como: menor complexidade de implementação quando comparada com a estratégia assíncrona e universalidade algorítmica, ou seja, é possível desenvolver um núcleo de propósito geral para simulação de sistemas dinâmicos.

\footnotetext{
${ }^{1}$ Como entidades podem ser considerados todos os modelos que possuem evolução temporal
} 


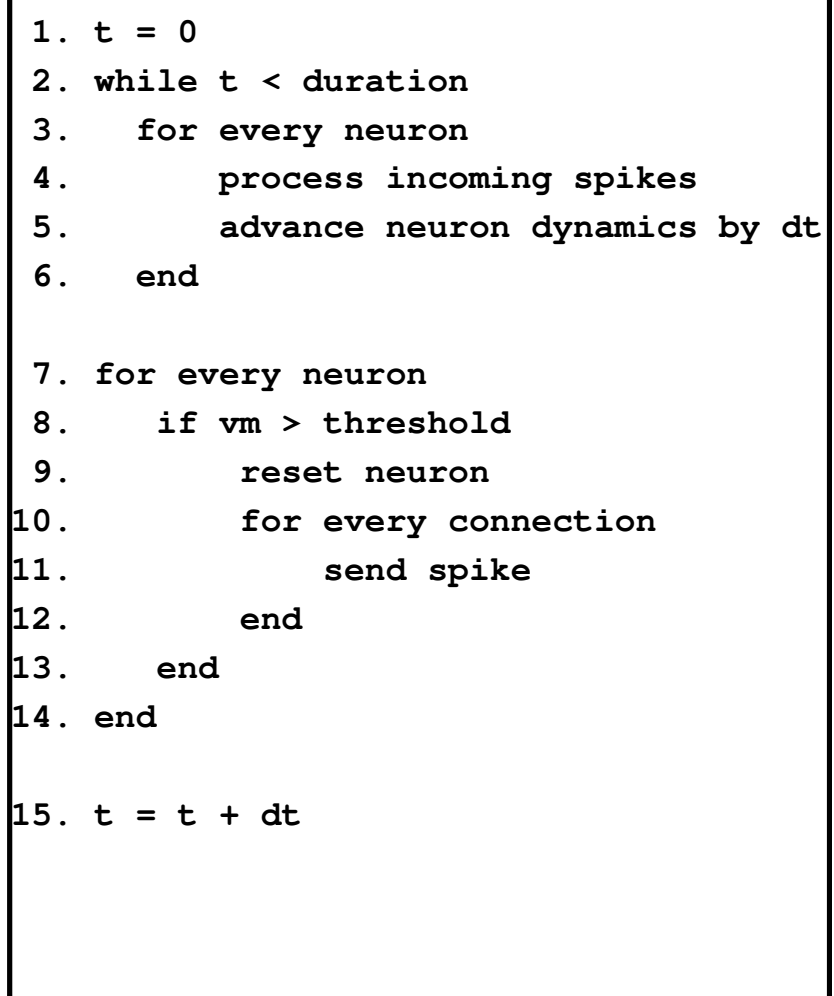

Figura 3.1: Pseudo-código de uma Simulação Síncrona.

Para que o pseudo-código síncrono pudesse ser implementado com o máximo de coesão e mínimo de acoplamento entre os módulos de programação, uma arquitertua orientada a objetos foi especificada para tal fim.

\subsection{Arquitetura Básica do Nemos}

O Nemos possui uma estrutura de pacotes (diretórios) bem definida (Figura 3.2). Podemos ver na Figura 3.2 que todas as classes usadas para simulação estão abaixo do pacote nemos. Os nomes dos pacotes são auto-explicativos e auxiliam o usuário a localizar os itens desejados, por exemplo, todos os modelos de neurônios estão no pacote neurons, o mesmo acontecendo com as sinapses, redes e mecanismos de estímulo (clamps). Além disso, os pacotes de suporte são independentes dos pacotes de modelos, ou seja, para gravarmos qualquer variável devemos usar os itens presentes 
no pacote recorders, mas para manipularmos eventos que podem ocorrer numa simulação, tais como evolução temporal ou chegada de disparos às sinapses, recorremos aos itens do pacote simulations. Além disso, todo o suporte matemático, tais como as ferramentas de integração de equações diferenciais, bem como as ferramentas de vizualização estão nos pacotes math e views, respectivamente.

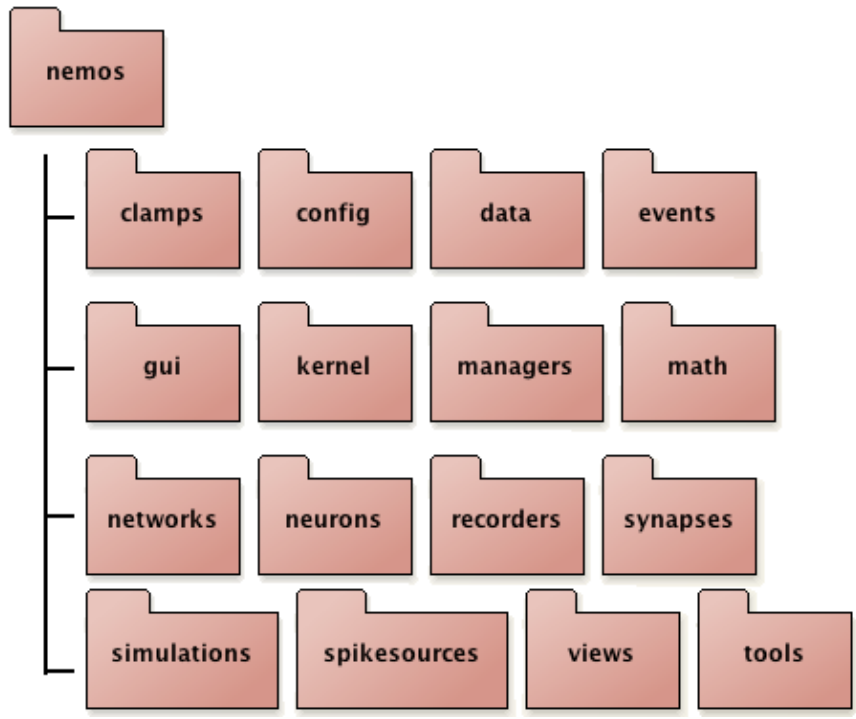

Figura 3.2: Pacotes nos quais se dividem os principais itens do Nemos de acordo com sua funcionalidade.

A Figura 3.3 apresenta as classes do pacote básico da plataforma, que representa o núcleo de propósito geral para simulação síncrona. Não entraremos em detalhes sobre a implementação do núcleo, entretanto é necessário fazer algumas considerações a partir dessa figura. A classe Time é responsável por manter as informações temporais da simulação em questão e por controlar como e a que passo o tempo deve evoluir, garantindo assim que as equações diferenciais e demais itens da simulação possam integrar seus resultados e interagir em sincronia.

Todas as entidades do sistema, ou seja, aqueles que evoluem no tempo são objetos da classe Agent. Esta classe provê o funcionamento básico de cada entidade, ou seja, fornece um identificador único através da classe IdGenerator, nome da entidade, que faz a ligação com o tempo global do sistema instanciado pela classe Time, garatindo assim que todas as entidades acessem às mesmas informações sobre o tempo de simulação. A classe Agent possui duas subclasses diretas: a classe AgentODE, que é 
responsável por implementar funcionalidades para as variáveis do sistema dinâmico em questão, tais como técnicas para resolução das equações diferenciais; e a classe AgentStep, que dá suporte às variáveis do sistema dinâmico evoluindo no tempo, mas não têm equações diferenciais para serem integradas.

Outra consideração a ser feita diz respeito à classe Nemos, que é a classe básica responsável por controlar toda a simulação e determinar a ordem de execução dos agentes do sistema, sejam eles equações diferenciais ou não. Além disso, esta classe também coordena a resposta aos eventos previamente programados durante o desenvolvimento do código de simulação em questão.

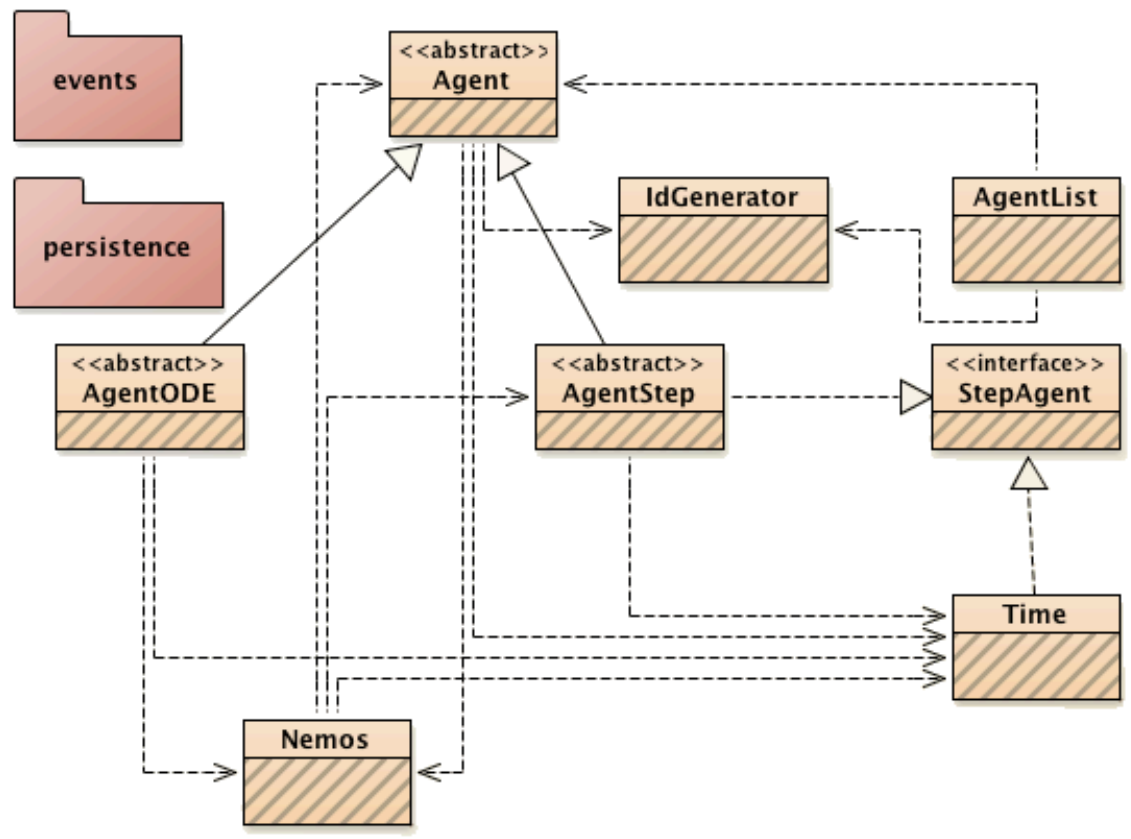

Figura 3.3: Diagrama de classes representando o kernel do Nemos.

Apesar de não estar apresentado, é importante fazer uma observação quanto ao tipo de dados que as entidades trocam entre si, pois isto consititui um desafio à manutenção da universalidade e da capacidade de generalização do kernel, uma vez que diferentes problemas necessitam de diferentes tipos de dados para a simulação ser bem sucedida. Para isso, especificamos a classe abstrata DataAgent de maneira que as entidades trocam objetos desta classe entre si. A vantagem dessa abordagem é que de acordo com a simulação podemos derivar novas classes a partir de DataAgent e em tais classes armazenar nossos dados. Por exemplo, a classe RealData armazena 
dados de números reais; já a classe SpikeData armazena todos os disparos emitidos por um neurônio, i.e. derivados da classe AgentODE, até o tempo atual.

\subsubsection{Métodos de Integração}

Como o Nemos pode ser utilizado para implementação e simulação de qualquer sistema dinâmico, ele deve prover diferentes técnicas de integração de equações diferenciais ordinárias (EDOs), pois diferentes sistemas de EDOs necessitam de diferentes abordagens de integração. A Figura 3.4 ilustra a estrutura proposta para a implementação disso no Nemos. O usuário implementa apenas a técnica a ser utilizada independentemente das demais existentes. Desta forma, mesmo os sistemas de EDOs já implementados podem fazer uso de qualquer uma das técnicas de integração presentes no Nemos.

No Nemos os modelos, ou entidades, que são descritos por EDOs implementam a interface $O D E$, enviam e recebem dados através da classe ODEData, que é utilizada pelo ODESolver que, por sua vez, é responsável por controlar o sistema de EDOs contido em ODESystem. Por questões de usabilidade e comodidade, já disponibilizamos no Nemos pacotes que implementam algumas técnicas de integração existentes, a saber Euler, Backward euler, Runge-Kutta de quarta ordem e Runge-Kutta de quarta ordem com passo variável.

\subsection{Modelos de Neurônios e Sinapses}

Para a modelagem de neurônios especificamos uma hierarquia (Figura 3.5) simples de ser usada, pois já existem modelos de neurônios implementados, e também simples de ser extendida, ou seja, novos modelos podem ser adicionados usando como base os modelos já existentes. Na Figura 3.5 apresentamos a hierarquia de classes, onde há duas classes básicas: a classe Neuron, que provê as funcionalidades básicas de um modelo de neurônio, tais como, extensão da classe AgentODE, variável de potencial de membrana, lista de ligação com sinapses, entre outros; e a classe SpikeNeuron, que controla a geração de potenciais de ação e armazena os tempos em que os mesmos ocorreram. Essas classes não são usadas diretamente, entretanto elas deixam o Nemos mais transparente para o usuário e reduzem a reescrita de código. 


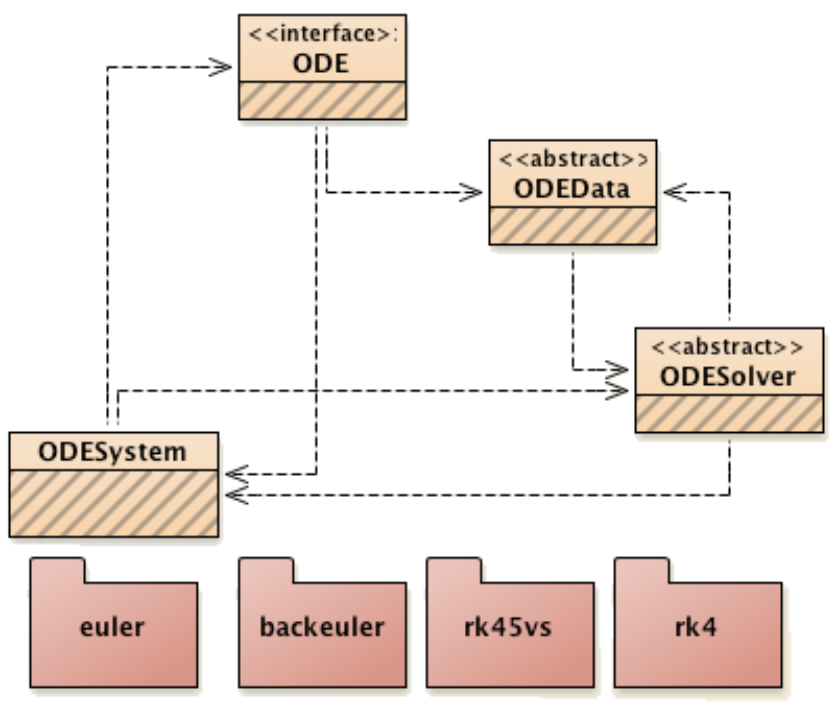

Figura 3.4: Diagrama de classes representando as funções matemáticas disponíveis no Nemos, bem como as classes contendo as técnicas de integração para as equações diferenciais.

Além disso, o Nemos possui cinco modelos de neurônios que podem ser utilizados pelos usuários em suas simulações. As classes IzhiNeuron, e SimpleNeuron implementam duas versões do formalismo de Izhikevich [Izhikevich 2000, Izhikevich 2003, Izhikevich 2004, Izhikevich 2007] apresentado no Capítulo 2 e as classes IFNeuron, IFBurst e AdExNeuron implementam modelos da família integrae-dispara, sendo que a primeira é a versão tradicional [Gerstner e Kistler 2002] com apenas uma EDO, a segunda apresenta um comportamento em rajada [Gerstner 1995, Gerstner e Kistler 2002] e a terceira possui comportamento adaptativo exponencial [Brette e Gerstner 2005].

O usuário pode criar seus próprios modelos estendendo as classes Neuron, SpikeNeuron, ou mesmo os modelos já existentes no Nemos. Desta forma temos uma estrutura em que o usuário se concentra apenas na sua implementação.

No caso das sinapses, que possuem o papel de transmitir informações entre dois neurônios (o pré- e o pós-sináptico), o Nemos implementa as sinapses como funções $\alpha$, conforme visto no Capítulo 2. É importante ressaltar que as sinapses implementadas, bem como sua classe base Synapse, são do tipo spike-triggered, ou seja, elas são ativadas a partir do disparo ocorrido no neurônio pré-sináptico somado a um atraso temporal pré-estabelecido. Além disso, é possível inserir nas sinapses mecanismos 


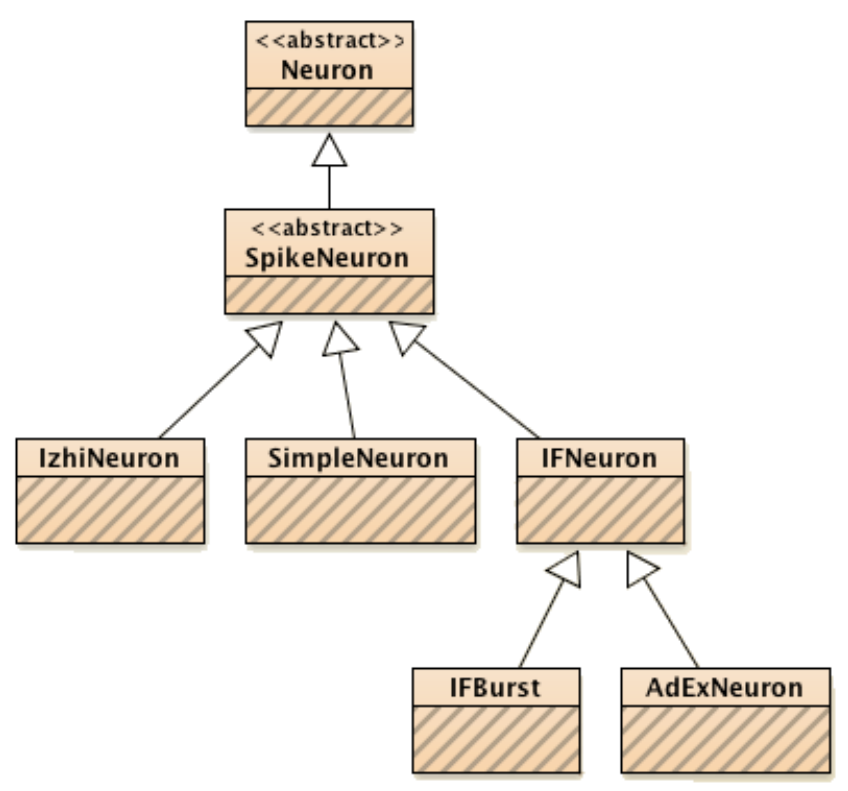

Figura 3.5: Diagrama de classes representando os modelos de neurônios disponíveis no Nemos. Os modelos seguem uma hierarquia, onde os modelos mais altos são mais gerais e servem de base para os modelos com propósitos mais específicos.

de plasticidade, e dinâmica temporal.

\subsection{Redes de Neurônios}

Apesar de os neurônios e sinapses não possuírem estrutura espacial, as redes geradas a partir da criação e conexão dos neurônios podem ter que levar em conta a posição dos neurônios no espaço euclidiano. Para fazer isso no Nemos, desenvolvemos um pacote chamado networks, que contém a classe NeuralNetwork que coleciona neurônios e suas sinapses sem considerar sua eventual posição no espaço. Esta classe é útil para simulações onde a política de conexões e interações entre os neurônios não leva em conta o fator espacial. Já a classe NeuronPool possui as mesmas características da classe NeuralNetwork e, além disso, armazena a estrutura espacial da rede neural em questão, ou seja, ela torna possível determinar/consultar onde está cada um dos neurônios.

Podemos visualizar a classe NeuronPool como se fosse uma caixa onde podemos armazenar os neurônios. Essa caixa pode ser posicionada em um local no espaço euclidiano, de maneira que podemos ter vários objetos to tipo NeuronPool dispostos 
espacialmente e gerenciados pela classe NeuralMicrocircuit. O desenho da Figura 3.6 mostra um exemplo de quatro pools de neurônios dentro do espaço determinado pelo microcircuito, assim é possível determinar a posição de cada neurônio, seja a posição relativa ao seu pool ou a posição relativa ao espaço do microcircuito. A classe NeuronPool associa uma coordenada em três dimensões para todos os seus neurônios.

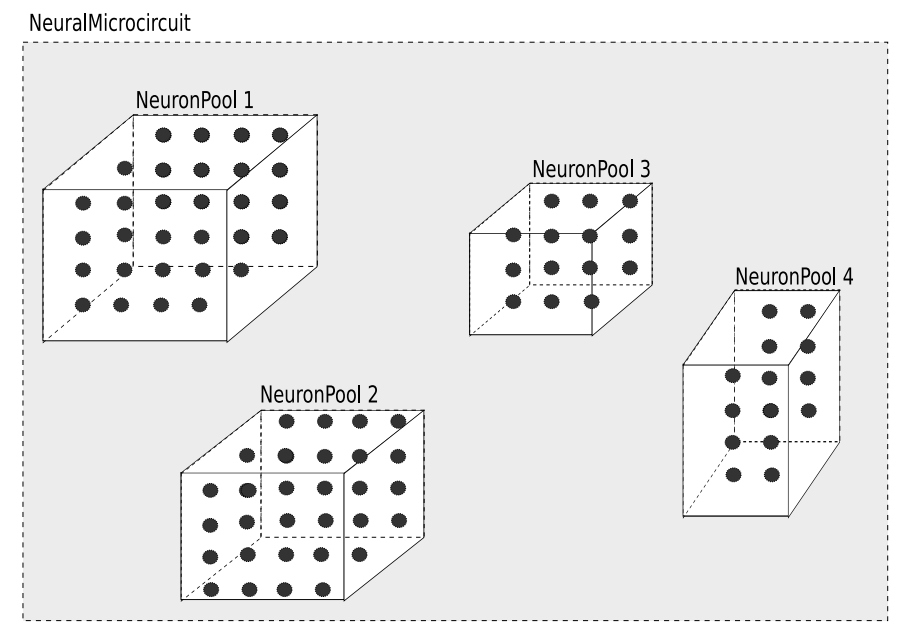

Figura 3.6: Espaco euclidiano 3D utilizado pelo Nemos, onde as esferas indicam os neurônios.

\subsection{Usando o Nemos}

Nesta seção apresentaremos três exemplos de uso direto do Nemos com objetivo de ressaltar sua boa usabilidade e flexibilidade para a construção de diversas simulações. É importante frisar que estes exemplos de uso não cobrem toda a versatilidade e características do Nemos. Para auxiliar o usuário sobre todos os recursos do Nemos, planeja-se incluir tutoriais próprios para esse fim (em uma versão futura a ser disponibilizada pela internet).

O primeiro exemplo, apresentado no Algoritmo 3.1 abaixo, tem como objetivo verificar a resposta de três modelos de neurônios do tipo integra-e-dispara, os quais são estimulados por diferentes valores de corrente. Inicialmente, na linha dois do referido algoritmo, configuramos o tempo de simulação, ou seja, o início e o fim da simulação e o passo de tempo utilizados. A seguir, na linha quatro do algoritmo, 
invocamos a interface gráfica do Nemos, que nos apresenta o tempo corrente de simulação, além de funções visuais para que possamos alterar e verificar valores das propriedades dos modelos utilizados. Para a criação dos modelos, que consistem em três grampeamentos de corrente (Iclamp) e três neurônios integra-e-dispara (IFNeuron), utilizamos o comando Nemos.createModels() nas linhas seis e vinte, respectivamente. Este comando é responsável por criar os modelos, na quantidade desejada, e registrá-los no Nemos para a simulação. Além disso, tal comando retorna uma lista com os objetos referentes aos modelos, tornando possível manipulá-los como desejarmos. Por exemplo, o comando Nemos.setValues(), na linha dezesseis, altera as propriedades, indicadas pelo vetor att declarado na linha oito, dos objetos contidos na lista stims, a partir da matriz declarada nas linhas onze, doze e treze. O mesmo comando (Nemos.setValues()) ainda é utilizado na linha vinte e quatro para ligarmos cada um dos estímulos de corrente em stims com os modelos integra-e-dispara respectivos na lista nrns. As linhas dezenove e vinte e dois apresentam o comando Nemos.addPlot(), que cria gráficos para apresentar as correntes dos estímulos e os potenciais de ação dos neurônios, respectivamente. Por fim, as linhas vinte e seis e vinte e oito preparam o Nemos criando os mecanismos necessários para a simulação e executam a mesma.

O resultado da execução do Algoritmo 3.1 é apresentado na Figura 3.7. Nesta figura, a primeira janela diz respeito à interface gráfica do Nemos, invocada por Nemos.gui(); a segunda janela possui os gráficos da corrente dos três estímulos utilizados; e, por fim, a terceira janela apresenta o potencial de cada um dos modelos integra-e-dispara em resposta aos estímulos aplicados, onde é possível notar que cada neurônio responde de maneira diferente em comparação aos outros, pois as correntes que os estimulam diferem em valor, atraso e duração.

O segundo exemplo, apresentado no Algoritmo 3.2, é bastante semelhante ao primeiro, ou seja, temos modelos de neurônios estimulados por grampeamento de corrente. Neste caso, porém, temos dois neurônios de Izhikevich estimulados por grampeamento de corrente (linhas quatro a quinze). Esses dois neurônios estão conectados a um terceiro neurônio, criado na linha dezessete, através de uma sinapse. A linha vinte e um faz exatamente essa conexão, ou seja, cria dois modelos de sinapses e adiciona em cada um neurônio de Izhikevich contido em nrnsIn como 
$\overline{\text { Algoritmo 3.1 Simulação de } 3 \text { modelos de neurônios integra-e-dispara estimulados }}$ por 3 correntes que diferem em valor, atraso e duração.

// Configurando o tempo (início, duração, passo)

2 Time.globalTime.configure $(0.0,1000.0,0.1)$;

3 // Ativando a interface visual do Nemos

Nemos.gui ( ) ;

5 // Criando 3 modelos para grampeamento de corrente

List $\mathbf{s t i m}=$ Nemos. createModels ( "nemos.clamps.Iclamp" ,3);

7 // Criando o vetor de propriedades de Iclamp que serão alteradas

8 String att[] $=\{$ "Imax", "Delay", "Duration" $\}$;

9 // Criando a matriz de valores para cada propriedade (coluna)

10 // de cada um dos 3 Iclamp (linha)

11 Double $\operatorname{val}[][]=$

$12\{\{5.0,50.0,600.0\}$,

$13\{15.0,200.0,600.0\}$,

$14\{20.0,550.0,10.0\}\}$;

15 // Inserindo a matriz val na lista stim de acordo com as propriedades em att

16 Nemos.setValues (stim, att, val);

17 // Criando um gráfico que mostrará o valor de Iclamp no tempo

18 Nemos . addPlot ( "pStims", stim, "Signal" );

19 // Criando 3 modelos integra-e-dispara

20 List nrns $=$ Nemos. createModels ( "nemos.neurons.IFNeuron" , 3);

21 // Criando um gráfico que mostrará o potencial (V) dos IFNeuron criados

22 Nemos.addPlot ("pNrns", nrns, "V");

23 // Connectando cada um dos Iclamp em stim em um IFNeuron em nrns

24 Nemos. set Values (nrns, "Iclamp" , stim );

25 // Prepara a simulação para ser executada

26 Nemos.prepare ( );

27 // Executa a simulação

28 Nemos.run ( );

pré-sináptico e, em ambas, o neurônio de Izikevich em nrnOut como pós-sináptico.

Como resultado a simulação do Algoritmo 3.2 gera quatro gráficos apresentados na Figura 3.8. Nesta figura, o gráfico (a) indica os valores de corrente que estimulam os neurônios, de mesma cor, no gráfico (b), onde é possível perceber as diferenças entre os potenciais de ação dos neurônios em termos de latência e frequência. O terceiro neurônio, mostrado no gráfico (d), responde aos neurônios em (b) através das sinapses apresentadas em (c). É importante notar que o Nemos fornece várias funcionalidades que permitem ao usuário controlar e verificar os resultados de sua 


\section{Finished}
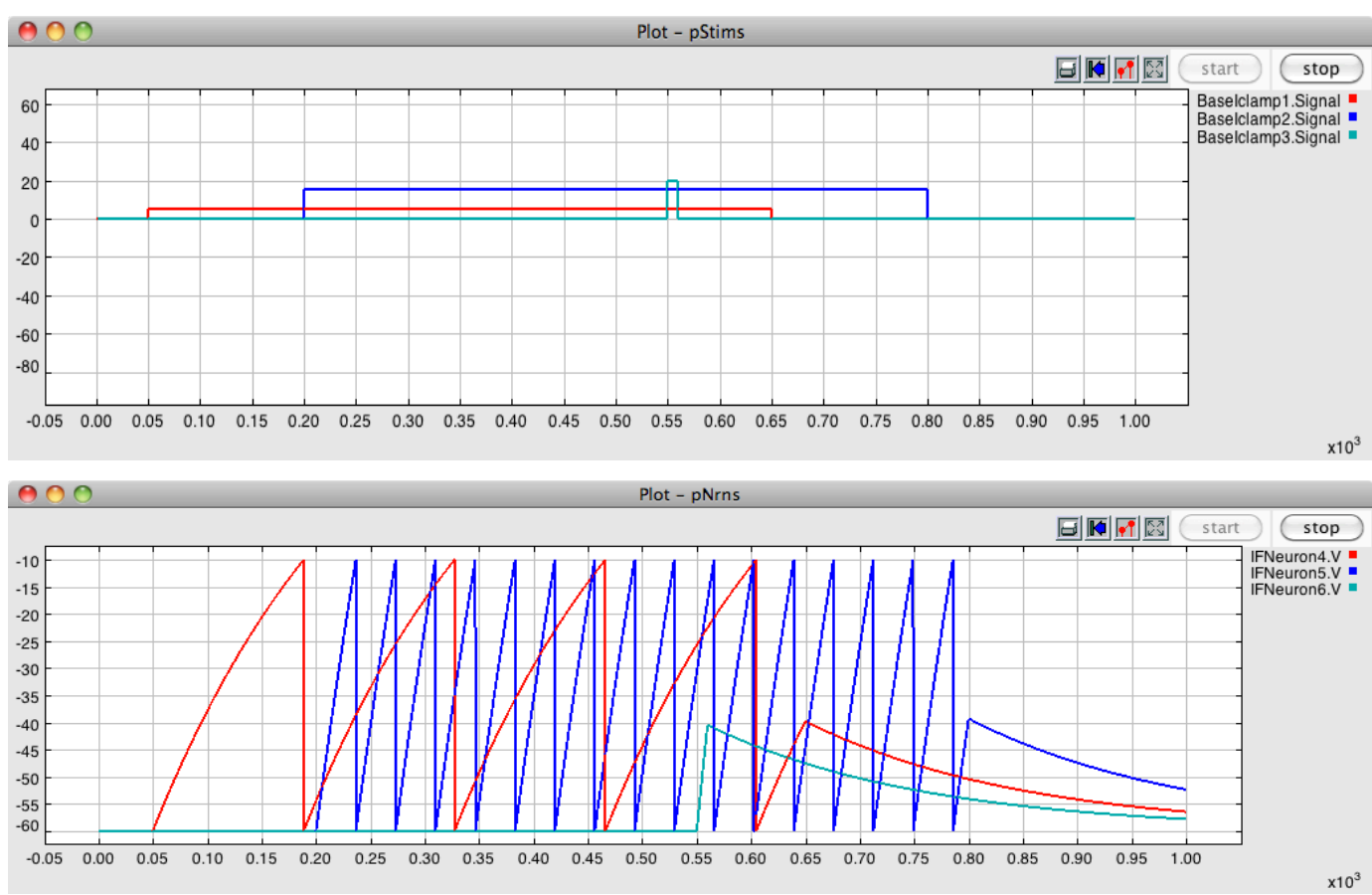

Figura 3.7: Resultado da simulação do Algoritmo 3.1. A primeira janela é a parte de interação visual do Nemos, a segunda representa os estímulos de corrente e a terceira mostra as respostas dos neurônios aos estímulos. A cor em ambas as janelas faz o par estímulo-potencial.

simulação. Por exemplo, é possível verificar a influência dos estímulos de corrente nos dois primeiros neurônios e como os mesmos excitam o terceiro neurônio através de conexões sinápticas.

O último exemplo (Algoritmo 3.3) trata da criação e manipulação de redes de neurônios. São criados quinhentos neurônios de Izhikevich (linha quatro) em uma lista, os quais são adicionamos a um objeto do tipo NeuronPool. A linha seis mostra a criação do objeto através da lista de neurônios e da disposição em três dimensões dos mesmos, neste caso com coordenadas $(10,10,5)$. Na linha oito conectamos os neurônios entre si usando um objeto do tipo AlphaSynapse com probabilidade de 0.1, ou seja, cada neurônio estará conectado a, no máximo, $10 \%$ de seus pares. É importante ressaltar que, apesar de não mostrado, o Nemos possui regras de conexão 
$\overline{\text { Algoritmo 3.2 Simulação de } 3 \text { neurônios de Izhikevich onde dois neurônios, estimu- }}$ lados diretamente por grampeamento de corrente, se conectam através de sinapses excitatórias com um terceiro neurônio.

1 Time.globalTime.configure $(0.0,1000.0,0.1)$;

2 Nemos.gui ();

3

List $\mathbf{s t i m}=$ Nemos. createModels ( "nemos.clamps.Iclamp" ,2);

String att[] $=\{$ "Imax", "Delay", "Duration" $\}$;

Double val[][] =

$\{\{4.0,50.0,400.0\}$,

$\{6.0,300.0,600.0\}\}$;

Nemos . set Values ( $\mathbf{s t i m}$, att, val);

Nemos . addPlot ( "pStims", stim, "Signal" );

List $\mathbf{n r n s I n}=$ Nemos. createModels ( "nemos.neurons.IzhiNeuron" , 2 );

Nemos . addPlot ( "pNrnsIn" , nrnsIn, "V");

Nemos . set V alues (nrnsIn, "Iclamp", stim );

List nrnsOut $=$ Nemos. createModels ( nemos.neurons.IzhiNeuron" );

Nemos . add Plot ( "pNrnsOut", nrnsOut, "V" );

// Conecta dois neurônios a um terceiro através de sinapse alpha

List synapses $=$ Nemos. connectManyToOne

(nrnsIn , nrnsOut . get ( 0$)$, "nemos.synapses.AlphaSynapse" );

Nemos . addPlot ( "pSy", synapses , "I");

Nemos.prepare ( );

Nemos.run ();

que levam em conta a posição espacial do neurônio em questão, promovendo assim maior plausibilidade biológica. Ajustamos, nas linhas dez e onze respectivamente, os pesos sinápticos para 0.1 , sendo que $20 \%$ deles serão inibitórios. A seguir, criamos um gerador de disparos poissonianos na linha quinze e conectamos tal objeto com o primeiro neurônio da lista (linha 19). O Nemos possui uma série de geradores de potenciais de ação que servem a diversos propósitos, de acordo com o objetivo da simulação em questão. Por fim, as linhas vinte e três a vinte e nove criam um objeto do tipo NeuralMicrocircuit, que é capaz de ser vizualizado.

A Figura 3.9 apresenta a gráfico de vizualização da rede no espaço 3D, que 
Figura 3.8: Resultado da simulação do Algoritmo 3.2. (a) Estímulos de corrente. (b) Respostas de dois neurônios de Izhikevich aos estímulos em (a). A mesma cor é usada para um estímulo e a resposta do neurônio que o recebe. (c) Correntes sinápticas referentes a sinapses excitatórias feitas pelos neurônios em (b) em um terceiro neurônio de Izhikevich. (d) Resposta do neurônio de Izhikevich que recebe as entradas sinápticas mostradas em (c).

permite também ver as conexões de um neurônio desde que o mesmo seja selecionado no gráfico. Além disso, a figura apresenta também o rasterplot da rede. O rasterplot é um diagrama em que o tempo é colocado ao longo do eixo das abscissas e os neurônios, numerados em ordem sequencial, são colocados ao longo do eixo das ordenadas. Cada vez que um dado neurônio emite um disparo, um ponto é colocado no diagrama na intersecção das linhas que correspondem ao neurônio e ao instante de tempo em que ocorreu o disparo. Desta forma, pode-se ver como os disparos de toda a população de neurônios se comportam ao longo do tempo da simulação.

Os três exemplos aqui apresentados são simples, mas mostram a facilidade de uso do Nemos, em que é possível espeficificar uma simulação com poucas linhas de código. A seguir, discutiremos o desempenho do Nemos e como ele pode ser melhorado. 
$\overline{\text { Algoritmo 3.3 Simulação de uma rede com } 500 \text { neurônios espacialmente dispostos, }}$ onde cada neurônio está conectado com 10\% do total de neurônios e $20 \%$ das sinapses são inibitórias.

1 Time.globalTime.configure $(0.0,1000.0,0.1)$;

2 Nemos.gui ();

3

List $\operatorname{nrnp} 1=$ Nemos. createModels ( "nemos.neurons.IzhiNeuron" , $10 * 10 * 5$ );

// Dispondo a lista de neurônios nrnp1 no espaço euclidiano

NeuronPool p1 = Nemos. createPool (nrnp1, "10,10,5" , "0,0,0" );

// Conectando os neurônios da rede entre si com probabilidade de 0.1

List $\mathbf{s y n a p s e s}=$ Nemos. connect $(\mathbf{n r n p 1}, \mathbf{n r n p 1}$, "nemos.synapses.AlphaSynapse" , 0.1$)$;

// Ajustando valores dos pesos sinápticos

Nemos . setValues (synapses, "Weight" ,0 .1);

// $20 \%$ dos pesos sinápticos são inibitórios

Nemos. setValues (synapses, "Weight", - 0.1,0.2);

Criando o um gerador de disparos poissonianos

List stims $=$ Nemos. createModels ( "nemos.spikesources.PoissonSpikes" );

Double lambda[] $=\{0.1\}$;

Nemos. setValues (stims, "Lambda" , lambda);

// Conectando o gerador de disparos ao primeiro neurônio da lista

List conns $=$ Nemos. connectOneToOne( stims, nrnp1, "nemos.synapses.AlphaSynapse" );

Nemos. set Values (conns, "Weight",0.1);

\section{/ Criando o circuito neural}

NeuralMicrocircuit circuit $=$

circuit . addPool (p1);

new NeuralMicrocircuit ("Neural Net");

// Criando a vizualização espacial dos neurônios

new NeuralMicrocircuitView (circuit);

// Criando um rasterplot

Nemos. addRasterPlot ( "rasterPlot" ,nrnp1);

Nemos . prepare ( );

Nemos.run ();

\subsection{Testes e Comparações}

Fizemos testes de desempenho, em termos de tempo real de simulação, comparando o Nemos e o Nest [Gewaltig e Diesmann 2007]. Este último é um pacote escrito em $\mathrm{C}++$ com o propósito em simular redes de neurônios simplificados. Ob- 

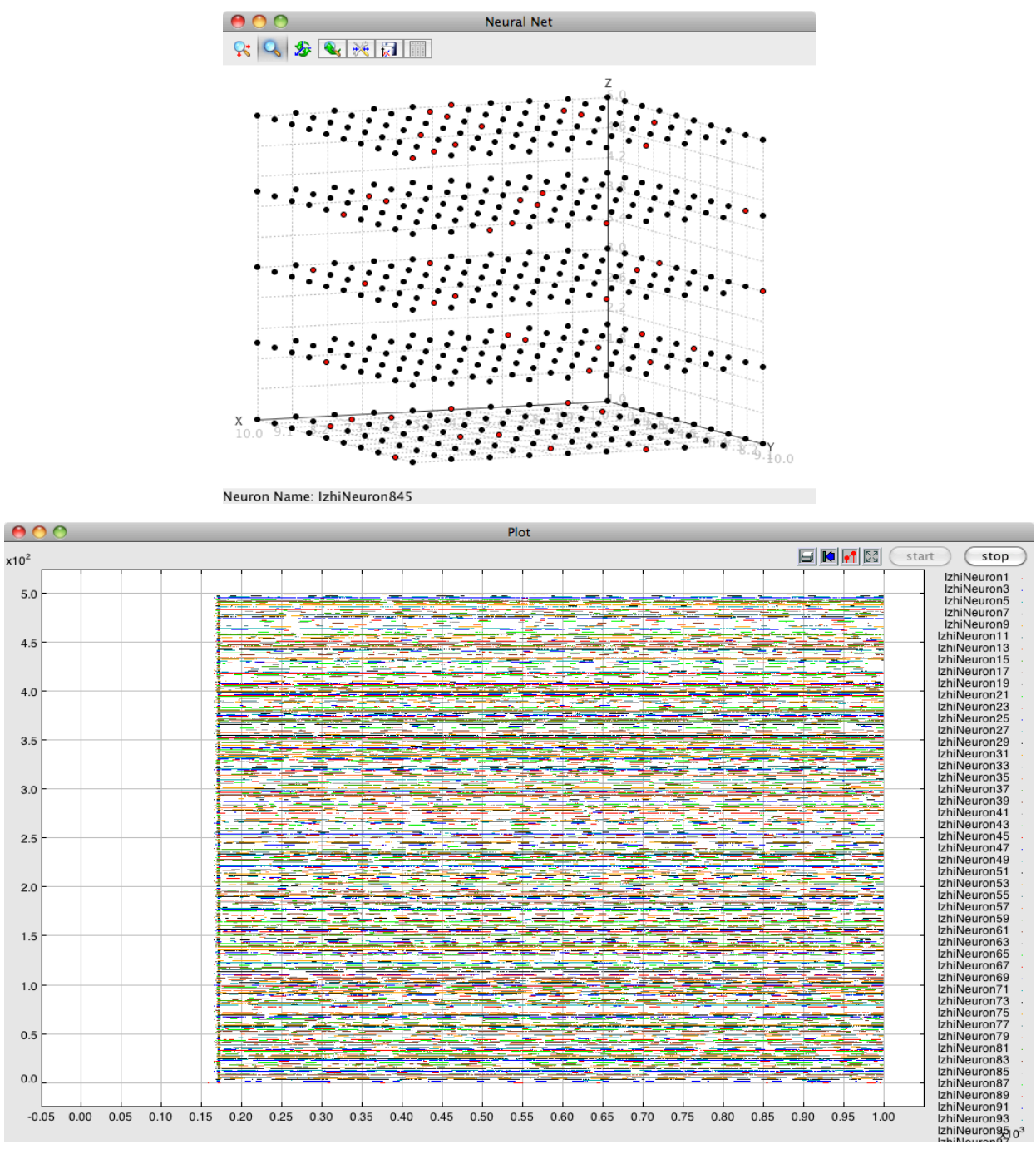

Figura 3.9: Resultado da simulação do Algoritmo 3.3. A janela superior mostra a disposição tridimensional dos neurônios e a janela inferior mostra o rasterplot da rede simulada.

viamente esperamos que o Nemos seja mais lento que o Nest, uma vez que o Nemos, além de ser escrito em Java, que é, relativamente mais lento que o $\mathrm{C}++$, não teve o seu código otimizado visando menor tempo real de simulação. Entretanto, desejamos saber, quantitativamente, a distância entre os desempenhos do Nemos e do Nest para que possamos definir uma futura estratégia de otimização do código do Nemos.

Todas as simulações com o Nemos e o Nest para efeitos comparativos foram rodadas em um computador Apple iMac com processador i3, 4GB de memória RAM 
DDR3 rodando Mac OS X 10.6. Além disso, é importante ressaltar que a medida de desempenho do Nemos é feita usando tempo de simulação do mesmo em relação ao tempo do Nest, ou seja,

$$
\left(t_{\text {Nest }}-t_{\text {Nemos }}\right) * 100 / t_{\text {Nest }}
$$

onde $t_{N e s t}$, e $t_{\text {Nemos }}$ é o tempo de duração da simulação no Nest, e no Nemos, respectivamente.

Inicialmente, simulamos os modelos integra-e-dispara, integra-e-dispara exponencial, integra-e-dispara adaptativo e o modelo de Izhikevich estimulados por uma determinada corrente durante 1 segundo. A Figura 3.10 mostra que o Nemos é um pouco mais rápido na simulação dos neurônios isoladamente, ou seja, o desempenho do Nemos em relação ao Nest é positivo. Entretanto, a diferença não é muito significativa já que o desempenho do Nemos, para todos os modelos, alcança, no máximo, $7 \%$ de diferença positiva.

Outra comparação que fizemos diz respeito a uma série de simulações onde, em cada uma, o modelo de Izhikevich recebe estímulos de uma quantidade variável de sinapses ativadas. O resultado, mostrado na Figura 3.11, mostra que o Nemos apresenta desempenho ligeiramente melhor quando a quantidade de sinapses é baixa, mas à medida que essa quantidade aumenta o Nemos começa a ter desempenho pior chegando a ser $40 \%$ mais lento que o Nest.

Por fim comparamos o desempenho do Nemos e do Nest em redes de modelos de Izhikevich com o mesmo número de sinapses por neurônio. À medida que se aumenta o número de neurônios na rede o Nemos se torna mais lento (Figura 3.12), sobretudo para o número de neurônios igual a 10.000 e 50.000 .

Em função dos estudos comparativos feitos, pudemos identificar os elementos do Nemos que precisam ser otimizados. Por exemplo, o agendamento de cada modelo para seu devido processamento no passo de tempo terá que ser revisado e algumas soluções alternativas podem ser aplicadas. Além disso, é possível otimizar a Java Virtual Machine (JVM) para que ela use o mecanismo de Just In Time (JIT), compilando as partes do código mais utilizadas e tornando sua execução mais rápida. 


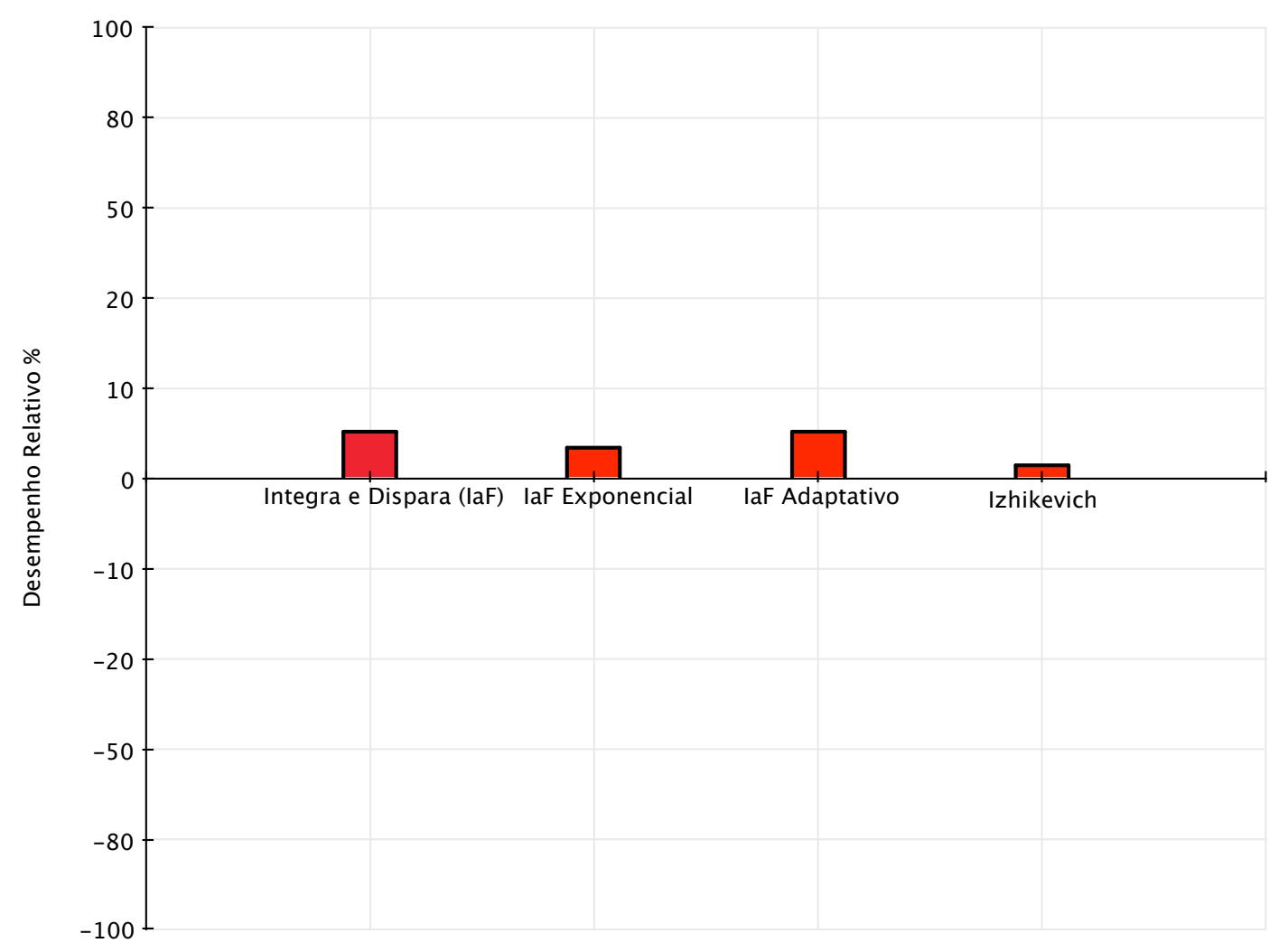

Modelos de Neurônios.

Figura 3.10: Desempenho do Nemos em relação ao Nest para simulações de quatro modelos de neurônios. Valores positivos indicam que o Nemos apresentou melhor desempenho.

\subsection{Considerações Finais}

Neste capítulo apresentamos o Nemos (Neural Models Simulation System), bem como sua arquitetura básica, estratégia de simulação, núcleo e mecanismos de integração. Também mostramos exemplos básicos de uso da ferramenta e resultados de comparações entre o desempenho do Nemos e o desempenho do Nest, uma ferramenta já existente e de amplo uso pela comunidade de modeladores de neurônios e redes de neurônios. Finalmente, comentamos que o Nemos pode receber várias atualizações e otimizações com intuito de torná-lo mais eficiente, uma vez que sua eficácia foi demostrada neste capítulo. 


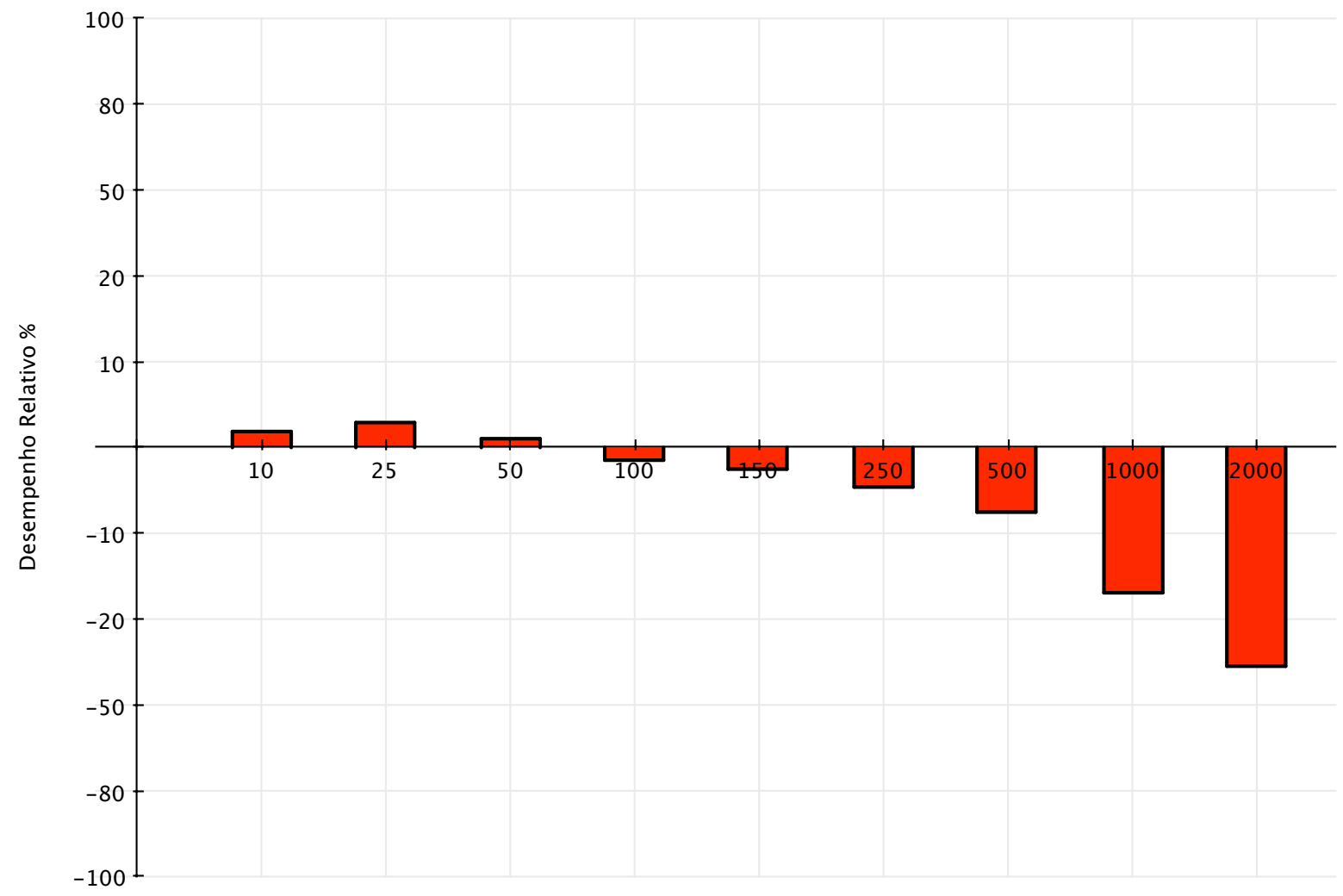

Número de Sinapses Conectadas ao Modelo de Izhikevich

Figura 3.11: Desempenho do Nemos em relação ao Nest em simulações onde varia-se a quantidade de sinapses conectadas ao modelo de Izhikevich. 


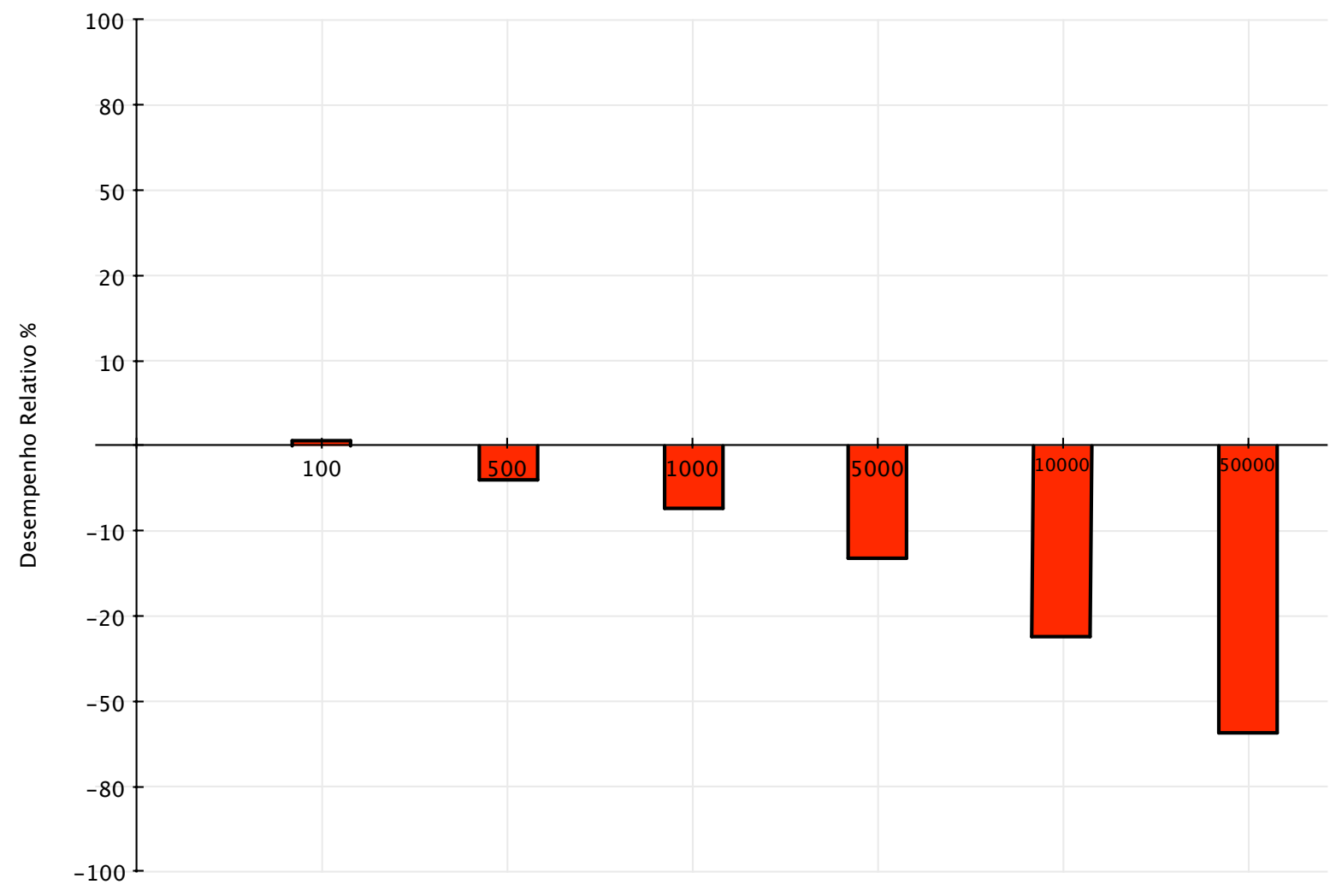

Número Total de Neurônios (Izhikevich) na Rede

Figura 3.12: Desempenho do Nemos em relação ao Nest para simulações de redes com número variável de neurônios de Izhikevich. 


\section{CAPÍTUlo}

\section{SisTEMA COMPUTACIONAL INSPIRADO NO BULBO OLFATÓRIO}

\subsection{Considerações Iniciais}

Neste capítulo apresentaremos o sistema computacional de reconhecimento de padrões inspirado no bulbo olfatório. Inicialmente, iremos abordar como a modelagem do bulbo foi feita e que decisões foram tomadas com relação a quais elementos do bulbo seriam incluídos no modelo. Em seguida, os mecanismos de codificação das entradas do bulbo serão apresentados e, por fim, teremos a descrição do algoritmo de aprendizado usado como leitor de saída para o bulbo.

\subsection{Arquitetura do Sistema}

Basicamente a arquitetura usada possui dois compomentes básicos, a saber:

- Um mecanismo de processamento de informação recorrente, por exemplo, uma rede neural pulsada, ou uma rede neural retro-alimentada.

- Um mecanismo capaz de ler o estado atual do mecanismo anterior e transformá-lo numa saída inteligível; podemos chamá-lo de leitor de saída.

Tal arquitetura com os dois componentes explicados acima é similar aos modelos chamados Máquina de Estado Líquido [Maass, Natschläger e Markram 2002, Maass, Natschläger e Markran 2004], e Redes de Estados de Eco [Jaeger 2002]. Como mostrado na Figura 4.1, o mecanismo usado para o processamento de informação recorrente nesta tese é justamente o modelo do bulbo olfatório, o qual 
recebe uma determinada entrada $i(\cdot)$, que pode ou não variar no tempo, e agrega esta entrada ao fluxo de informação já presente na rede. O leitor de saída $r$ tem a função de ler o estado ${ }^{1} x(t)$ da rede e mapear esse estado para uma saída $y(t)$ que possa ser inteligível.

O leitor de saída pode ser qualquer algoritmo que aprenda através de um método indutivo, ou seja, a partir da apresentação de alguns estados pertencentes a uma determinada classe o leitor deverá ser capaz de generalizar, observando a informação relevante, e classificar novos estados nunca vistos.

É importante frisar que no modelo do bulbo olfatório apenas as células mitrais e tufosas (células $\mathrm{m} / \mathrm{t}$ ) recebem entradas e fornecem saídas, pois esta é a característica do sistema biológico.

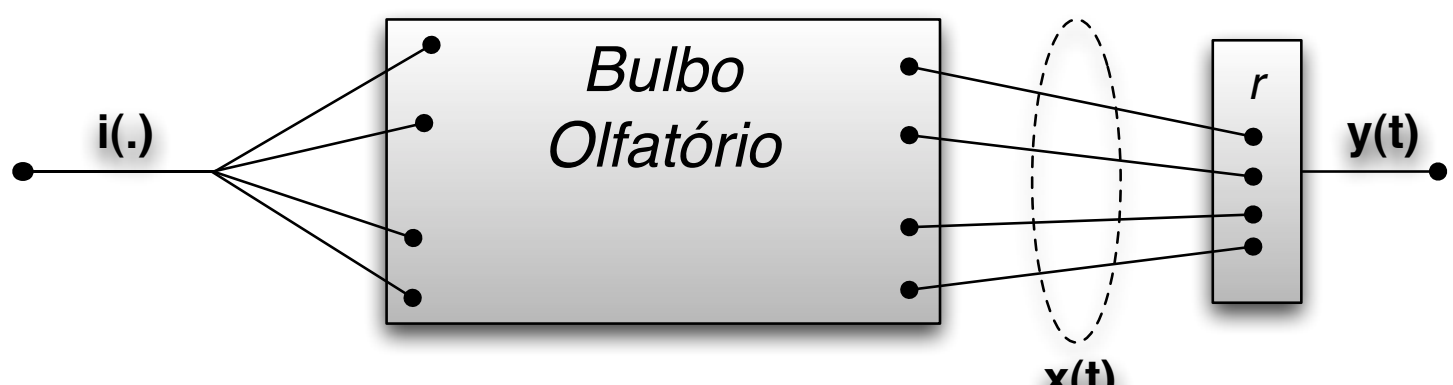

Figura 4.1: Arquitetura básica do sistema computacional desenvolvido nesta tese, onde $i(\cdot)$ corresponde à entrada para o bulbo olfatório, que produz um fluxo contínuo de informação $x(t)$ que é lido e identificado pelo leitor de saída gerando assim uma saída $y(t)$.

\subsection{Modelagem do Bulbo Olfatório}

Uma das questões centrais da modelagem de sistemas neurais diz respeito à decisão sobre o que será modelado e o que será deixado de fora. Como comentamos anteriormente, não é objetivo desta tese criar um modelo realista do bulbo, mas sim um modelo que possua os elementos que, acredita-se, são fundamentais para o

\footnotetext{
${ }^{1} \mathrm{O}$ estado $x(t)$ pode ser comparado a uma foto de algo em movimento no instante de tempo $t$
} 
processamento de informação pelo bulbo. Portanto, faremos uma série de simplificações e reduções para que o modelo possa ser avaliado e simulado com um custo computacional aceitável.

Primeiramente, consideraremos apenas as células mitrais como as unidades de entrada e saída do bulbo, responsáveis pelo processamento vertical de informação. Isto quer dizer que não incluiremos as células tufosas na modelagem. Esta não é considerada uma simplificação muito forte, pois as células tufosas são muito parecidas, tanto anatômica como fisiologicamente, com as células mitrais [Davison, Feng e Brown 2003].

Em segundo lugar, as sinapses dendrodendríticas entre as células mitrais e granulares conduzem, de maneira considerada decisiva, o processamento lateral de informação no bulbo olfatório, estando também associadas aos mecanismos de sincronização da atividade do bulbo [Davison, Feng e Brown 2003, Shepherd 2004, Egger, Svoboda e Mainen 2005, Migliore e Shepherd 2008, Galán, Ermentrout e Urban 2006]. Portanto, é necessário que o modelo simplificado do bulbo contenha células mitrais e granulares e as sinapses recíprocas entre elas.

Finalmente, com relação às células periglomerulares existem poucos estudos experimentais sobre elas em comparação com as células mitrais e granulares. Por exemplo, não há dados sobre como é o padrão de disparos de potenciais de ação de uma célula periglomerular quando excitada por uma corrente externa. Torna-se então difícil construir um modelo simplificado para este tipo de célula e, por causa disso, ela não foi incluída em nosso modelo. Outra razão para a não inclusão da célula periglomerular se deve ao fato de que, em termos evolutivos, tal célula apareceu depois das células mitrais e granulares, pois ela não é encontrada na maioria dos peixes [Dryer e Graziadei 1994]. Isto sugere que a função das células periglomerulares não é essencial para o processamento olfatório, mas seria mais voltada para o refinamento do processamento feito pelas células mitrais e granulares. Ainda outro motivo para a não inclusão de células periglomerulares é que, essencialmente, elas medeiam interações laterais entre células do bulbo olfatório e esta função já é levada em conta no modelo pelas células granulares. 


\subsubsection{Modelo da Célula Mitral}

Experimentos realizados em células mitrais de roedores [Heyward et al. 2001] indicam que existem células mitrais bi-estáveis, aproximadamente $67 \%$ do total, e células mitrais não bi-estáveis. Em [Izhikevich 2007] é proposto um modelo simplificado da célula mitral bi-estável, o qual possui 2 compartimentos com voltagens distintas $\left(v\right.$ e $\left.v_{d}\right)$ e uma variável de recuperação $u$, descrito pelas equações abaixo:

$$
\begin{aligned}
& \frac{d v}{d t}=\left[(v+55)(v+50)+0.5\left(v_{d}-v\right)-u+I\right] / 40 \\
& \frac{d u}{d t}=0.4(U(v)-u) \\
& \frac{d v_{d}}{d t}=0.0125\left(v-v_{d}\right)
\end{aligned}
$$

Nestas equações, $U(v)=0$ enquanto $v<v_{b}$ e $U(v)=b\left(v-v_{b}\right), b=20$, enquanto $v \geq v_{b}=-48 m V$. Se $v \geq 35 m V$, então $v \leftarrow-50 m V$.

As células mitrais bi-estáveis possuem dois potenciais de repouso, um a $-55.5 \pm$ $0.7 m V$ denominado downstate, e outro, mais despolarizado, a $-46 \pm 0.6 m V$, que é chamado de upstate. A transição entre esses dois potenciais pode ocorrer através de um estímulo positivo, elevando o potencial do downstate para o upstate, ou viceversa através de um estímulo negativo (veja Figura 4.2 (a)). O comportamento do potencial de membrana no upstate é semelhante ao de um ressonador (Figura 4.2 (b)) e, portanto, um potencial de ação pode ser deflagrado a partir de uma faixa de estímulos e de tempo (Figura 4.2 (c)). Dependendo do valor da corrente de entrada a transição entre os potenciais pode ser quase imperceptível gerando assim uma sequência de disparos (Figura $4.2(\mathrm{~d})$ ).

Para entendermos melhor como as equações 4.1 modelam a bi-estabilidade da célula mitral, precisamos analisar o comportamento do modelo no espaço de fases $(u, v)$, apresentado na Figura 4.3. Neste diagrama são mostradas quatro trajetórias possíveis para o sistema (A, B, C e D). Pode-se ver que as trajetórias A e B tendem ao ponto fixo que representa o downstate, enquanto que a trajetória $\mathrm{C}$ tende ao ponto fixo que representa o upstate. Pode-se notar também que o comportamento de tipo ressonador visto na Figura 4.2 (b) também é exibido pela trajetória C, indicando que o upstate é um foco estável. Após a ocorrência de um disparo, quando as variáveis 

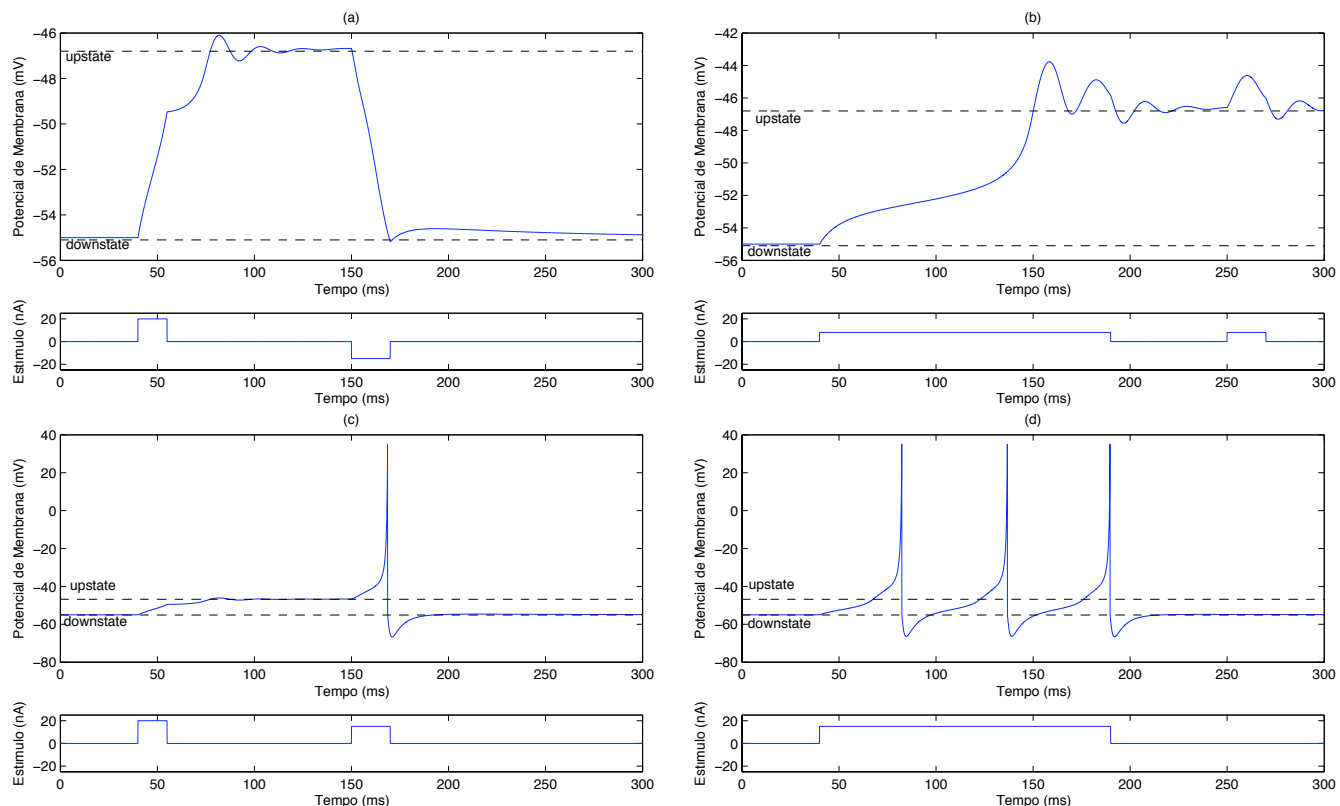

Figura 4.2: Potenciais de membrana do modelo de célula mitral bi-estável em resposta a diferentes tipos de estímulos. (a) Transição entre os estados de respouso downstate e upstate. (b) Comportamento de ressonador do estado upstate quando excitado de forma sublimiar. (c) Geração de potencial de ação a partir do estado upstate. (d) Geração de potenciais de ação a partir do estado downstate.

$v$ e $u$ tendem a se afastar dos pontos estáveis, o potencial de membrana tende ao downstate (ramo da esquerda da trajetória $\mathrm{D}$ ), razão pelo qual a variável $v$ recebe o valor $-50 \mathrm{mV}$ ao atingir o valor $35 \mathrm{mV}$ (trajetória D na extrema direita do gráfico).

No caso das células mitrais não bi-estáveis, que possuem apenas um potencial de repouso semelhante ao upstate, é possível deflagrar um potencial de ação a partir de pequenos pulsos de corrente. Logo após a ocorrência do disparo, o potencial se dirige ao valor de repouso em upstate. Para modelar isto, modificamos as equações 4.1 para que o seu diagrama no espaço de fases seja o da Figura 4.4. Neste caso, a condição $U(v)=0$ enquanto $v<v_{b}$ é alterada para $U(v)=-10$ enquanto $v<v_{b}$.

Esta modificação provoca o desaparecimento do estado downstate, e faz com que a trajetória do sistema após um potencial de ação (trajetória A da Figura 4.4) retorne ao upstate e que qualquer outra trajetória que não resulte em disparo seja como a trajetória B da Figura 4.4. A Figura 4.5 apresenta a resposta do modelo não biestável aos mesmos estímulos usados para estimular o modelo bi-estável (Figura 4.3). É possível perceber as diferentes respostas do modelo não bi-estável e a ausência do 


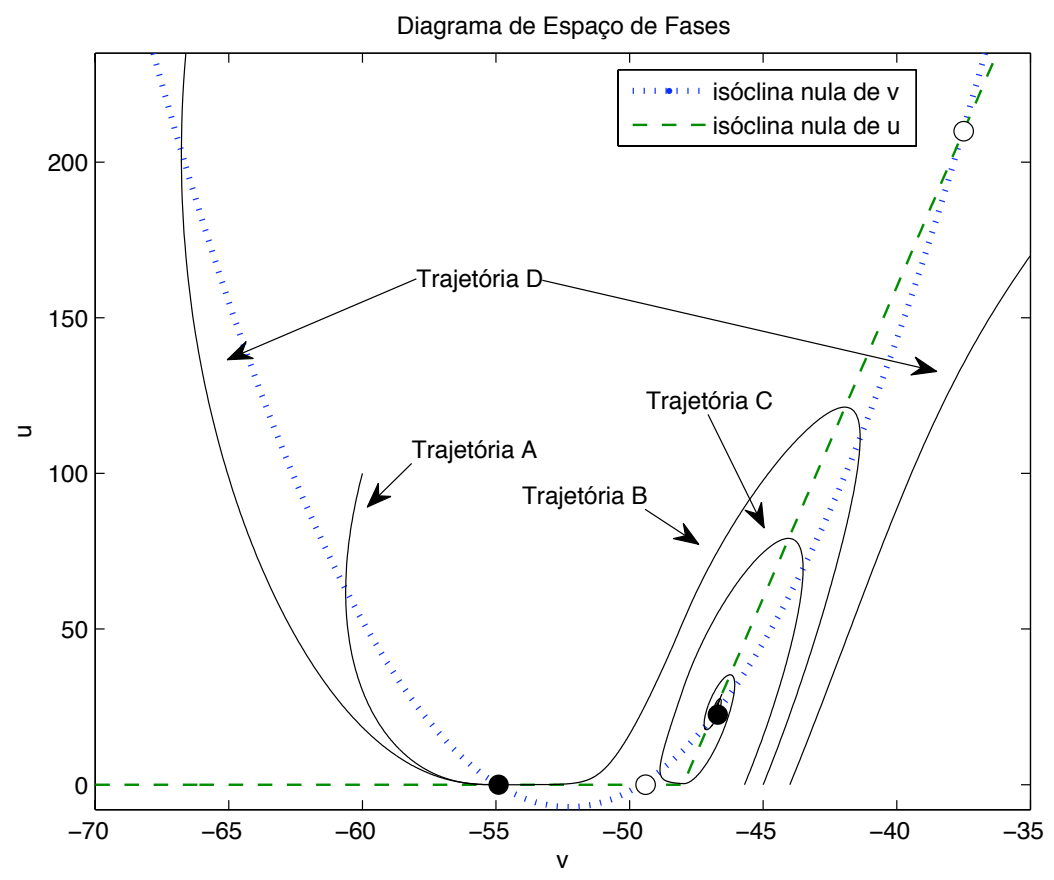

Figura 4.3: Diagrama do espaço de fases do modelo de célula mitral bi-estável das equações 4.1, mostrando diversas trajetórias possíveis. Os pontos escuros indicam os pontos fixos estáveis e os pontos claros indicam a os pontos fixos instáveis.

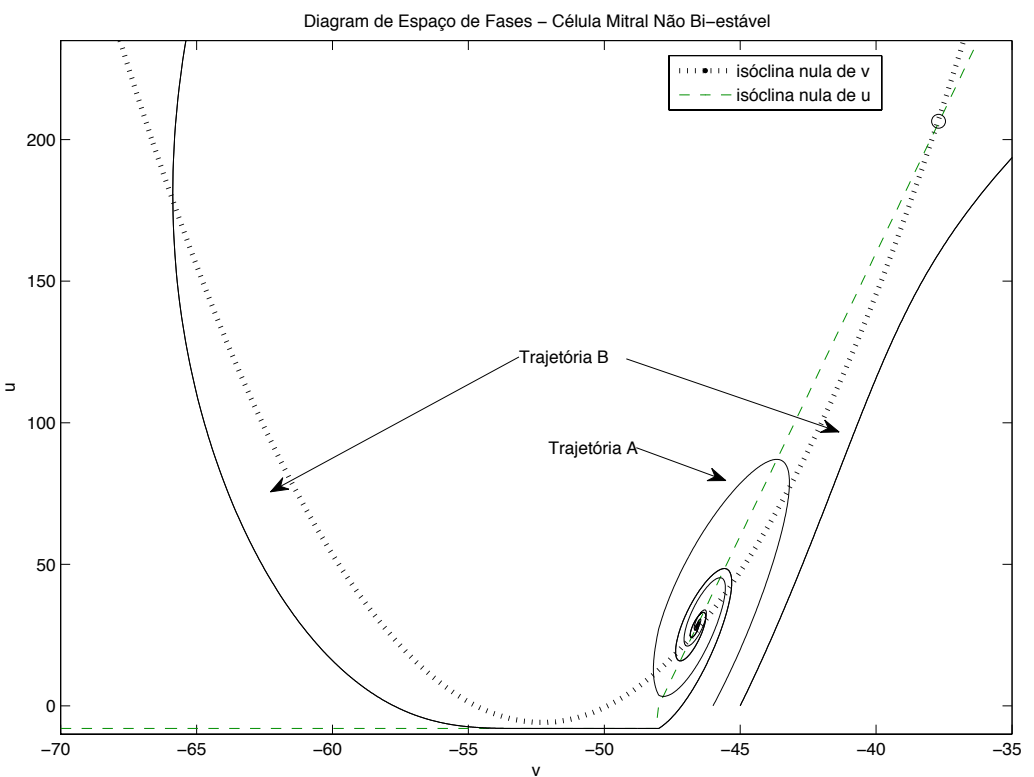

Figura 4.4: Diagrama do espaço de fases referente ao modelo da célula mitral não bi-estável. Os pontos escuros indicam os pontos fixos estáveis e os pontos claros indicam a os pontos fixos instáveis. 
downstate.
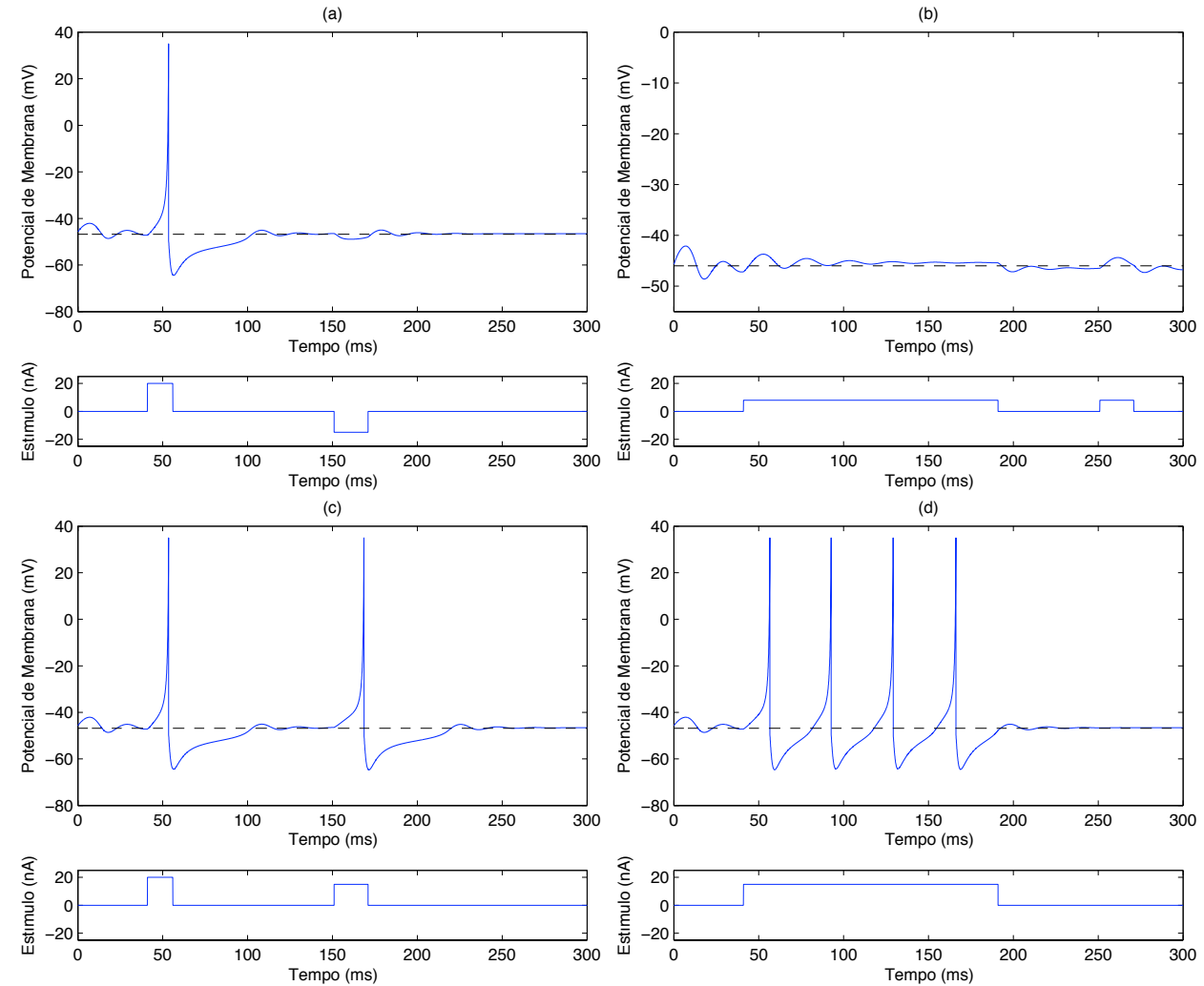

Figura 4.5: Potenciais de membrana do modelo não bi-estável em resposta a diferentes tipos de estímulos. (a) Geração de um potencial seguida de uma inibição por estímulo direto. (b) Comportamento sublimiar de tipo ressonador exibido pelo modelo não-biestável. (c) Geração de potenciais de ação a partir de dois estímulos diferentes em duração e intensidade. (d) Geração de uma sequência de potenciais de ação.

\subsubsection{Célula Granular}

Experimentos realizados apontam que as células granulares possuem canais iônicos de $\mathrm{Na}^{+}$e de $K^{+}$do tipo A (chamado de $K A$ ) tanto nos dendritos quanto no soma [Schoppa e Westbrook 1999, Zelles et al. 2006], já os chamados canais de $K^{+}$retificadores com atraso (chamados de $K D R$ ) estão presentes apenas no soma [Schoppa e Westbrook 1999]. A partir dessas evidências experimentais um modelo baseado em condutância ao estilo de Hodgkin-Huxley foi proposto [Migliore e Shepherd 2008] com três compartimentos (soma, dendrito primário e dendrito secundário). Simplificamos tal modelo com o intuito de obter um modelo 
capaz de reproduzir um padrão de disparos equivalente usando o modelo proposto em [Izhikevich 2007], dado pelas equações 2.9 que são reapresentadas abaixo:

$$
\begin{aligned}
& C \dot{v}=k\left(v-v_{r}\right)\left(v-v_{t}\right)-u+I \\
& \dot{u}=a\left\{b\left(v-v_{r}\right)-u\right\} \\
& \text { se } v \geq v_{\text {peak }} \text { ento } v \leftarrow c, u \leftarrow u+d
\end{aligned}
$$

Para ajustar as equações acima ao comportamento do modelo de três compartimentos de [Migliore e Shepherd 2008], foi necessário encontrar valores para os parâmetros $k, a, b, c, d, C, v_{\text {peak }}, v_{t}$ e $v_{r}$. Isto foi feito construindo-se uma implementação do modelo de [Migliore e Shepherd 2008] e simulando-a sob várias condições. Inicialmente, a partir de experimentos computacionais simulando grampos de corrente no modelo de [Migliore e Shepherd 2008], foram determinados os valores dos seguintes quatro parâmetros: $C=100 p F, v_{\text {peak }}=51 \mathrm{mV}, v_{t}=-43 \mathrm{mV}$ e $v_{r}=-65 \mathrm{mV}$. Em seguida, determinamos a corrente de reobase ${ }^{2}$ do modelo de três compartimentos, cujo valor é, aproximadamente, igual a $0.032 n A$, e a sua curva $\mathrm{FI}^{3}$ (mostrada na Figura 4.6). Uma análise da curva FI do modelo de [Migliore e Shepherd 2008] indica que este modelo corresponde ao que se chama de integrador de classe 1 na classificação de Hodgkin [Izhikevich 2007]. Em outras palavras, tal modelo não apresenta oscilações sublimiares amortecidas e pode emitir potenciais de ação a baixas frequências dependo da corrente injetada, indicando que o parâmetro $b$ deve ser positivo [Izhikevich 2007].

Verificamos, também, a influência de cada um dos canais iônicos presentes no modelo de [Migliore e Shepherd 2008] e vimos que, na ausência do canal KDR o modelo apresenta disparos regulares e frequências mais altas, ou seja, tal canal é responsável pelo mecanismo de adaptação e redução da latência presente paras correntes mais altas (veja Figura 4.7).

Sabendo que a corrente de reobase do modelo de [Migliore e Shepherd 2008] é $0.032 n A$, que o modelo é um integrador e que emite disparos regulares na ausên-

\footnotetext{
${ }^{2} \mathrm{~A}$ corrente de reobase é a corrente mínima necessária para que uma determinada célula emita potenciais de ação

${ }^{3}$ A curva FI de um neurônio indica, para cada valor de corrente constante injetada nele, a sua correspondente frequência de disparos; ela dá a função de transferência do neurônio.
} 


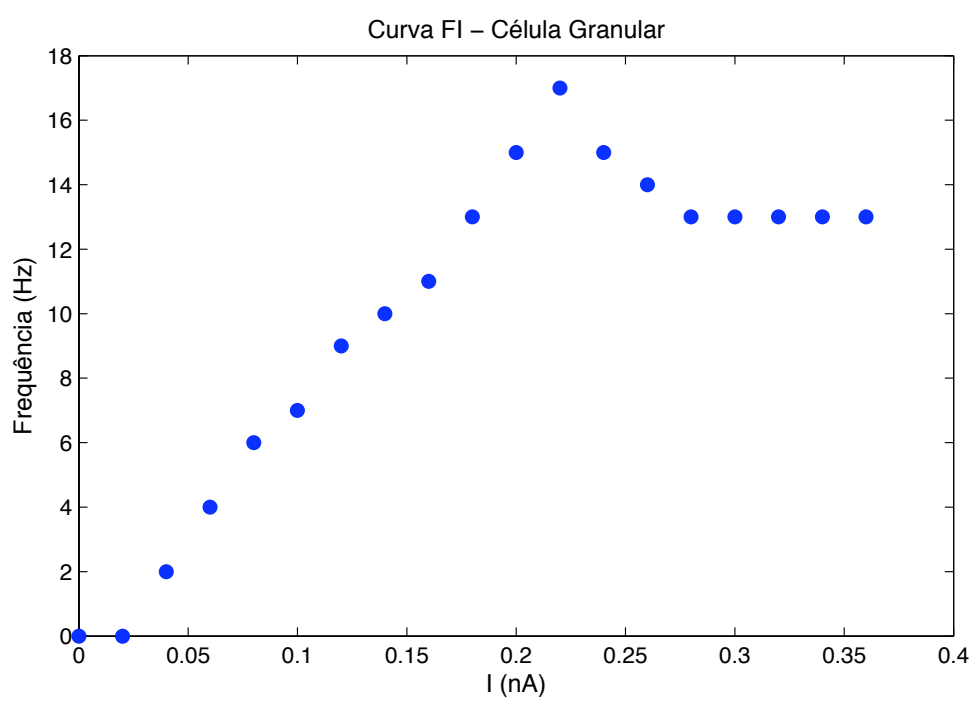

Figura 4.6: Curva FI do modelo compartimental de [Migliore e Shepherd 2008] para a célula granular.

cia do canal $K D R$, os parâmetros $k, b, c, d$ e $a$ foram ajustados empiricamente, levando em consideração tais informações, para os valores $0.195,0.7,-70 m \mathrm{~V}, 20$, 0.07 respectivamente.

A Figura 4.8 apresenta a resposta do modelo simplificado para diferentes valores de corrente injetada. É possível perceber que tal modelo passa a emitir disparos regulares a partir da corrente de reobase $(32 p A)$.

Apesar dos ajustes feitos, o comportamento do modelo simplificado difere do comportamento do modelo de [Migliore e Shepherd 2008], pois o modelo simplificado não exibe os efeitos de adaptação e redução de latência do modelo de [Migliore e Shepherd 2008] (veja a Figura 4.7 coluna esquerda). Isto implica que é necessário considerar em maior detalhe o efeito de adaptação e redução de latência que o canal $K D R$ provoca. Sendo assim, foi feito um ajuste mais detalhado do valor do parâmetro $a$, que determina o tempo característico de recuperação da variável $u$. Como não foi possível estabelecer um valor constante pra $a$ que fosse satisfatório, determinamos empiricamente o valor do parâmetro a para vários tipos de corrente e fitamos os valores através de um polinomio de 3a. ordem $a=4.722\left(10^{-8}\right) x^{3}-7.883\left(10^{-6}\right) x^{2}+0.0004552 x-0.007633$ (veja Figura 4.10).

A Figura 4.9 mostra os comportamentos de disparo do modelo de [Migliore e Shepherd 2008] (coluna da esquerda) e do modelo simplificado construído 

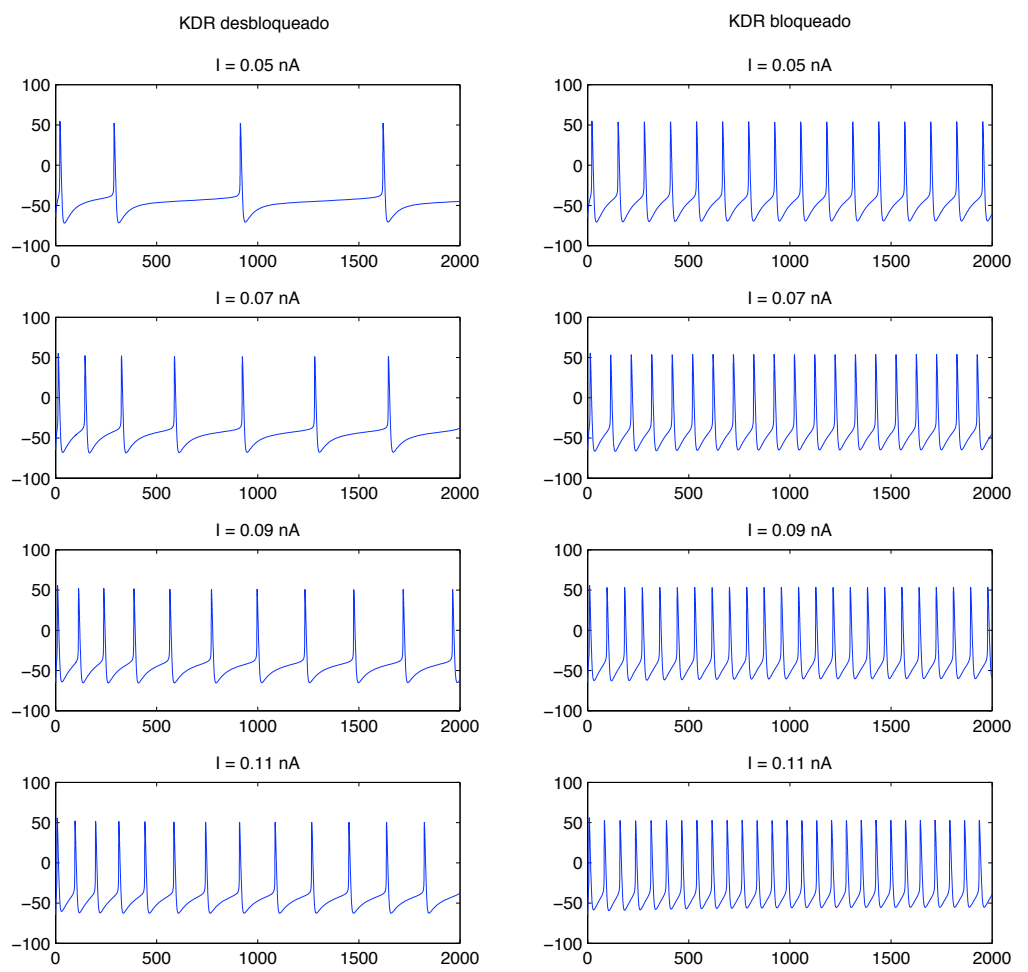

Figura 4.7: Potencial de membrana do modelo compartimental de [Migliore e Shepherd 2008] para a célula granular em resposta a diferentes estímulos $(0.05,0.07,0.09,0.11 \mathrm{nA})$. A coluna da esquerda mostra os resultados para o modelo com canais de $K D R$ e a coluna da direita mostra os resultados para o modelo sem canais de $K D R$.

depois de todos os ajustes mencionados acima (colua da direita) submetidos às mesmas correntes injetadas. É possível perceber a correspondência entre os dois modelos, indicando que o modelo simplificado se assemelha ao modelo compartimental (pelo menos quanto ao padrão de disparos) com a vantagem de possuir um menor custo computacional.

Apesar de todos os ajustes relatados acima, ainda existem algumas diferenças entre o comportamento do modelo simplificado e o do modelo compartimental de [Migliore e Shepherd 2008] para grandes valores de corrente injetada, que podem ser observadas na comparação entre suas curvas FI (Figura 4.11). Esta discrepância talvez possa ser corrigida a partir de uma análise e ajustes mais precisos do modelo simplificado, mas ela não foi feita aqui. A Tabela 4.1 apresenta os valores finais para 

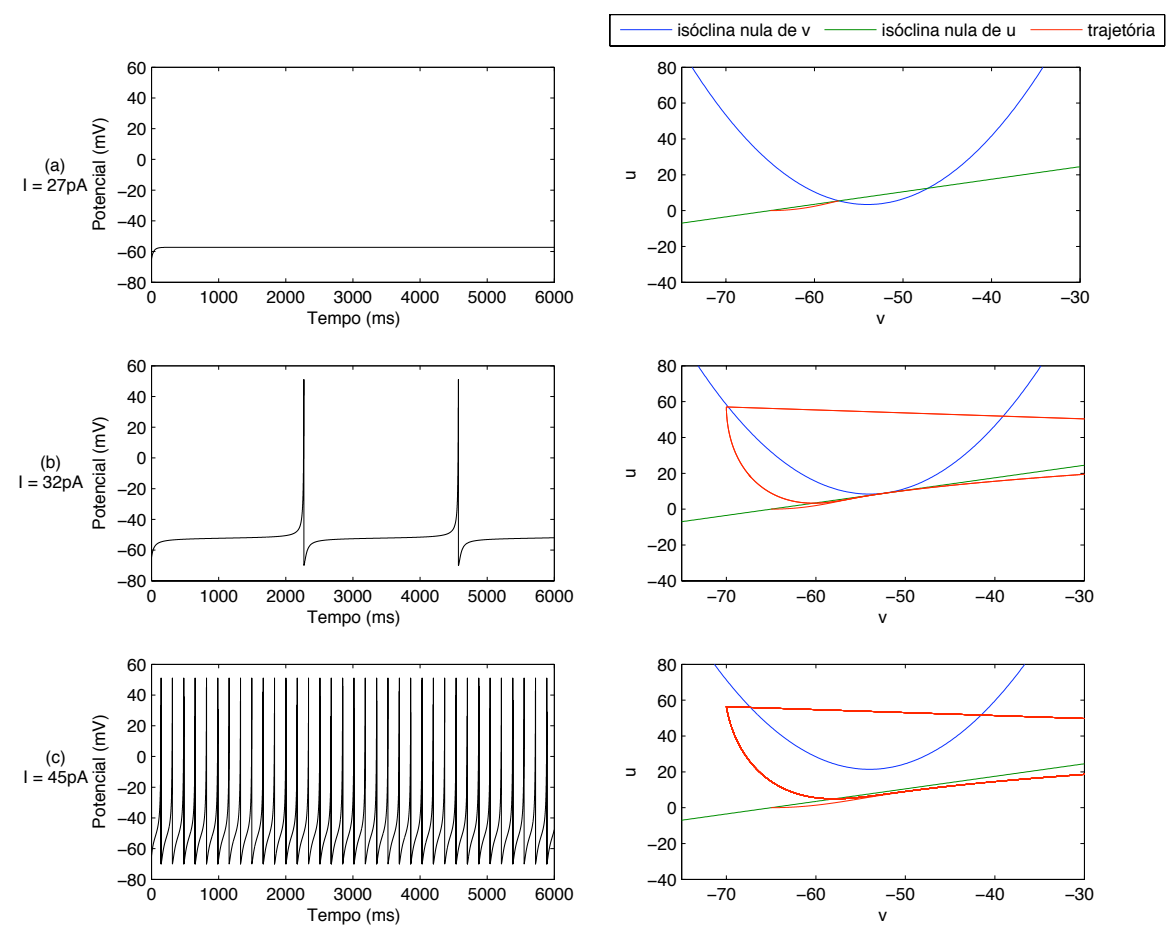

Figura 4.8: Potencial de membrana (coluna da esquerda) e seu respectivo espaço de fases (coluna da direita) do modelo simplificado de célula granular em resposta a diferentes valores de corrente injetada: (a) $I=27 p A$, (b) $I=32 p A$ (reobase) e (C) $I=45 p A$.

o modelo simplificado da célula granular do bulbo olfatório:

\subsubsection{Conectividade}

Determinar a quantidade de células mitrais e granulares, bem como o padrão de conectividade entre elas, é um dos maiores desafios para a modelagem simplificada do bulbo olfatório. Algumas reduções e simplificações foram feitas para que o modelo seja computacionalmente viável. São elas: (1) cada glómerulo tem apenas uma célula mitral; (2) para cada célula mitral há 5 células granulares, uma vez que existem células granulares em número superior ao das mitrais [Shepherd 2004]; (3) as células mitrais e as células granulares são dispostas em grades (ou camadas) bidimensionais com topologia quadrada, pois o bulbo olfatório é separado por lâminas de células. No modelo construído essas camadas possuem o mesmo tamanho, porém como existem mais células granulares do que mitrais o espaçamento entre as células 
Tabela 4.1: Parâmetros do modelo simplificado da célula granular.

\begin{tabular}{cc} 
Parâmetro & Valor \\
\hline$v_{r}$ & $-65 m V$ \\
$v_{t}$ & $-43 m V$ \\
$v_{\text {peak }}$ & $51 m V$ \\
$C$ & $100 p F$ \\
$k$ & 0.195 \\
$b$ & 0.7 \\
$c$ & $-70 m V$ \\
$d$ & 20 \\
$a$ & $4.722\left(10^{-8}\right) I^{3}-7.883\left(10^{-6}\right) I^{2}+0.0004552 I-0.007633$ \\
\hline
\end{tabular}
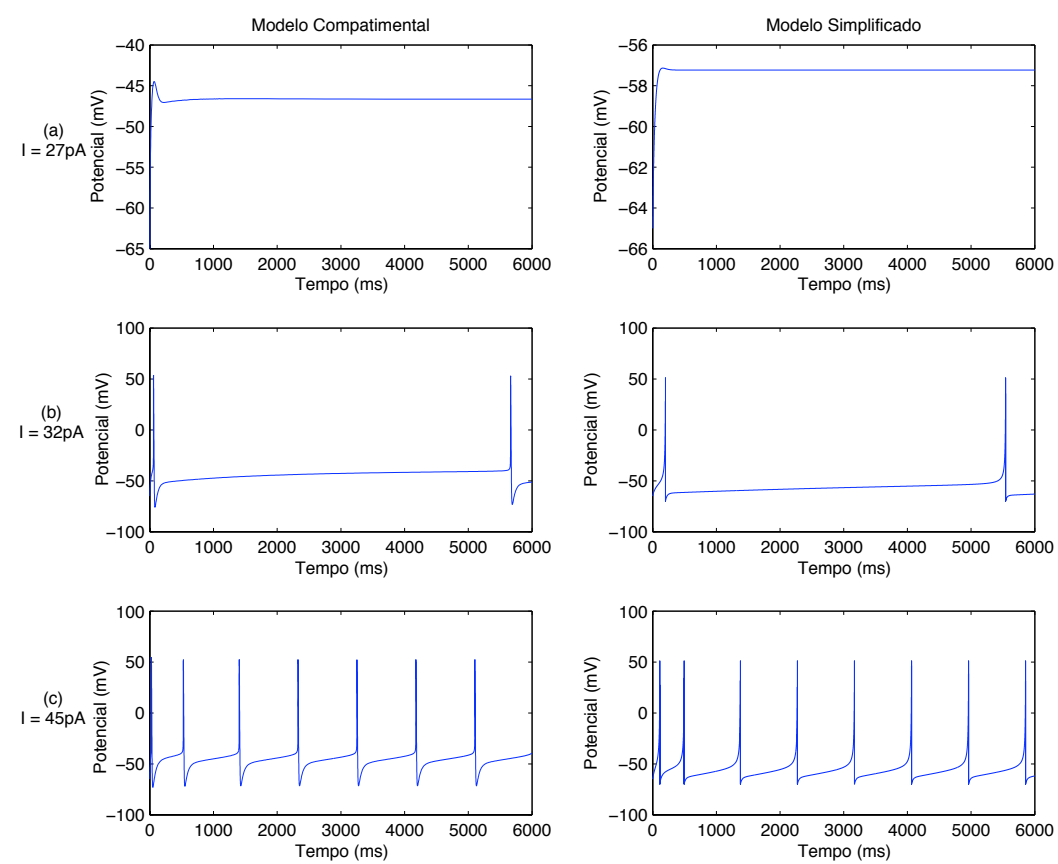

Figura 4.9: Padrão de disparos do modelo compartimental de [Migliore e Shepherd 2008] (coluna da esquerda) e do modelo simplificado (coluna direita) para diferentes estímulos (correntes injetadas). 


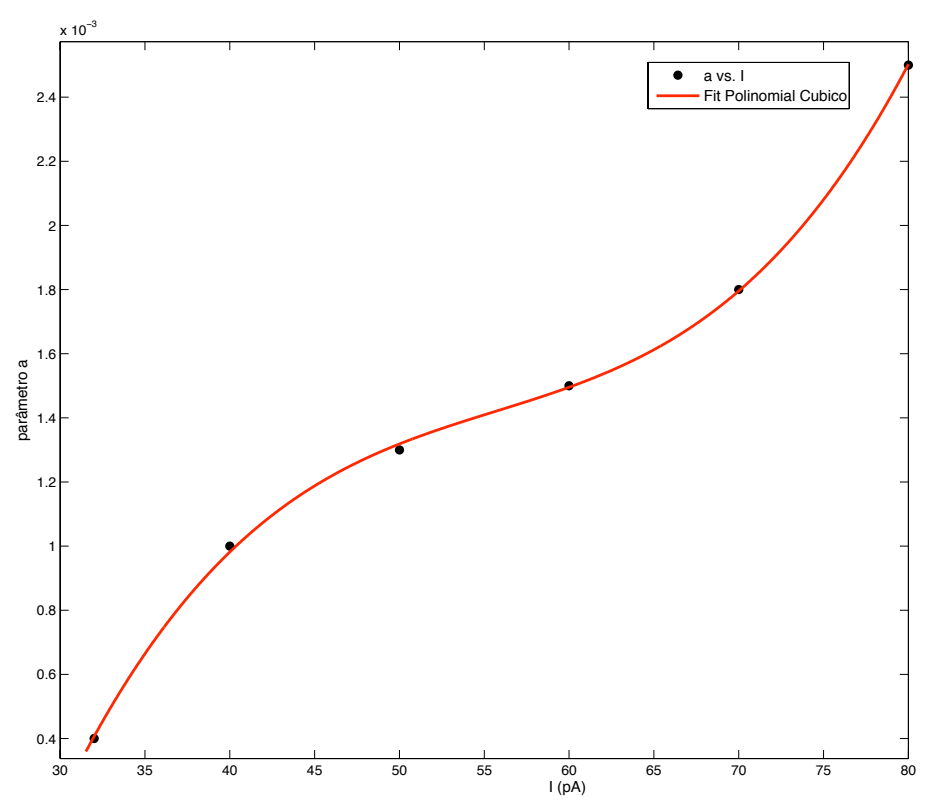

Figura 4.10: Valores do parâmetro $a$ do modelo simplificado da célula granular ajustados para diferentes valores de corrente injetada (pontos). A curva contínua corresponde a um ajuste cúbico para os pontos.

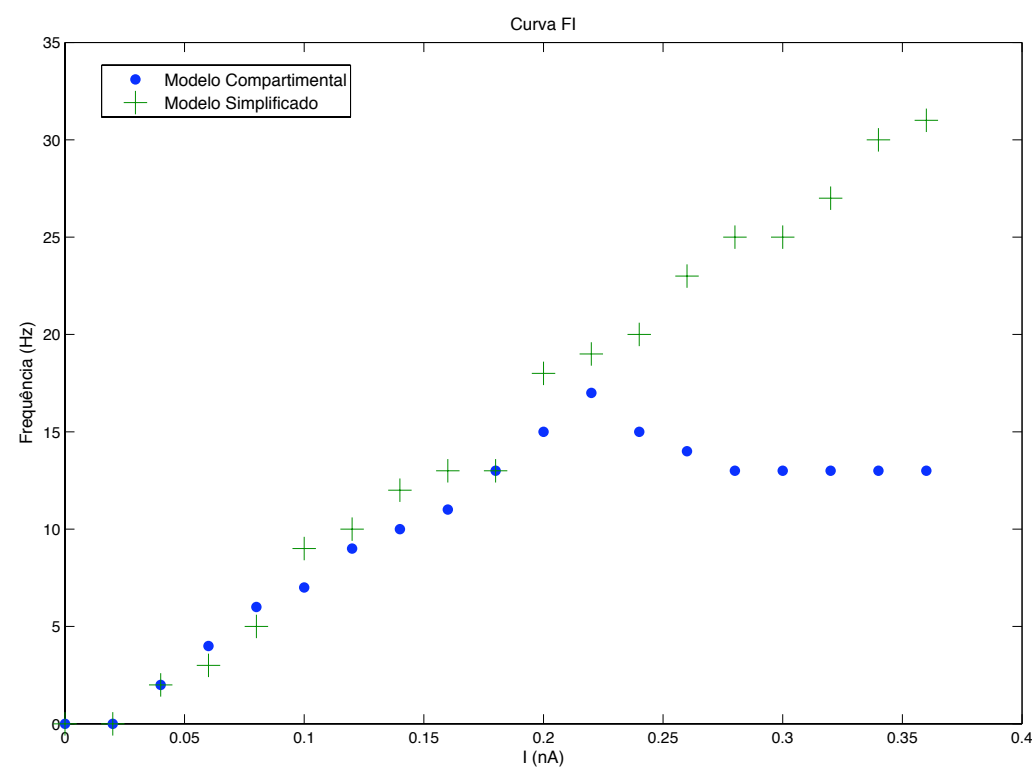

Figura 4.11: Curvas FI dos modelos compartimental de [Migliore e Shepherd 2008] e simplificado para a célula granular.

mitrais é maior do que o espaçamento entre as células granulares (veja Figura 4.12).

Para estabelecer as conexões sinápticas entre as células mitrais e granulares (não existem conexões entre as células mitrais, mas existem conexões entre as células 
granulares; ver mais adiante) usou-se uma regra probabilística baseada na distância euclidiana entre as células. A probabilidade $P_{m, g}$ de uma dada célula mitral estabelecer um contato sináptico com uma dada célula granular é dada pela equação 4.3, onde $D(m, g)$ é a distância euclidiana entre as duas células (calculada como se as duas camadas estivessem projetadas sobre o mesmo plano). Observe que a probabilidade $P_{m, g}$ decai exponencialmente com $D(m, g)$ e o decaimento é governado por um parâmetro $\lambda$, ou seja, quanto maior $\lambda$ mais conexões existem no modelo e há um maior grau de interatividade entre as células.

$$
P_{m, g}=e^{D(m, g) / \lambda}
$$

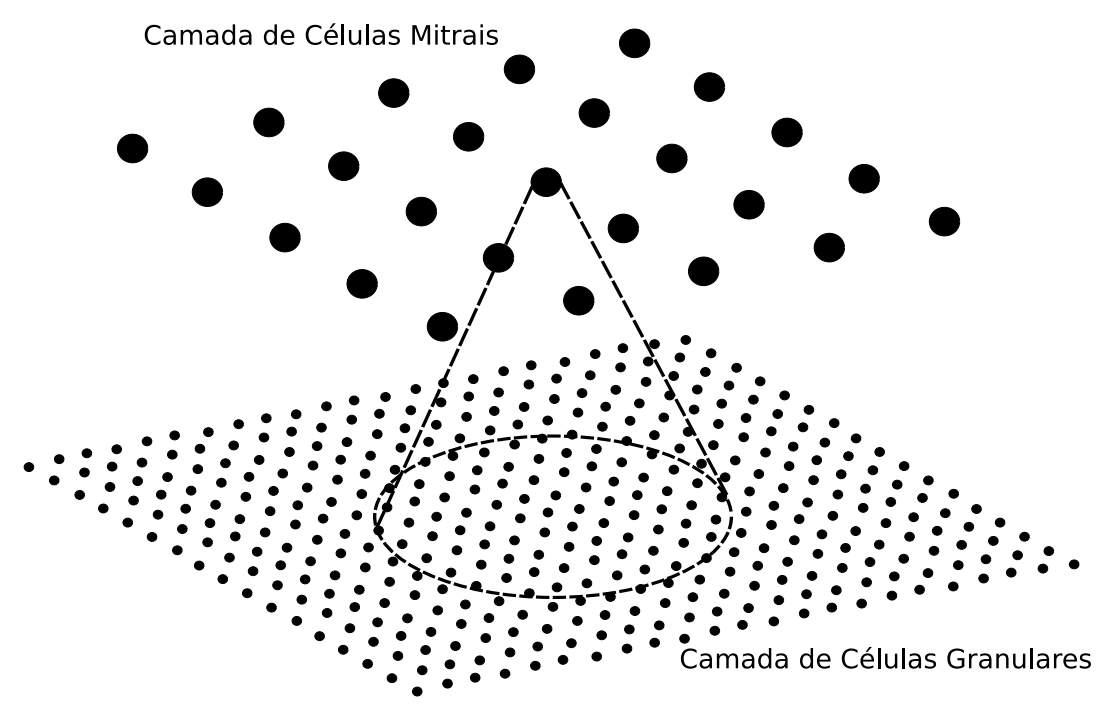

Figura 4.12: Disposição espacial das células mitrais e granulares no modelo simplificado do bulbo olfatório. A conectividade entre mitrais e granulares é determinada pela equação 4.3 usando a distância euclidiana $D(m, g)$ entre mitrais e granulares.

É importante ressaltar que quando uma conexão é estabelecida entre uma célula mitral e uma célula granular, uma sinapse excitatória é criada da célula mitral na célula granular e uma sinapse inibitória é criada da célula granular na célula mitral, pois as sinapses são recíprocas. Também é importante ressaltar que no modelo simplificado construído os modelos de neurônios são pontuais, ou seja, não possuem dendritos (na realidade, não possuem qualquer estrutura), de maneira que o uso do 
termo "dendrodendríticas"para se referir a elas é um abuso de linguagem (que será mantido nesta tese, no entanto).

Além das sinapses dendrodendríticas, modelamos também sinapses inibitórias entre as células granulares conforme evidência experimental [Shepherd 2004, Shepherd et al. 2007]. Para tal, foi usada a mesma regra de conectividade da equação 4.3 , mas com $D(m, g)$ substituído por $D\left(g_{1}, g_{2}\right)$, que dá a distância eucldiana entre quaisquer duas células granulares pertencentes à camada granular.

\section{Sinapse Dinâmica}

Cada sinapse é modelada como uma função $\alpha$ (equação 2.11) com facilitação e depressão sinápticas modeladas com base no modelo de sinapse dinâmica introduzido por Markran et al. [Markram, Wang e Tsodyks 1998] e Tsodyks et al. [Tsodyks, Pawelzik e Markram 1998].

Neste modelo, a condutância sináptica máxima é multiplicada por um peso cuja magnitude $\mu_{k}$ para o $k_{\text {simo }}$ disparo de uma sequência de disparos cujos intervalos entre disparos são dados pela sequência $\Delta_{1}, \Delta_{2}, \Delta_{3}, \cdots, \Delta_{k-1}$ é dada por:

$$
\begin{aligned}
& \mu_{k}=A R_{k} u_{k} \\
& u_{k}=U+u_{k-1}(1-U) e^{-\Delta_{k-1} / F} \\
& R_{k}=1+\left(R_{k-1}-u_{k-1} R_{k-1}-1\right) e^{-\Delta_{k-1} / D}
\end{aligned}
$$

Nas equações acima $u_{k}$ and $R_{k}$ são variáveis que medem a utilização e a disponibilidade dos neurotransmissores da sinapse, respectivamente, e $A$ é um peso sináptico arbitrario que independe da dinâmica proposta. O valor inicial do parâmetro de utilização é $u_{1}=U$ e a sua variação temporal é modulada pela constante temporal de facilitação $F$. Já o valor inicial do parâmetro de disponibilidade é $R_{k}=1$ e ele varia no tempo de acordo com a constante temporal de depressão $D$. Os valores usados para os parâmetros $U, F$ e $D$ são, respectivamente, 0.5, 125 e 1200 [Markram, Wang e Tsodyks 1998]. A Figura 4.13 mostra o o potencial pós-sináptico $(\mathrm{I}(\mathrm{nA}))$ de um neurônio recebendo disparos regulares em $10 \mathrm{~Hz}$ através de uma sinapse dinâmica regida pela equação 4.4 sendo que no gráfico (a) a sinapse foi configurada para apresentar depressão, e no gráfico (b) para apresentar facilitação. 
(a)

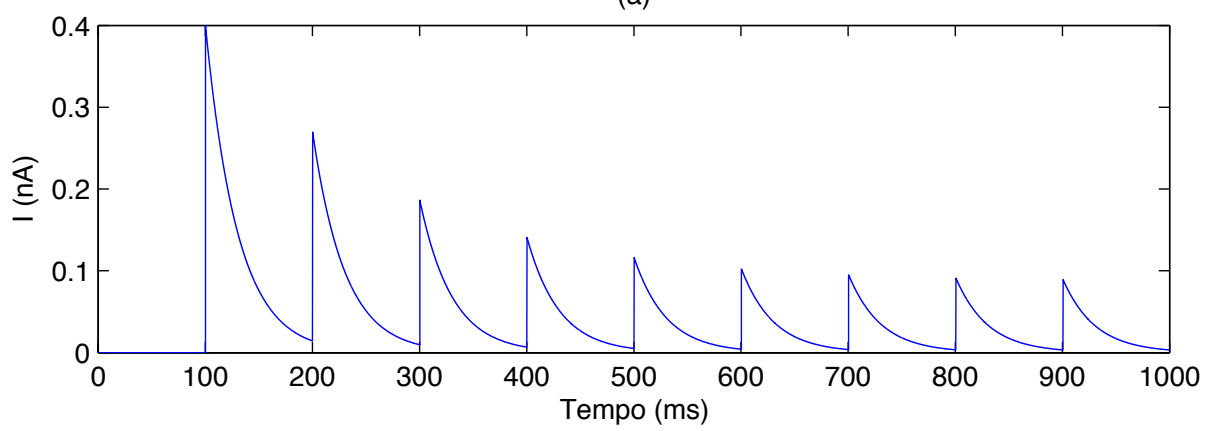

(b)

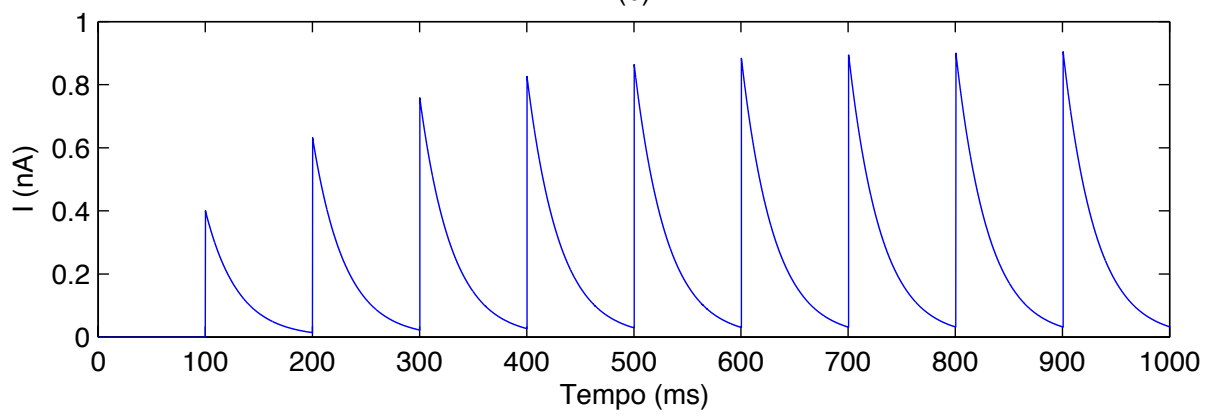

Figura 4.13: Efeitos da equação 4.4 na sinapse. (a) Depressão sináptica e (b) facilitação sináptica, ambos em resposta a disparos regulares.

\subsection{Codificação das Entradas}

Para alimentar o modelo do bulbo olfatório com padrões de entrada, é preciso codificar de alguma maneira as instâncias (padrões) de uma determinada base de dados. Para esta tese, usamos três métodos para a codificação das entradas, que são comentados a seguir.

- Estímulo Direto: este não é, estritamente, um método que codifica entradas, uma vez que os atributos das instâncias em questão são usados como correntes aplicadas diretamente às células mitrais durante um determinado tempo. A única adequação feita é uma normalização dos valores para que eles estimulem as células mitrais de forma que elas disparem com frequências limitadas entre $5 \mathrm{~Hz}$ e $40 \mathrm{~Hz}$, evitando tanto um excesso de disparos como a ausência total deles.

- Valores Reais para Sequências de Disparo: este método de codificação se baseia numa idéia simples para a transformação de valores reais em uma 
sequência de disparos. Ela é baseada no funcionamento do modelo integra-edispara e, além disso, permite a existência de uma probabilidade de remoção de disparos e de uma quantidade de deslocamento (adiantamento ou atraso) temporal dos mesmos. O Algoritmo 4.1 apresentado abaixo ilustra este método, onde podemos ver que cada valor de entrada é convertido numa sequência de disparos com duração de $500 \mathrm{~ms}$ e intervalos entre disparos obedecendo ao comportamento de um modelo integra-e-dispara. A remoção de um determinado disparo $s$ se dá através do parâmetro $r$ e seu deslocamento é dado pelo

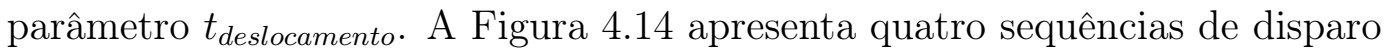
geradas pelo algoritmo a partir do vetor $(10,20,13,42)$.

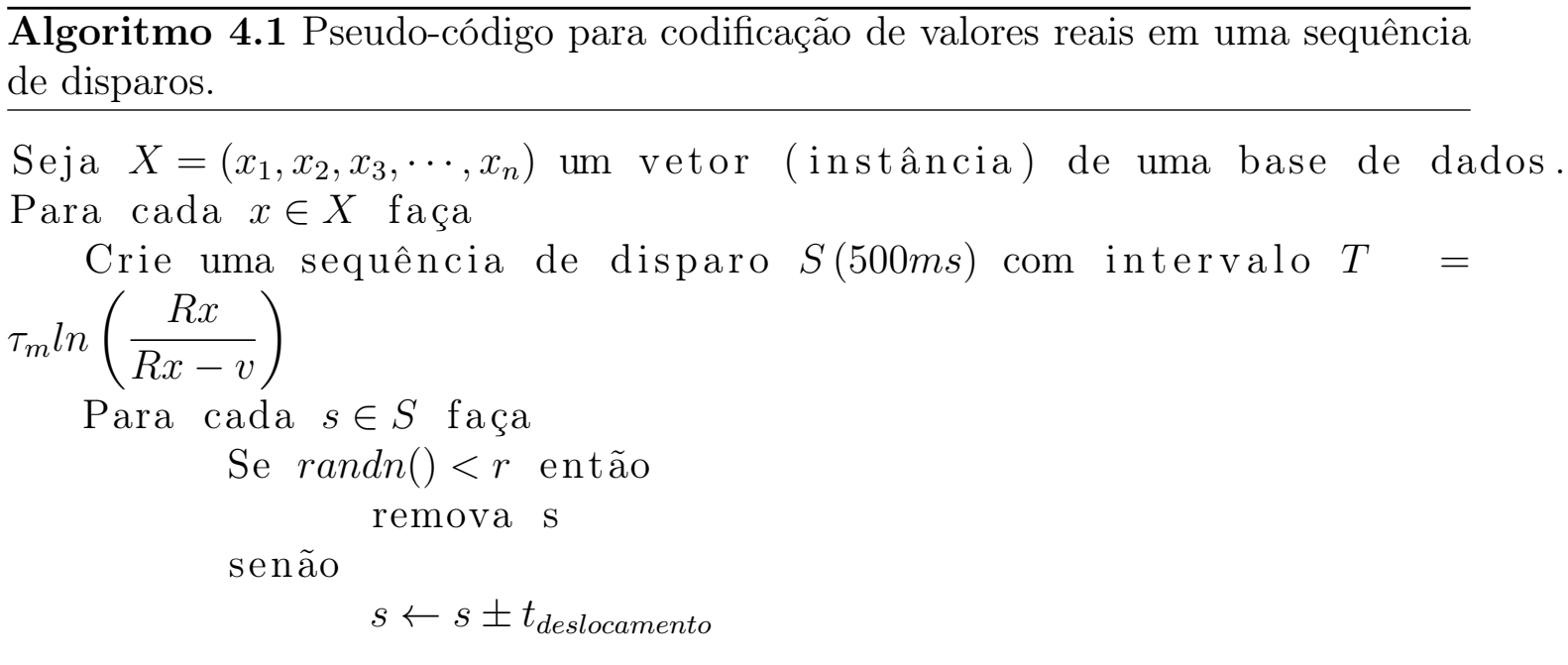

- Análise de Componentes Principais: o terceiro método é, na verdade, uma técnica aplicada aos vetores de uma base de dados e pode ser usado junto com os métodos anteriomente citados. A Análise de Componentes Principais (ACP) [Jolliffe 2002, Wold, Esbensen e Geladi 1987] é um método multivariado fatorial baseado na variância total dos fatores envolvidos com o intuito de capturar os principais atributos de uma determinada base de dados.

\subsection{Parallel Perceptron como Leitor de Saída}

Os leitores de saída são importantes no sistema computacional proposto, pois são os responsáveis pelo mapeamento das saídas das células mitrais do bulbo olfatório 

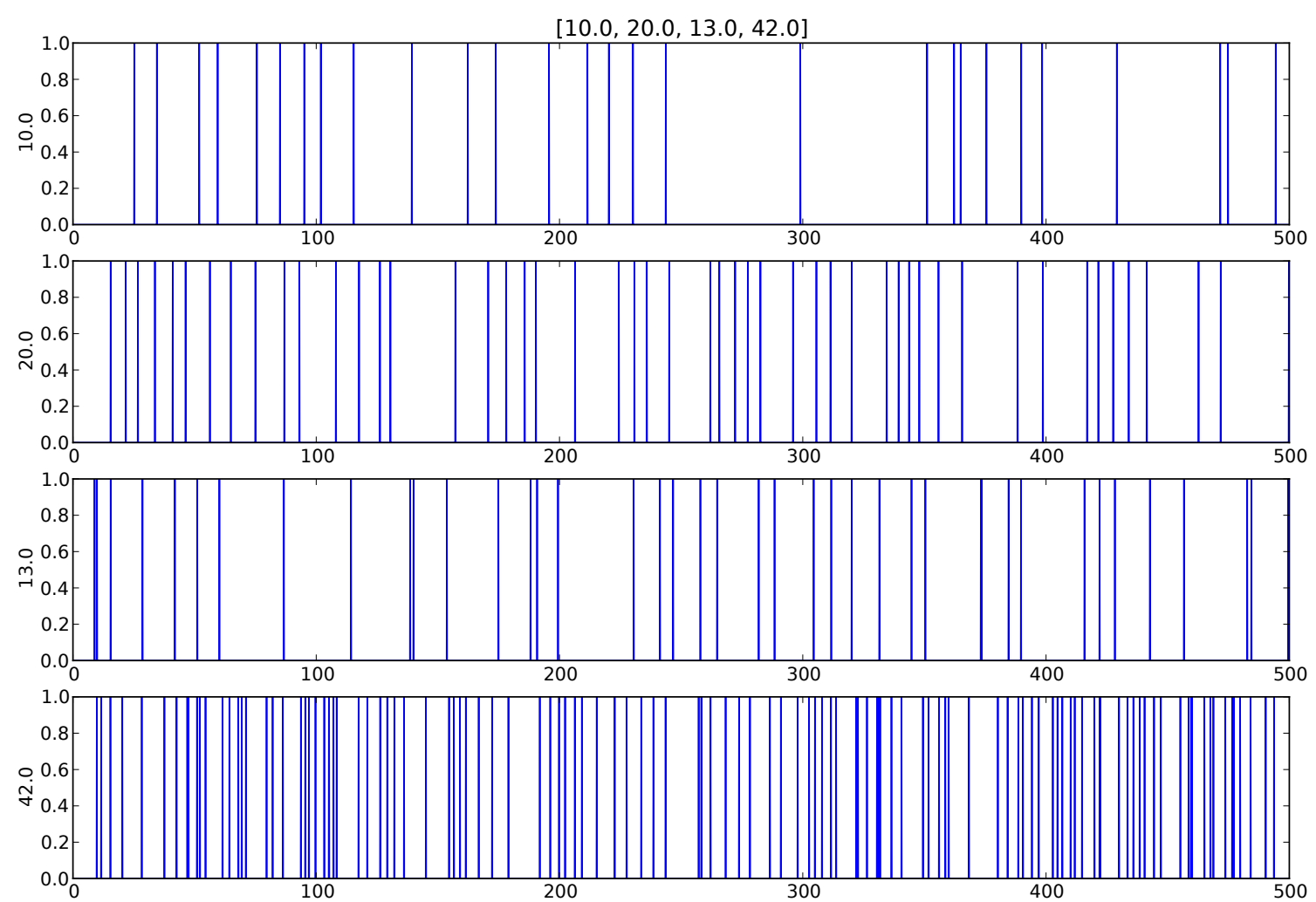

Figura 4.14: Sequência de disparos geradas pelo algoritmo 4.1 a partir do vetor indicado no título do gráfico. Cada valor está também indicado ao lado do eixo-y de sua respectiva sequência e o eixo-x representa o tempo em ms.

em uma informação inteligível para o usuário. Para isso o leitor de saída deve ser treinado com vários estados gerados a partir de uma determinada instância usada como entrada para o bulbo, sendo assim capaz de classificar novos estados.

Qualquer algoritmo de aprendizado indutivo poderia ser usado como leitor de saída. Nesta tese usamos o Parallel Perceptron [Auer, Burgsteiner e Maass 2002, Auer, Burgsteiner e Maass 2008], que é uma rede neural artificial que contém uma única camada de perceptrons, os quais têm seus pesos modificados através da chamada regra delta modificada. A seguir, apresentamos os principais conceitos e fundamentos de tal rede.

Um perceptron pode ser definido como, 


$$
f(\mathbf{z})=\left\{\begin{array}{l}
1, \text { se } \alpha \cdot \mathbf{z} \geq 0 \\
-1, \text { caso contrário }
\end{array}\right.
$$

Ele é uma função que mapeia $\mathbb{R}^{d}$ para $\{-1,1\}$, onde $d$ é o tamanho do vetor de entrada $\mathbf{z}$, incluindo a constante, 1 , multiplicadora do bias, e $\alpha$ é o vetor de pesos. A partir dessa definição, podemos considerar que um perceptron paralelo é uma série de $f_{1}, f_{2}, \cdots, f_{n}$ perceptrons com saída dada por:

$$
\begin{gathered}
p=\sum_{i=1}^{n} f_{i}(\mathbf{z}) \\
o(p)=\left\{\begin{array}{l}
-1, \text { se } p<0 \\
1, \text { se } p \geq 0
\end{array}\right.
\end{gathered}
$$

Sendo assim, temos como mecanismo de ajuste dos pesos $\alpha_{i}$ para cada perceptron a regra p-delta, que atualiza os perceptrons de acordo com a sua saída individual, ou seja, para cada instância de treinamento z, temos,

$$
\alpha_{\mathbf{i}} \leftarrow \alpha_{\mathbf{i}}-\eta\left(\left\|\alpha_{\mathbf{i}}\right\|^{2}-1\right) \alpha_{\mathbf{i}}+\eta\left\{\begin{array}{l}
-\mathbf{z} \text { se } \hat{\mathbf{o}}>o \text { and } \alpha_{\mathbf{i}} \cdot \mathbf{z} \geq 0 \\
\mathbf{z} \text { se } \hat{\mathbf{o}}<o \text { and } \alpha_{\mathbf{i}} \cdot \mathbf{z}<0 \\
\mu \cdot \mathbf{z} \text { se } \hat{\mathbf{o}}=o \text { and } 0 \leq \alpha_{\mathbf{i}} \cdot \mathbf{z}<\gamma \\
-\mu \cdot \mathbf{z} \text { se } \hat{\mathbf{o}}=o \text { and } \gamma<\alpha_{\mathbf{i}} \cdot \mathbf{z}<0 \\
0, \text { caso contrário }
\end{array}\right.
$$

onde ô é a saída desejada, ou seja, o que o perceptron paralelo deveria apresentar dada a instância $\mathbf{z}$ em questão e $\eta$ é a taxa de aprendizado responsável pelo deslocamento de $\alpha_{\mathbf{i}}$. Além disso, devemos observar que nos casos onde a saída do perceptron paralelo difere da saída desejada, ou seja, ô $>o$ ou $\hat{\mathbf{o}}<o$, apenas os perceptrons que contriburíram pra tal saída equivocada são modificados. A modificação de pesos também ocorre nos casos de igualdade entre a saída do perceptron paralelo e a saída desejada, mas apenas para aqueles perceptrons que colaboraram para o acerto da 
rede mas estão perto demais do limite de decisão. Isto é implementado por uma área, determinada por $\gamma$, tal que os perpectrons que colaboram para o acerto da rede sejam deslocados para fora dela, de acordo com o parâmetro $\mu$.

\subsection{Considerações Finais}

Neste capítulo apresentamos o sistema computacional para reconhecimento de padrões baseado no bulbo olfatório, o qual possui mecanismos de codificação de entradas, o próprio modelo do bulbo, jutamente com as de células mitrais e granulares, regras de conectividade e modelos de sinapse, e por fim, o mecanismo usado como leitor de saída. No próximo capítulo apresentaremos alguns experimentos e testes realizados com esse sistema computacional implementado no Nemos. 


\section{Capítulo}

\section{EXPERIMENTOS E TESTES}

\subsection{Considerações Iniciais}

Neste capítulo mostramos resultados de alguns experimentos e testes com o sistema proposto no capítulo 4 com o intuito de avaliar o seu desempenho. Descreveremos, inicialmente, os protocolos e parâmetros usados nos testes bem como as bases de dados avaliadas. Em seguida, mostraremos os resultados obtidos, avaliando as capacidades de separação e de classificação de padrões do sistema.

\subsection{Metodologia e Protocolos}

\subsubsection{Bases de Dados}

Os experimentos realizados e descritos nesse capítulo utilizaram dados de sete domínios de conhecimento, sendo que alguns são artificiais e outros reais; estes últimos estão disponíveis em repositórios de dados. Mais precisamente, quatro dos grupos de padrões foram extraídos do UC-Irvine Repository [Blake e Merz 1998], um foi extraído do Face Recognition Homepage [Gross 2005] e dois foram gerados artificialmente. Eles estão descritos abaixo:

- Îris: este é um domínio dos mais conhecidos e utilizados para reconhecimento de padrões [Duda e Hart 1973, Fisher 1936] e, por esta razão, foi um dos escolhidos para testes nesta tese. Ele possui três classes de padrões, cada uma com 50 instâncias, totalizando 150 registros na base de dados, onde cara registro é descrito por quatro atributos. Vale ressaltar que uma das classes (Íris-Setosa) é linearmente separável das outras duas (Íris-Versicolor e Íris-Virgínica) en- 
quanto que estas duas últimas não são linearmente separáveis entre si. A Tabela 5.1 apresenta a divisão de instâncias por classe.

Tabela 5.1: Distribuição de Classes - Domínio Iris

\begin{tabular}{lcc} 
Classes & Ocorrência & $\%$ \\
\hline Íris-Setosa & 50 & 33,3 \\
Íris-Versicolor & 50 & 33,3 \\
Íris-Virgínica & 50 & 33,3 \\
\hline
\end{tabular}

- Breast Cancer (BC): este domínio possui duas classes representando instâncias consideradas como cancêr benigno ou maligno [Wolberg e Mangasarian 1990, Zhang 1992]. Cada instância possui dez atributos reais que representam características consideradas na classificação. Este domínio possui 699 instâncias, das quais, aproximadamente, $20 \%$ possuem atributos ausentes. A Tabela 5.2 apresenta as ocorrências de instâncias em cada classe.

Tabela 5.2: Distribuição de Classes - Domínio Breast Cancer

\begin{tabular}{lcc} 
Classes & Ocorrência & $\%$ \\
\hline Benigno & 444 & 63,5 \\
Maligno & 255 & 36,5 \\
\hline
\end{tabular}

- Heart Disease: este domínio possui 303 instâncias com 75 atributos cada, entretanto há vários atributos ausentes em algumas instâncias. As instâncias são divididas em duas classes, com presença ou ausência de alguma doença no coração [Detrano et al. 1989]. A Tabela 5.3 apesenta a divisão de instâncias por classe neste domínio.

- Parkinson Disease: Cento e noventa e cinco instâncias compõem, através de 23 atributos, este domínio. Ele está relacionado com o registro de voz de indivíduos saudáveis e com mal de Parkinson, que dividem os registros desta base de dados nestas duas classes [Little et al. 2009]. A Tabela 5.4 apresenta as ocorrências de instâncias em cada uma das classes. 
Tabela 5.3: Distribuição de Classes - Domínio Heart Disease

\begin{tabular}{lcc} 
Classes & Ocorrência & \% \\
\hline Presença & 139 & 45,9 \\
Ausência & 194 & 54,1 \\
\hline
\end{tabular}

Tabela 5.4: Distribuição de Classes - Domínio Parkinson Disease

\begin{tabular}{lcc} 
Classes & Ocorrência & $\%$ \\
\hline Presença & 103 & 52,8 \\
Ausência & 92 & 47,2 \\
\hline
\end{tabular}

- Faces: este domínio possui 100 imagens em preto-e-branco de pessoas do sexo feminino (50 imagens) e do sexo masculino (50 imagens), as quais possuem fundo de diferentes naturezas. Cada imagem representa uma instância da base de dados e elas são classificadas em masculino e feminino. A Tabela 5.5 apresenta o sumário de instâncias dessa classe.

Tabela 5.5: Distribuição de Classes - Domínio Faces

\begin{tabular}{lcc} 
Classes & Ocorrência & $\%$ \\
\hline Masculino & 50 & 50 \\
Feminino & 50 & 50 \\
\hline
\end{tabular}

- Domínios A e B: estes são os grupos de padrões artificiais criados neste trabalho para avaliação do sistema. As instâncias desses dois domínios são formadas por trens de disparo gerados a partir de distribuições poissonianas. Mais precisamente, os trens de disparo de uma determinada classe são gerados a partir de um trem de diparos padrão (template) onde, para cada instância, os disparos são deslocados para frente ou para trás (jitter) dentro de uma faixa estabelecida. Para os dois domínios estipulamos o jitter em 30ms. Como ambos os domínios possuem duas classes, para cada um deles geramos dois templates a partir de distribuições poissonianas de disparos de $30 \mathrm{~Hz}$. O que difere cada um dos domínios é a correlação (coeficiente de correlação de 
Pearson) entre os tempos de disparo das instâncias de classes diferentes, que no caso do domínio A é de 0.3 e no caso do domínio B é de 0.5. A Tabela 5.6 apresenta a quantidade de instâncias por classe.

Tabela 5.6: Distribuição de Classes - Domínios A e B

\begin{tabular}{lcc} 
Classes & Ocorrência & $\%$ \\
\hline Um & 200 & 50 \\
Dois & 200 & 50 \\
\hline
\end{tabular}

\subsubsection{Pararâmetros Default}

A Tabela 5.7 apresenta os valores utilizados para cada um dos parâmetros necessários para a criação do modelo do bulbo olfatório. Tais parâmetros estão ligados intimamente às sinapses entre as células mitrais e granulares. Em todos os testes estes foram os valores utilizados para os parâmetros, salvo quando explicitamente indicado. Note que todos os valores são definidos como intervalos, ou seja, para cada caso o valor usado foi sorteado aleatoriamente de uma distribuição gaussiana com média e desvio padrão especificados pelos valores dados na Tabela 5.7. Além disso, o bulbo sempre é modelado com 100 células mitrais e 400 células granulares, ambas dispostas espacialmente em matrizes bi-dimensionais de mesmo tamanho, conforme descrito no capítulo 4.

Os valores dos parâmetros em todos os experimentos que envolveram o uso do

Tabela 5.7: Parâmetros sinápticos usados entre as células mitrais (m) e granulares (g), onde a seta indica o sentido da sinapse.

\begin{tabular}{lccc} 
Conexão & $m \rightarrow g$ & $g \rightarrow m$ & $g \rightarrow g$ \\
\hline Pesos & $1.5 \pm 0.5$ & $-1.0 \pm 0.25$ & $-1.5 \pm 0.5$ \\
Atraso & $1.8 \pm 0.9$ & 0.625 & 0.625 \\
U & $0.5 \pm 0.2$ & $0.25 \pm 0.1$ & $0.32 \pm 0.1$ \\
$\mathbf{D}$ & $125.0 \pm 75.0$ & $700.0 \pm 350.0$ & $144.0 \pm 72.0$ \\
$\mathbf{F}$ & $1200.0 \pm 600.0$ & $20.0 \pm 10.0$ & $60.0 \pm 30.0$ \\
\hline
\end{tabular}


perceptron paralelo como leitor de saída são $\eta=0.2, \mu=0.1, \gamma=0.05$ e número de perceptrons $N=3$. Fixamos os parâmetros porque o foco da tese é avaliar a capacidade do modelo do bulbo em separar os padrões de maneira suficiente para que o leitor de saída em questão não precise ser ajustado para cada domínio apresentado ao sistema.

\subsubsection{Metodologia de Testes e Experimentos}

Como o modelo do bulbo olfatório possui conectividade variável, ou seja, os valores dos parâmetros sinápticos são escolhidos a partir de distribuições gaussianas, cada experimento foi repetido com 100 modelos de bulbo criados de acordo com as regras citadas anteriormente e a média dos resultados foi apresentada. Além disso, no caso do uso de leitores de saída, os mesmos foram submetidos a validação cruzada de 10 partes e seu desepenho médio foi apresentado.

\subsection{Análise de Comportamento de Frequência}

Inicialmente, procuramos verificar o comportamento do sistema em termos da frequência de respostas entre modelos com sinapse dinâmica e sem sinapse dinâmica, ou seja, uma sinapse estática representada apenas por uma função $\alpha$. Criamos 3 conjuntos de sequências de disparos poissonianos (cada conjunto com 500 sequências), com frequências de $5 \mathrm{~Hz}, 25 \mathrm{~Hz}$ e $50 \mathrm{~Hz}$ respectivamente, e verificamos a frequência média de respostas em cada conjunto. Além disso, variamos a conectividade do modelo do bulbo alterando os parâmetros $\lambda$, que determina o alcance das sinapses a partir de uma determinada célula mitral, e $A$, que altera a escala de pesos sinápticos e modifica a força das sinapses criadas.

A Figura 5.1 apresenta os resultados desse experimento, onde cada gráfico representa a frequência das células mitrais para modelos do bulbo gerados com diferentes pares de parâmetros $\lambda$ e $A$ em resposta aos diferentes estímulos aplicados indicados em cada coluna da figura. Os diagramas da linhas superior correspondem à situação com sinapse dinâmica e os diagramas da linha inferior correspondem à situação sem sinapse dinâmica (sinapse estática).

É possível perceber que para estímulos de baixa frequência $(5 \mathrm{~Hz})$ não há dife- 
renças significativas entre o uso de sinapse dinâmicas ou estáticas. Entretanto, para estímulos com maiores frequências (25 Hz e $50 \mathrm{~Hz}$ ), à medida que a conectividade $(\lambda)$ ou a força das sinapses $(A)$ do bulbo aumentam para o caso com sinapses estáticas (gráficos (e) e (f)), o bulbo passa a responder com frequências semelhantes às do caso onde não há conectividade ( $\lambda$ ou $A$ iguais à zero). Isso indica, em termos de frequência, uma ineficácia da interação dendodendrítica entre as células mitrais e as granulares. Em contraste, a interação dendodendrítica nos modelos do bulbo com sinapse dinâmica é evidente nas suas respostas para estímulos de maior frequência (veja os gráficos (b) e (c)), pois há inibição das células mitrais em resposta à atividade das células granulares, reduzindo as frequências das saídas do modelo. Observe, contudo, que valores altos dos parâmetros $\lambda$ ou $A$ em (c) (estímulo com 50 $\mathrm{Hz}$ ) apontam para um aumento da frequência de resposta das células mitrais.

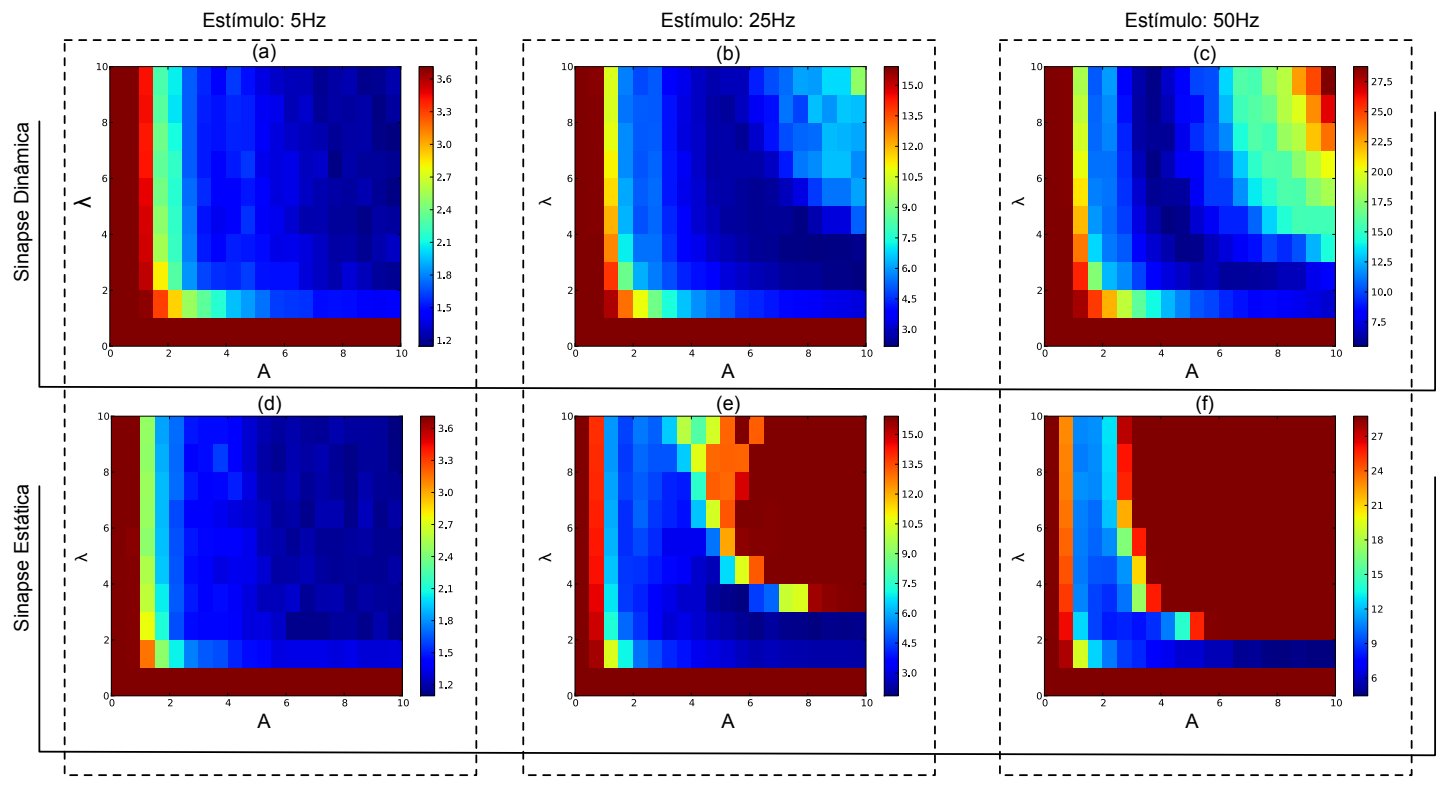

Figura 5.1: Resposta do modelo do bulbo, para diferentes combinações dos parâmetros $\lambda$ e $A$, a estímulos poissonianos co diferentes frequências $(5 \mathrm{~Hz}, 25 \mathrm{~Hz}$ e $50 \mathrm{~Hz})$, na presença de sinapses dinâmicas (linha superior) e na ausência de sinapses dinâmicas (linha inferior).

\subsection{Separabilidade do Sistema}

Nesta seção testamos a capacidade do sistema em separar padrões de entrada. A partir de pares de padrões de entrada $a(t)$ e $b(t)$ calculamos a distância entre os 
estados de saída $x_{a}(t)$ e $x_{b}(t)$ para todo o tempo $t$ de simulação. Cada padrão de entrada $(a$ ou $b)$ é um vetor binário com dimensão igual à do número de células mitrais no modelo do bulbo. A cada instante de tempo, as componentes desses vetores são 1 ou 0 , indicando a ocorrência ou não de um disparo (os trens de disparo dos domínios A e B descritos na subseção 5.2.1). Os estados de saída são os trens de disparo das células mitrais do bulbo, ou seja são vetores binários de mesma dimensão do número de células mitrais cujas componentes, a cada instante de tempo, indicam se houve um disparo (1) ou não (0). A distância entre os estados de saída correspondentes a dois padrões de entrada diferentes é a distância euclidiana entre os vetores binários de saída a cada instante de tempo.

Antes de testarmos a capacidade de separação de padrões do modelo do bulbo, verificamos a capacidade de separação de cada modelo de célula separadamente. Submetemos padrões de entrada unidimensionais $a$ e $b$, com diferentes níveis de correlação entre eles, exclusivamente a uma célula mitral e exclusivamente a uma célula granular e, para cada caso, medimos a distância entre os instantes de disparo da célula de saída (mitral ou granular) para os padrões a e b, durante 1000 ms. Os resultados deste estudo estão mostrados na Figura 5.2. Podemos observar que a distância entre os disparos (grau de separabilidade) das células mitrais (gráfico (a)) diminui à medida que aumentamos o grau de correlação entre as entradas. Essa diminuição não é linear, demostrando uma tolerância significativa na separação de padrões correlacionados. Já as células granulares apresentaram maior grau de separabilidade (gráfico (b)). A distância entre os padrões permanece alta até padrões com grau de correlação próximo de 0.8 , começando a cair a partir deste valor.

Passando agora para os resultados dos testes sobre a capacidade de separação de padrões com diferentes graus de correlação do modelo do bulbo, os gráficos da Figura 5.3 apresentam as distâncias entre os estados $x_{a}(t)$ e $x_{b}(t)$ durante $500 \mathrm{~ms}$ em resposta ao par de entradas $a$ e $b$, respectivamente. Cada gráfico corresponde a um modelo de bulbo com uma diferente combinação dos parâmetros $A$ e $\lambda$. O gráfico (a) mostra as distâncias entre as saídas do bulbo para o caso em que as células mitrais e granulares não estão conectadas. Neste caso, as distâncias mostradas são resultantes apenas do comportamento das células mitrais para pares de entrada com diferentes correlações. Vemos que a distâncias são pequenas para pares de padrões com altos 

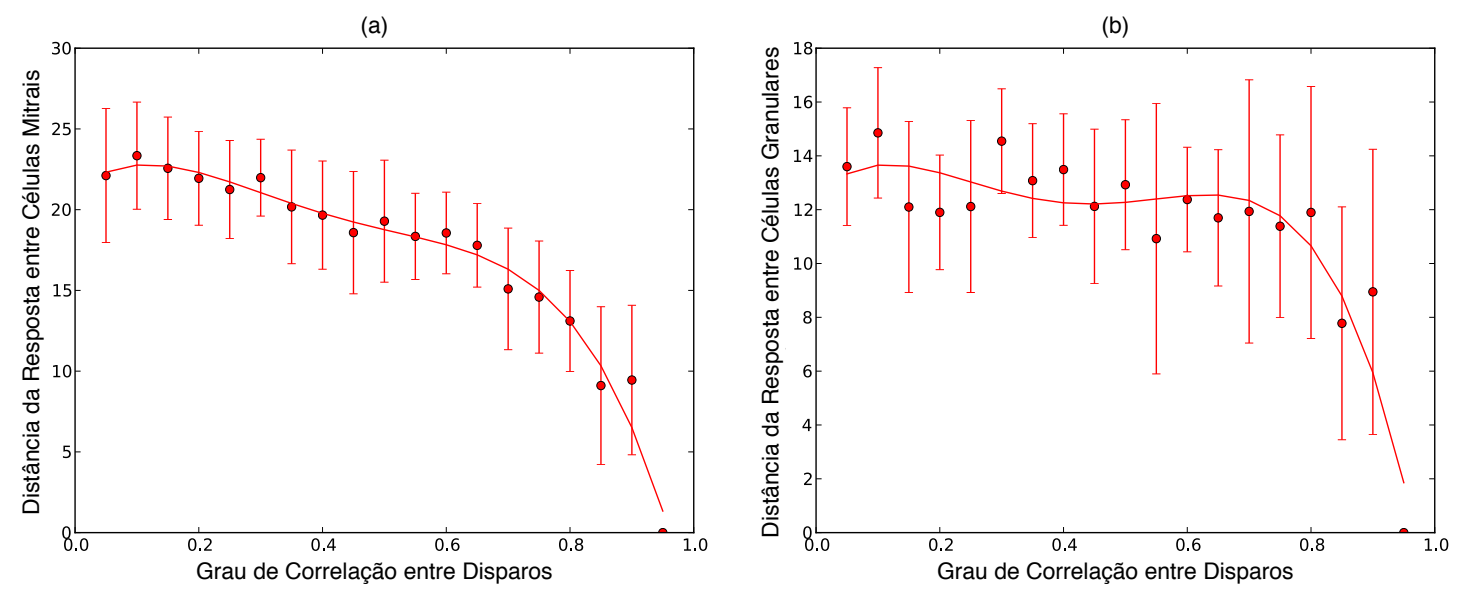

Figura 5.2: Separabilidade das células (a) mitrais e (b) granulares isoladas para pares de entradas com diferentes graus de correlação.

valores de correlação, como é o caso dos conjuntos com graus de correlação iguais a $0,7,0,8$ e 0,9 , e que as distâncias são grandes para pares de padrões com baixos graus de correlação, principalmente para 0,05. Ou seja, a separabilidade deste caso só é boa para padrões que já possuem pouca similaridade estatística entre si.

À medida que a conectividade $(\lambda)$ e a força das conexões $(A)$ são alteradas (gráficos (b), (c) e (d)), os pares com alta correlação são mais eficazmente separados à medida que o tempo avança. No caso de pares com grau de correlação 0,9 os modelos dos casos (c) e (d) alcançam um valor satisfatório e estável de distância a partir de 200 ms. É importante notar o comportamento dos modelos mostrados nos gráficos (e) e (f), com valores dos parâmetros $\lambda=2,0$ e $A=1,5$ e $\lambda=2,0$ e $A=2,0$, respectivamente. Para esses valores elevados de parâmetros (conectividade e força das conexões sinápticas), as distâncias entre as saídas da rede oscilam ao longo do tempo. Esta é uma propriedade observada experimentalmente no bulbo olfatório [Laurent et al. 2001] e é devida ao padrão intrínseco de conectividade entre suas células. Aparentemente, tal efeito poderia ser indesejável, pois a distância entre os padrões não se mantêm estável. Porém, se imaginarmos um leitor que efetue suas medidas da saída da rede também de maneira oscilatória e em fase com os picos das oscilações do modelo (como se estivesse cheirando), teríamos uma situação em que esse leitor obteria informação suficiente para separar os padrões. 
(a)

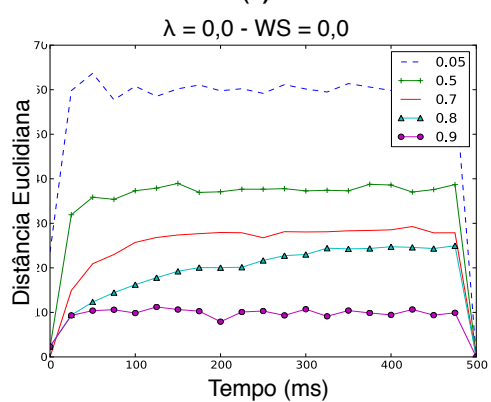

(d)

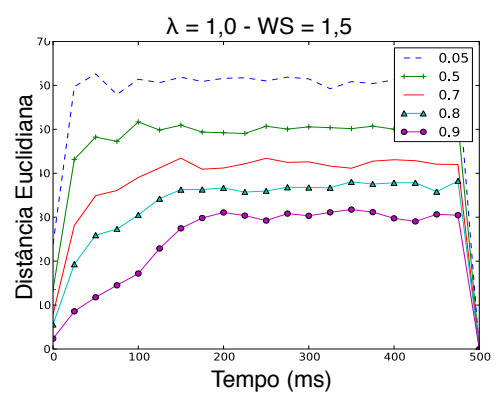

(b)

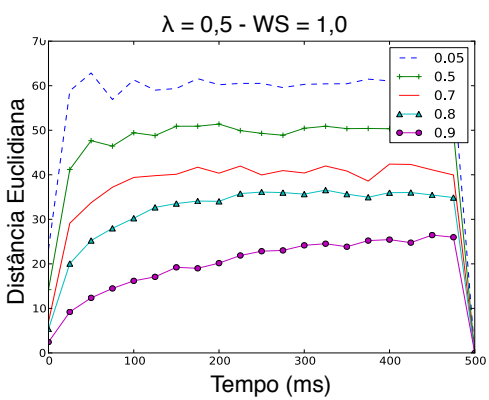

(e)

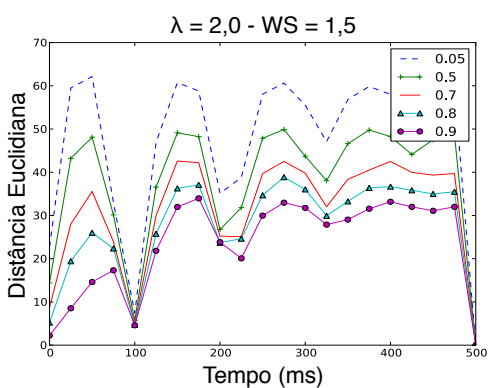

(c)

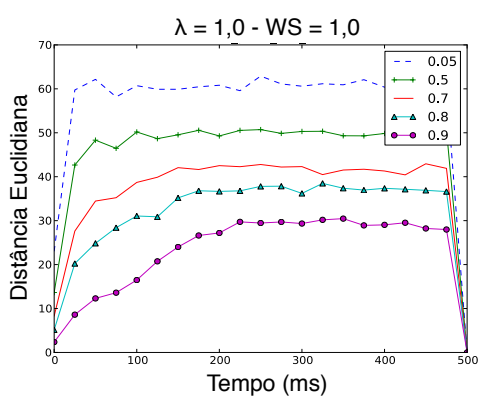

(f)

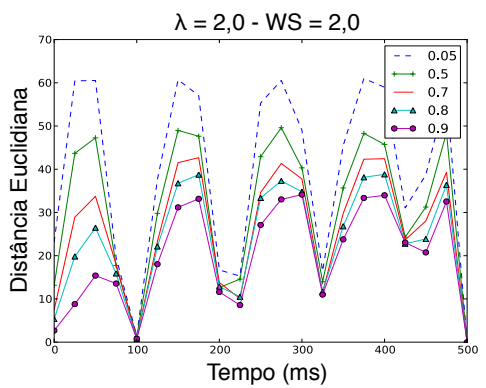

Figura 5.3: Gráficos de distância entre os estados $x_{a}(t)$ e $x_{b}(t)$ gerados por modelos de bulbos com diferentes valores dos parâmetros $A$ e $\lambda$ (mostrados nos cabeçalhos de cada gráfico) em resposta a pares de padrões $a$ e $b$ com diferentes graus de correlação entre eles (mostrados no retângulo superior direito (inset e codificados por cores diferentes).

A Figura 5.4 apresenta o rasterplot do modelo do bulbo com padrões $\lambda=2,0$ e $A=2,0$ em resposta a uma sequência de disparos. É possível verificar a oscilação na atividade do bulbo, sobretudo a oscilação da atividade das células mitrais verificada no gráfico (f) da Figura 5.3.

O mesmo procedimento descrito acima foi refeito em outro estudo com o modelo do bulbo, só que agora usando padrões de entrada constantes, isto é, ao invés de uma sequência de disparos usamos pares de estímulos constantes com diferentes graus de correlação. Os resultados desse estudo estão mostrados na Figura 5.5. Eles são muito semelhantes aos resultados da Figura 5.3. Novamente observa-se que para uma faixa de valores de $\lambda$ e $A$ o sistema é capaz de separar bem padrões com alto grau de correlação a partir de tempos da ordem de 400 ms e que, para valores altos de $\lambda$ e $A$ a resposta do sistema torna-se oscilatória com frequência em torno de 4-5 $\mathrm{Hz}$. 


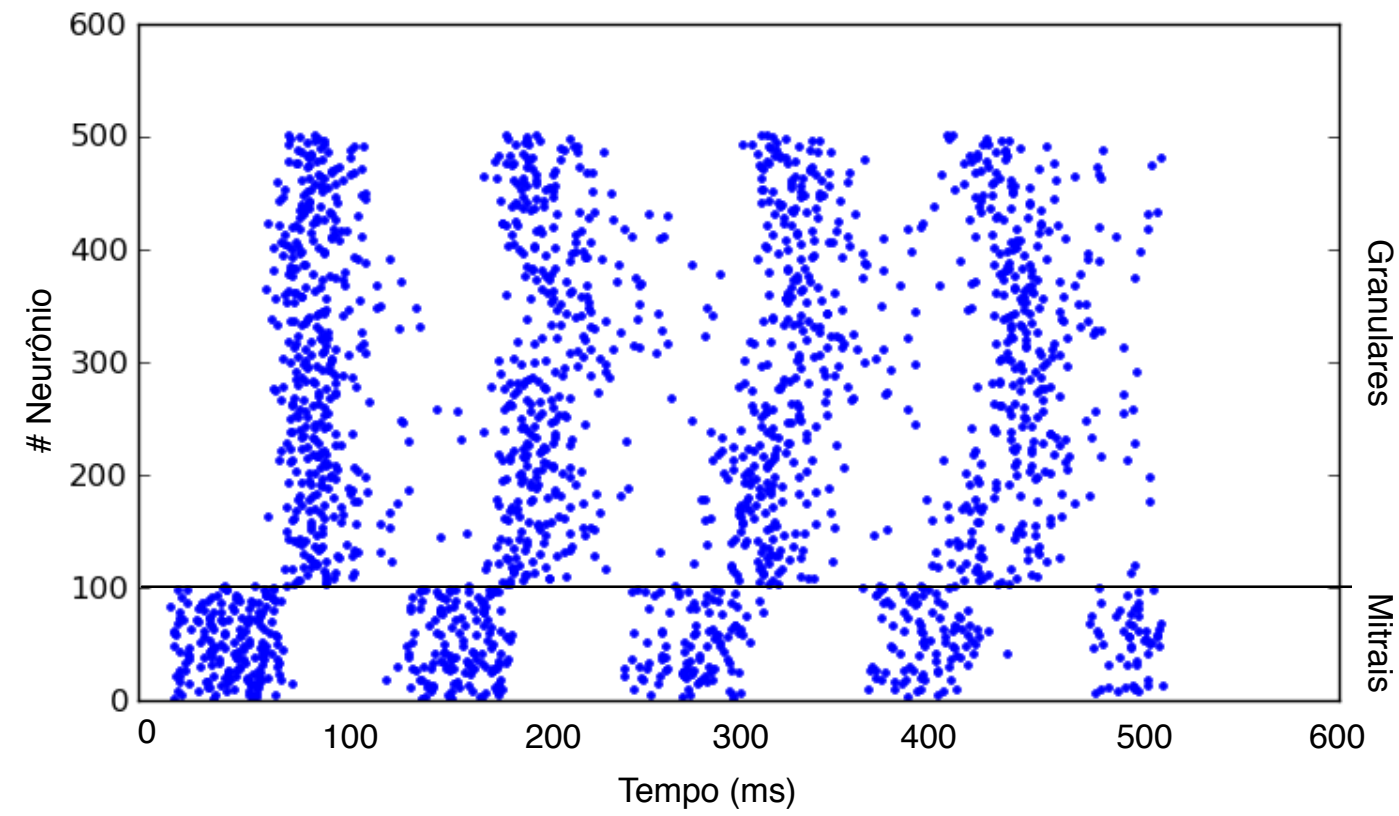

Figura 5.4: Rasterplot do modelo bulbo com parâmetros $\lambda=2,0, W A=2,0$, mostrando atividade oscilatória. Os índices de 0 a 100 representam as células mitrais e os índices acima de 100 representam as células granulares.

Tal semelhança comprova que o modelo construído possui boa capacidade de separação de padrões com diferentes graus de correlação, independentemente do tipo de padrão usado. Ela mostra também a robustez do comportamento oscilatório da resposta do sistema, decorrente de ele ser baseado no bulbo olfatório, que é uma estrutura que transforma padrões puramente espaciais e estáticos de entrada em padrões espaço-temporais [Laurent et al. 2001, Spors e Grinvald 2002].

\subsection{Memória do Modelo}

O próximo experimento é similar ao experimento apresentado por Maass [Maass, Natschläger e Markram 2002] e diz respeito à capacidade de retenção de memória do sistema, ou seja, desejamos avaliar por quanto tempo o modelo do bulbo é capaz de fornecer informações relevantes para os leitores de saída sobre um determinado padrão após o mesmo ter sido apresentado. Como está mostrado na Figura 5.6, criamos dois templates poissonianos compostos por $N$ trens de disparo com frequência de $25 \mathrm{~Hz}$ e duração de 1000 ms cada e os dividimos em quatro seg- 


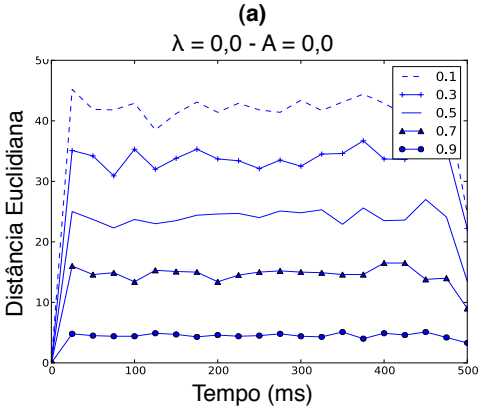

(d)

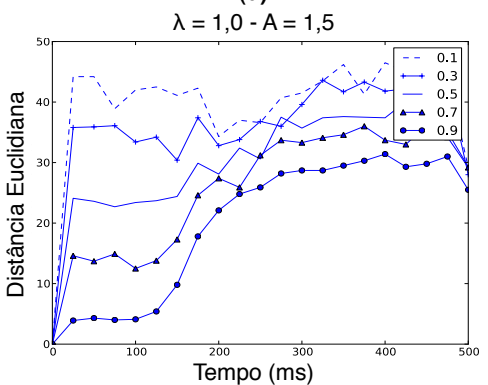

(b)

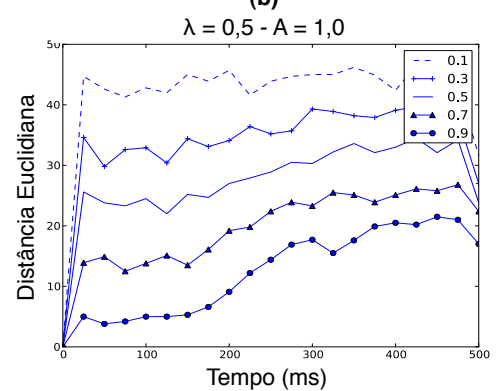

(e)

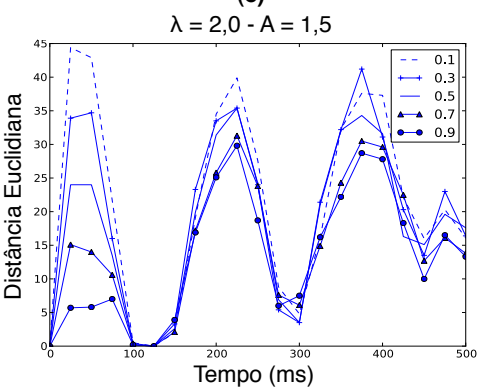

(c)

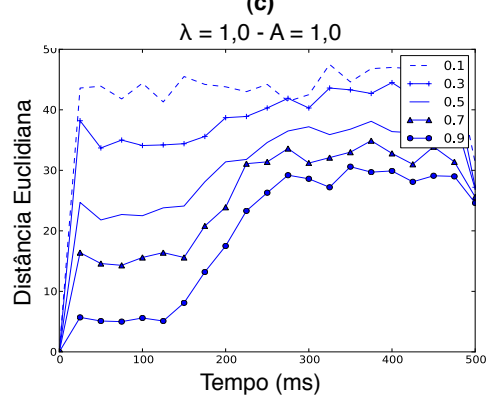

(f)

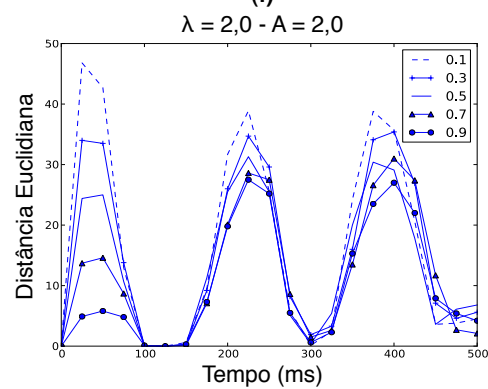

Figura 5.5: Gráficos de distância entre os estados $x_{a}(t)$ e $x_{b}(t)$ gerados por modelos de bulbos com diferentes valores dos parâmetros $A$ e $\lambda$ (mostrados nos cabeçalhos de cada gráfico) em resposta a pares de padrões $a$ e $b$ constantes com diferentes graus de correlação entre eles (mostrados no retângulo superior direito (inset e codificados por cores diferentes).

mentos de 250 ms. A partir desses templates 500 outras entradas com $N$ trens de disparo, foram geradas. Cada uma das entradas foi composta a partir de uma combinação dos segmentos dos templates originais, ou seja, uma determinada entrada é composta por quatro segmentos, escolhidos aleatóriamente, entre os template. Como exemplo podemos ver a Figura 5.6, onde a nova entrada foi composta tendo como segmentos 1 e 4 os respectivos segmentos do template 1 e como segmentos 2 e 3 os respectivos segmentos do template 2. Feito isso, todos os $N$ trens de disparo das 500 entradas geradas receberam um ruído na forma de deslocamento dos disparos em \pm 25 ms. Nos estudos realizados usou-se $N=100$, ou seja, cada entrada possui 100 trens de disparo, um pra cada célula mitral.

Quatro leitores de saída terão a tarefa de classificar o estado $\mathbf{x}_{\mathbf{i}}(\mathbf{1 0 0 0})$, ou seja, o estado no momento exato $(t=1000 \mathrm{~ms})$ em que uma determinada entrada $i$ (não utilizada no treinamento) acabar de ser apresentada. Em outras palavras, o leitor 1 deverá classsificar tal estado informando se o primeiro segmento de $250 \mathrm{~ms}$ da 


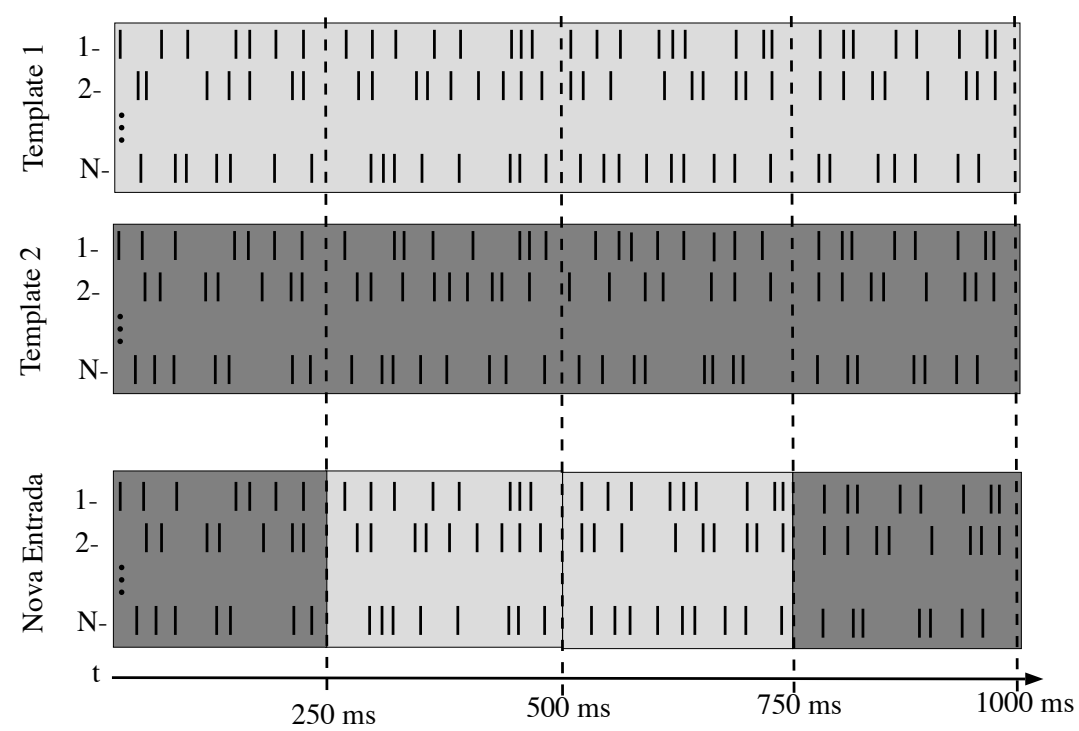

Figura 5.6: Nova entrada gerada a partir da combinação de segmentos dos templates 1 e 2 (ver texto para maiores detalhes).

entrada em questão faz parte do template 1 ou 2, o leitor 2 deverá informar se o segundo segmento de $250 \mathrm{~ms}$ dessa entrada vem do primeiro ou do segundo template, o leitor 3 deverá informar se o terceiro segmento de $250 \mathrm{~ms}$ faz parte do template 1 ou 2, e o leitor 4 deverá informar se o último segmento de $250 \mathrm{~ms}$ vem do primeiro ou do segundo template. Ou seja, cada um dos quatro leitores deve classificar de qual dos dois templates vem o segmento correspondente (1, 2, 3 ou 4) de uma entrada ao final da sua apresentação.

É importante ressaltar que cada leitor de saída foi treinado com o perceptron paralelo apenas com os estados do seu respectivo segmento, ou seja, o leitor 1 foi treinado com estados do segmento $1([0,250) \mathrm{ms})$, o leitor 2 com estados do segmento $2([250,500) \mathrm{ms})$, e assim, sucessivamente, para todos os leitores. Além disso, este experimento foi realizado em modelos de bulbo com diferentes valores dos parâmetros $A$ e $\lambda$.

A Figura 5.7 apresenta os gráficos de desempenho para cada um dos leitores de saída para diversos modelos de bulbo com diferentes valores dos parâmetros $A$ e $\lambda$. Pode-se observar que para qualquer modelo do bulbo o desempemho do leitor responsável pelo segmento 1 é pobre (gráfico (a)), ficando em torno de $50 \%$ e que o desempenho do leitor responsável pelo segmento 4 é bom, esperado, principalmente 


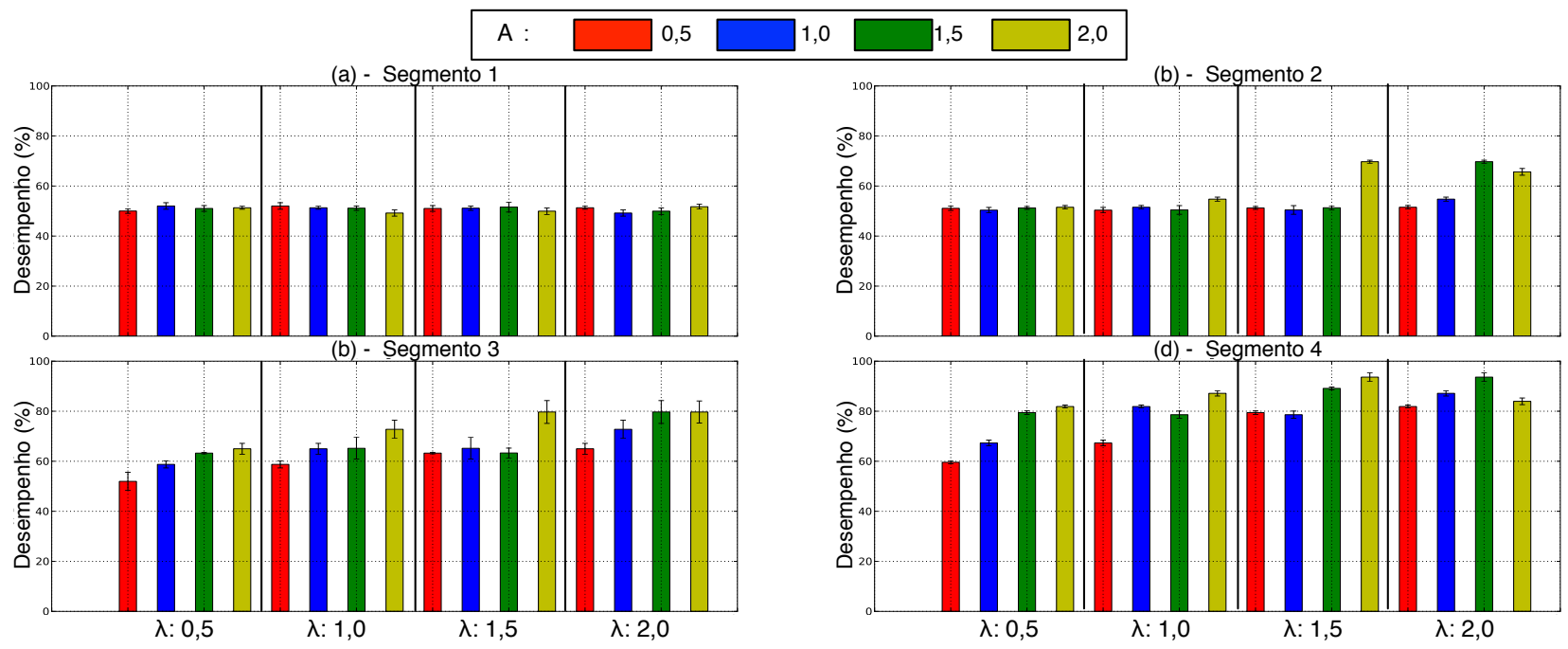

Figura 5.7: Desempenho apresentado pelos leitores de saída na identificação de cada um dos segmentos, gráficos de (a) a (d). As cores representam os diferentes valores de $A$, e o eixo-x especifica os valores de $\lambda$.

quando um dos parâmetros, ou ambos, tem valor maior ou igual a 1.0. Nestes casos o desempenho atinge valores acima de 80\%. Já os leitores responsáveis pelos segmentos 2 e 3 apresentam resultados intermediários. O leitor 2 apresenta resultados acima de $60 \%$ para $A=2,0$ e $\lambda=1,5$ ou $\lambda=2,0$ (gráfico (b)), e o leitor 3 (gráfico (c)) apresenta desempenho variável entre $60 \%$ e $80 \%$ dependendo dos valores dos parâmetros $A$ e $\lambda$; apenas quando ambos, $A$ e $\lambda$, são iguais a 0,5 é que o desempenho do leitor 3 fica abaixo de $60 \%$.

A partir de tal análise podemos afirmar que o modelo do bulbo, quando especificado com parâmetros $\lambda$ e $A$ no intervalo [1.0,2.0] apresenta memória com duração de aproximadamente $500 \mathrm{~ms}$, ou seja, o modelo do bulbo é capaz de fornecer ao leitor de saída informações relevantes sobre uma determinada entrada que foi apresenta 500 ms atrás. Sendo assim, o modelo não é apenas uma rede recorrente capaz de transformar estados de entrada em padrões dinâmicos, mas possui capacidade de fornecer informações sobre o passado recente das suas entradas. Neste sentido, ele se comporta como uma uma máquina de estado líquido [Maass, Natschläger e Markram 2002]. 


\subsection{Reconhecimento de Padrões}

Nos estudos relatados nesta seção verificamos a capacidade do sistema computacional (modelo do bulbo + leitor de saída perceptron paralelo) em reconhecer padrões artificiais e reais. Os padrões são aqueles descritos na subseção 5.2.1. Apenas um modelo de bulbo olfatório foi usado nos estudos desta subseção, aquele com parâmetros $A=1,5$ e $\lambda=2,0$.

Testamos, inicialmente, o sistema computacional com os dados de 5 domínios de conhecimento descritos na subseção 5.2.1 (A, B, Iris, BC e Heart). Os padrões desses domínios foram apresentados diretamente à entrada do sistema, ou seja, cada instância de treinamento e teste foi aplicada diretamente ao bulbo por 500 ms. Além disso, para comparar o desempenho do sistema computacional com o do perceptron paralelo isolado refizemos todos os treinamentos e testes feitos com o sistema usando apenas o perceptron paralelo. O objetivo deste estudo comparativo foi mensurar a eficácia do bulbo no fornecimento de informações para o leitor de saída.

A Figura 5.8 mostra os desempenhos (percentual de acertos na fase de testes) do sistema computacional (barras vermelhas) e do perceptron paralelo sozinho (barras cinzas) para os cinco domínios usados. É evidente a melhora no desempenho provocada pela adição do modelo do bulbo olfatório. Essa melhora deve ser devida à capacidade de separação de padrões do modelo do bulbo, a qual facilita a tarefa de classificação do leitor de saída.

Duas observações podem ser feitas com relação à Figura 5.8. A primeira diz respeito ao domínio Iris, para o qual o sistema computacional apresentou desempenho muito próximo do máximo possível e mesmo o perceptron paralelo, embora tenha tido desempenho bem inferior, também atingiu seu melhor desempenho. O fato de uma das classes deste domínio ser lineramente separável pode explicar ambos os percentuais de desempenho. A segunda observação também está relacionada com o domínio de conhecimento utilizado, neste caso o domínio Heart. O fato de este domínio ter várias instâncias com atributos ausentes pode ter colaborado para o baixo desempenho apresentado para ele pelo sistema computacional.

A seguir testamos o desempenho do sistema computacional para os domínios de conhecimento A, B, BC, Heart e Parkinson, sendo que os atributos dos domínios BC, 


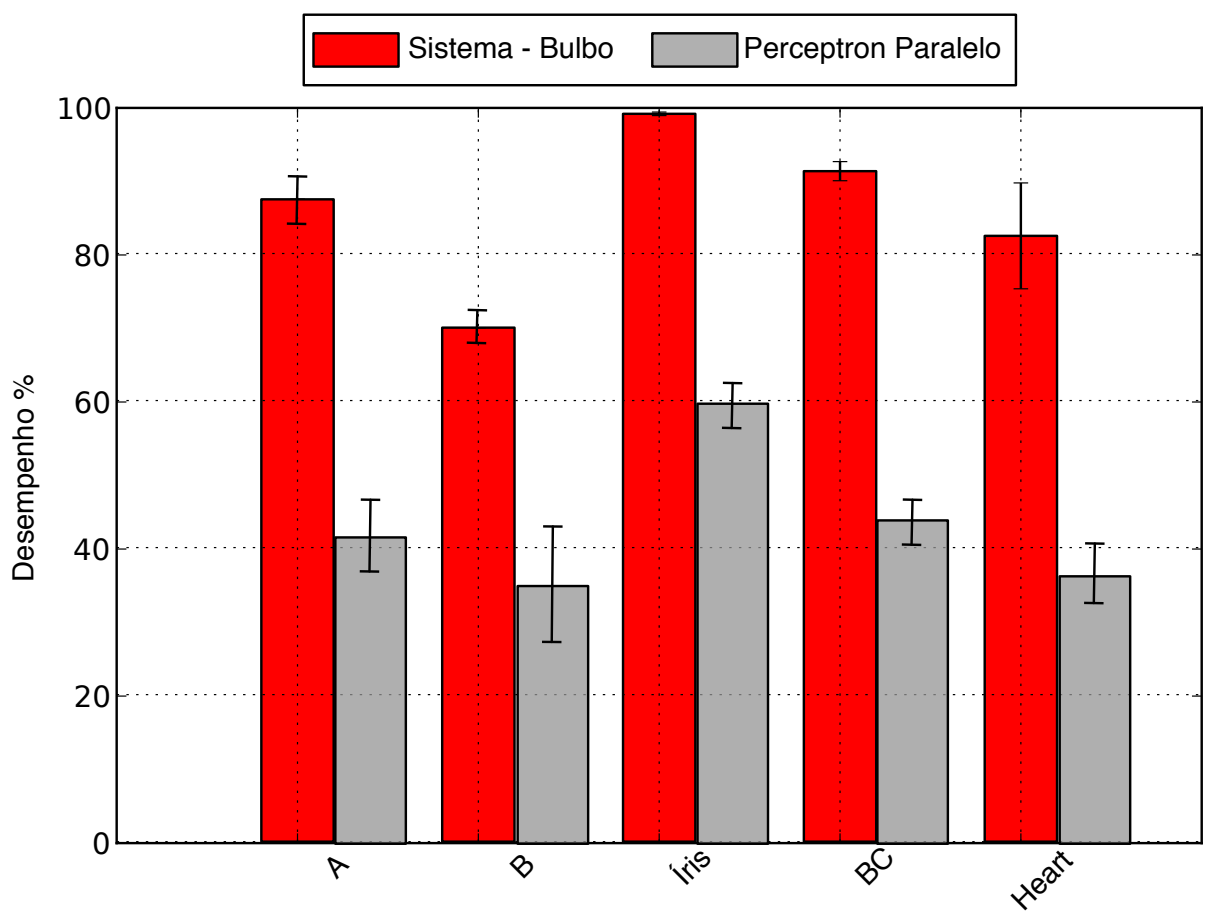

Figura 5.8: Desempenho do sistema computacional (vermelho) e do perceptron paralelo isolado (cinza) para os domínios de conhecimento indicados no eixo-x.

Heart e Parkinson foram codificados na forma de trens de disparos de acordo com o método descrito na subseção 4.4, com inserção de ruído determinado por $r=0.3$ e $t_{\text {deslocamento }}=30 \mathrm{~ms}$. Além disso, testamos cada domínio em duas situações, a primeira sem atividade prévia do bulbo, ou seja, o bulbo e todos os seus componentes estavam em estado de repouso quando receberam os estímulos, e a segunda situação na qual o bulbo recebia uma sequência de disparos poissoniana durante $300 \mathrm{~ms}$ antes do início da apresentação dos estímulos.

A Figura 5.9 apresenta o desepenho do sistema computacional na presença (barras verdes) e na ausência (barras vermelhas) da pré-entrada ruidosa, para os cinco domínios de conhecimento. Em três domínios, A, B e BC, não houve grande diferença entre o desempenho com e sem pré-entrada ruidosa. Sendo assim, notamos que o bulbo é relativamente eficaz em assumir novos estados que serão reconhecidos pelos leitores de saída responsáveis por classificar a entrada em questão.

Com relação aos outros dois domínios, Heart e Parkinson, as diferenças são maiores, sendo que o desempenho do sistema é menor quando ele recebe a pré-entrada 


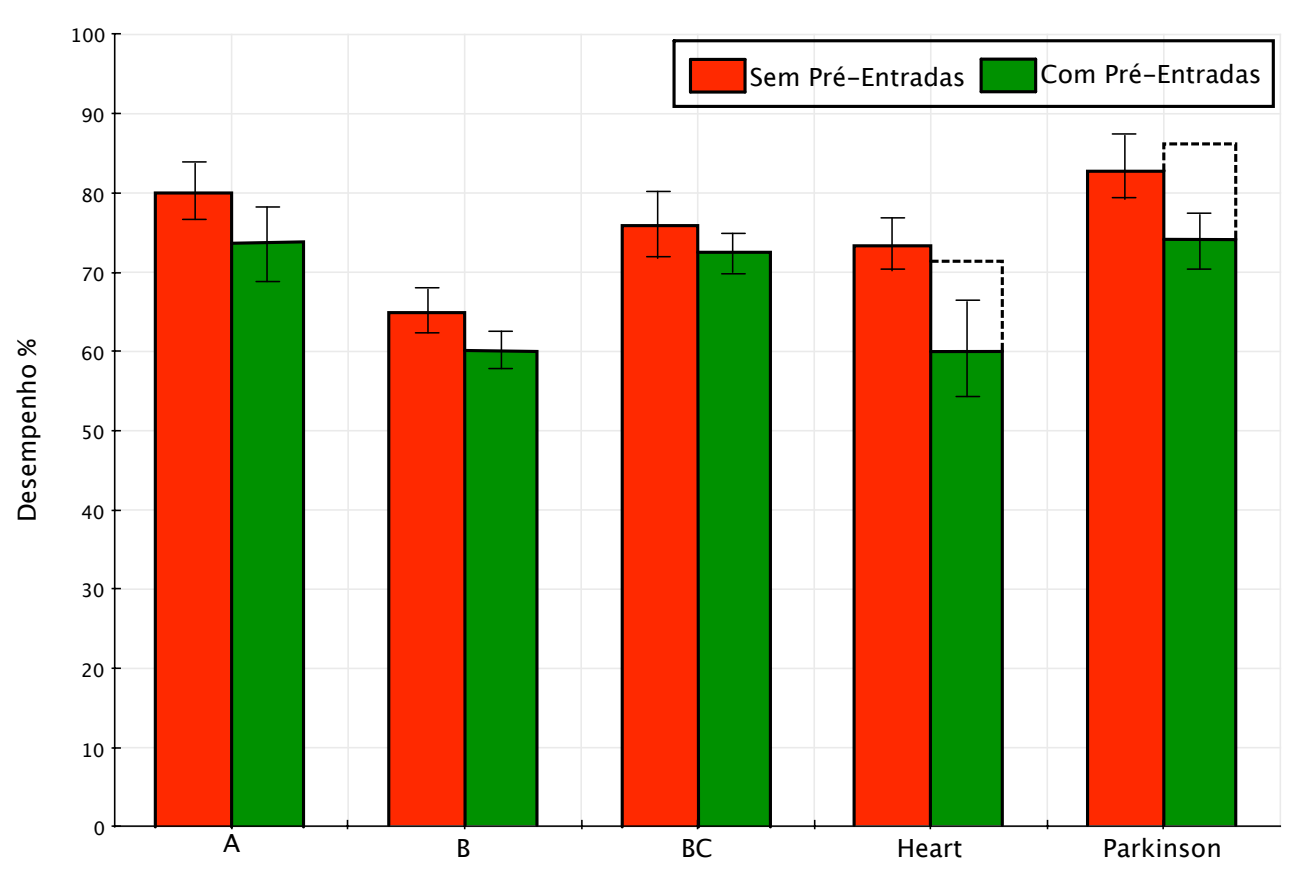

Figura 5.9: Desempenho do sistema computacional para entradas de cinco difrentes domínios codificadas na forma de trens de disparo. As barras vermelhas indicam o caso sem pré-entrada ruidosa e as barras verdes indicam o caso com pré-entrada ruidosa.

ruidosa. Tentando melhorar o desempenho para o caso com pré-entrada ruidosa, fizemos uma alteração nos leitores de saída para que eles passassem a classificar os estados apenas após $200 \mathrm{~ms}$ do término da apresentação da pré-entrada e do início da apresentação da instância (entrada) do domínio em questão. O resultado pode ser visto nas linhas contínuas complementando as barras verdes na Figura 5.9. Pode-se ver que o desempenho dos leitores de saída aumenta quando há um atraso antes que eles comecem a classificar os estados. Este tempo de atraso de $200 \mathrm{~ms}$ vai de encontro com os estudos sobre memória feitos anteriormente, onde verificamos que após 250 ms o bulbo já "esqueceu”, em parte, as pré-entradas.

Usamos o domínio Faces, o qual é composto por imagens de homens e mulheres, para executar o próximo experimento. Neste caso, segundo a Figura 5.10, usamos a técnica de Análise de Componentes Principais (ACP) para extrair os 100 componentes principais da imagem, os quais foram usados, (i) diretamente como estímulos para o sistema computacional, ou (ii) foram codificados na forma de trens de disparos para serem fornecidos como entradas para o sistema. Por fim, o leitor foi treinado 
para classificar se os estados de saida do sistema se referem a imagens masculinas ou femininas.

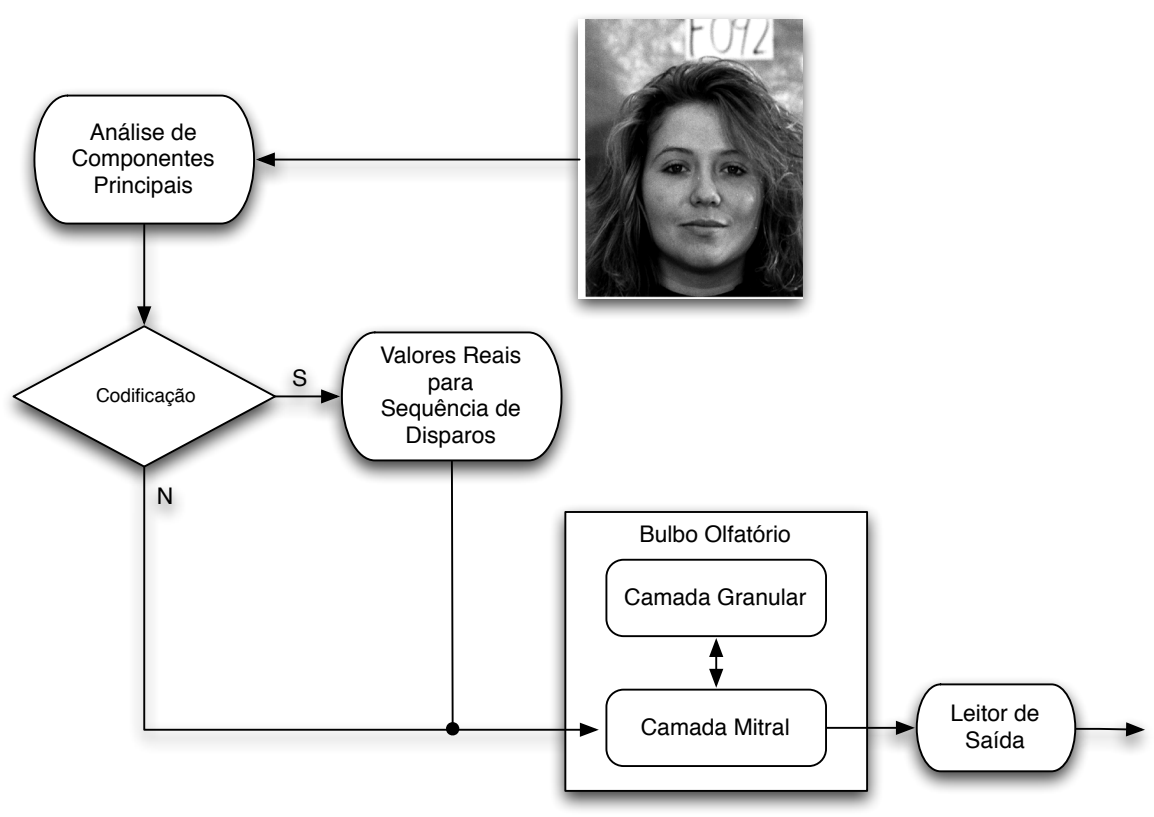

Figura 5.10: Esquema de treinamento e teste para o problema de classificação de imagens usando análise de componentes principais e o sistema computacional proposto. Os componentes principais selecionados podem ou não ser transformados em sequências (trens) de disparo.

Na Figura 5.11, apresentamos os resultados obtidos com o esquema apresentado na Figura 5.10 em três situações, a saber, com estímulo direto, com estímulo codificado na forma de trem de disparos e com pré-entrada ruidosa seguida da apresentação do estímulo codificado como trem de disparos. Também mostramos, para comparação, o resultado do fornecimento das componentes principais como entradas diretas para o perceptron paralelo. É possível perceber que o uso do modelo do bulbo, independente do modo de codificação de entradas utilizado, resulta em melhor desempenho em relação ao perceptron paralelo isolado. Pode-se notar também que não existem diferenças notáveis entre os desempenhos do sistema para as três formas de codificação utilizadas.

Outra constatação interessante que pode ser feita a partir deste último resultado é a de que o sistema pode ser usado em combinação com mais de um tipo de técnica de extração de características utilizada em aprendizado de máquina para fornecer um bom desempenho. Ele possui capacidade de se adaptar a diferentes domínios e 
ferramentas para produzir bons desempenhos.

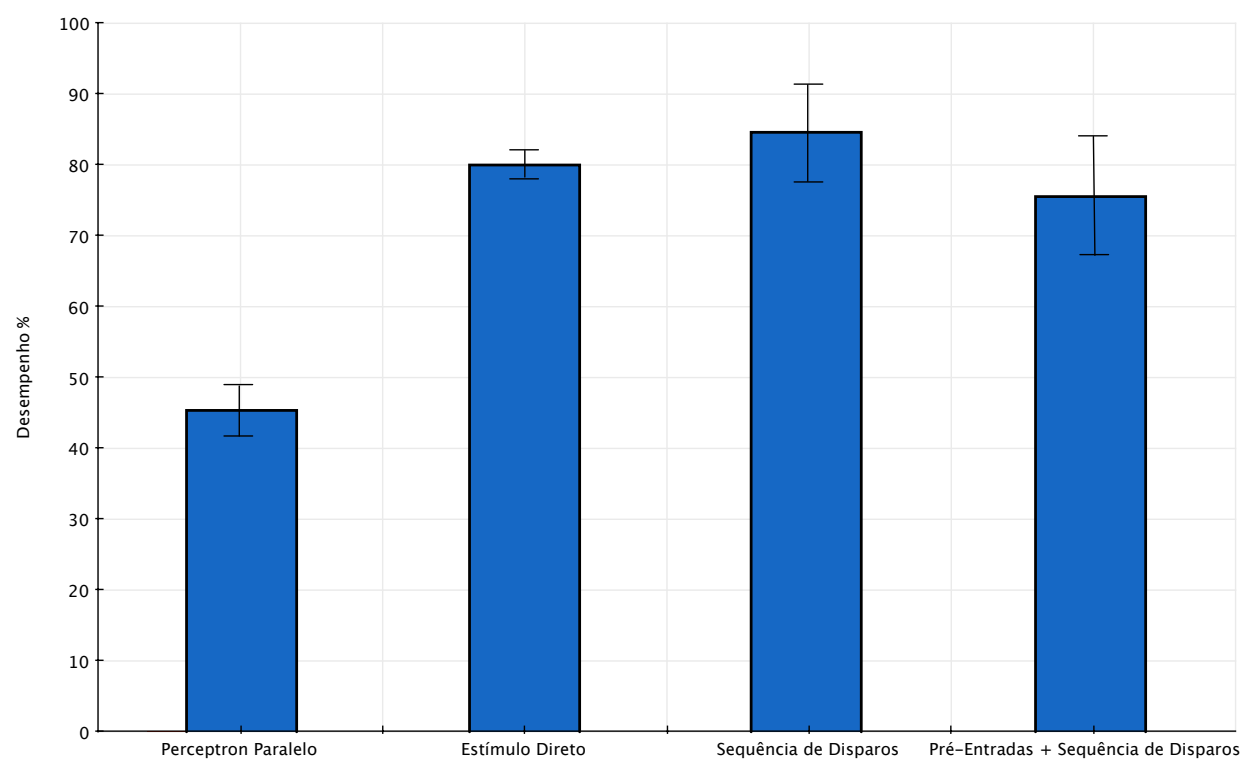

Figura 5.11: Desempenho de classificação para o domínio Faces. A primeira barra indica o desempenho do perceptron paralelo isolado e as outras três apresentam o desempenho do sistema com diferentes formas de codificação de entradas.

Por fim, testamos a resposta do sistema quando as entradas não estão completas, ou seja, alguns atributos não estão presentes no momento da apresentação dos mesmo ao sistema. Para cada um dos domínios verificados, retiramos, no momento do teste, $35 \%$ dos atributos das instâncias de forma aleatória. O desempenho do sistema para cinco diferentes domínios (A, B, BC, Heart e Faces) neste caso é apresentado na Figura 5.12. Podemos perceber que, apesar da queda no desempenho do sistema em relação aos casos com inst6ancias completas, o desempenho ainda permanece satisfatório, com valors entre $60 \%$ e $70 \%$. Isto indicando que o sistema bulbo possui robustez e um eficaz mecanismo de tolerâncias a falhas.

Vale ressaltar que tanto os parâmetros do bulbo quanto os parâmetros do perceptron paralelo não foram alterados em nenhum dos experimentos relatados neste Capítulo, ressaltando a generalidade e flexibilidade do sistema em questão.

\subsection{Considerações Finais}

Neste capítulo apresentamos os experimentos e testes realizados com o sistema computacional proposto nesta tese, com o intuito de avaliar e verificar a viabilidade 


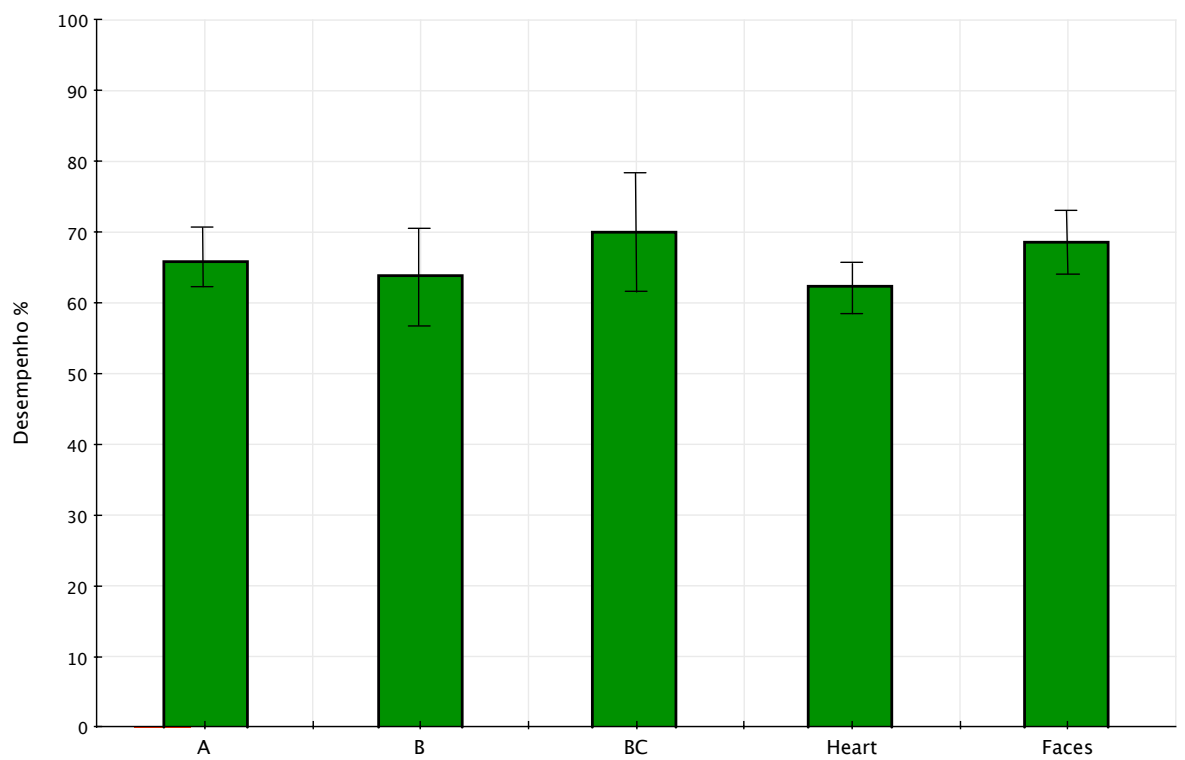

Figura 5.12: Desempenho do sistema computacional na classificação de instâncias com $40 \%$ de atributos ausentes.

do modelo do bulbo olfatório em problemas de reconhecimento de padrões, além de como o mesmo pode ser utilizado. No próximo capítulo faremos as conclusões desta tese, bem como comentaremos sobre os desdobramentos da mesma e os trabalhos futuros. 


\section{CAPÍTUlo}

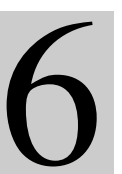

\section{CONCLUSÃO}

O trabalho desenvolvido nessa tese teve como objetivo a construção de um sistema de reconhecimento de padrões inspirado no sistema olfatório, mais especificamente no funcionamento do bulbo olfatório.

Inicialmente, fizemos uma revisão dos principais conceitos que envolvem a modelagem matemática e computacional dos neurônios e sinapses, tanto no nível iônico como no nível das redes neuronais, a seguir revisamos conceitos pertinentes à tese no que diz respeito ao bulbo olfatório, tais conceitos envolvem sua anatomia e fisiologia básica.

A seguir apresentamos um framework, chamado Nemos, nossa primeira proposta no desenvolvimento do objetivo principal desta tese. O Nemos foi apresentado com detalhes conceituais sobre seu funcionamento e arquitetura mostrando suas principais qualidades como ferramenta para espeficicação e modelagem de neurônios, sinapses e redes. Além disso, apresentamos como podemos usar os modelos prontos no Nemos para fazermos simulações com variadas demandas.

O próximo passo foi a especificação do modelo inspirado no bulbo olfatório, com a proposta de células mitrais, a modelagem de células granulares, a espeficicação espacial da rede, bem como a conectividade entre as camadas mitral e granular através de sinapses dendodendríticas, e das sinapses inibitórias na camada granular.

Finalmente, fizemos testes e experimentos com o intuito de avaliar o modelo do bulbo em problemas de reconhecimento de padrões, onde verificamos a viabilidade de tal modelo juntamento com leitores de saída. Alguns mecanismos de entrada foram testados, bem como algumas situações de reconhecimento de padrões. Além disso, pudemos avaliar a característica de separabilidade do bulbo. 
Sendo assim, a partir do que foi apresentado nesta tese podemos dizer que:

- o Nemos pode ser usado como ferramenta para simulação mesmo no caso em que se conheça pouco sobre programação, uma vez que o mesmo possui uma série de modelos de neurônios, de sinapses e redes já implementados. Além disso, o fato do Nemos possuir uma Graphical User Interface (GUI) facilita a interação com usuários iniciantes.

- pelo fato do Nemos possuir um núcleo de propósito geral, bem como um pacote matemático com vários métodos de integração, o mesmo pode ser usadado para a construção de simulações em outras áreas além da neurociência computacional.

- a desvantagem apresentada pelo Nemos está no tempo real de simulação, que em comparação com o Nest se mostrou acentuada quando milhares de equações diferenciais e eventos precisavam ser processadas em cada passo de tempo.

- os modelos de neurônios usados para o bulbo agregam características observadas em diversos experimentos, com um custo computacional baixo fazendo com que tais modelos possam ser usados futuramente em outras simulações.

- a conectividade e o uso da sinapse dinâmica promoveram a possibilidade de ajustes e verificação de parâmetros através da configuração de modelos de bulbos com diferentes conectividades.

- o modelo do bulbo, como um todo, apresentou uma característica importante para um sistema de reconhecimento de padrões: a separabilidade, de forma que os estados gerados pelo bulbo a partir de instâncias de diferentes classes são suficientemente separados durante o tempo de apresentação da mesma.

- o sistema apresentou uma característica interessante, também observada no bulbo olfatório de vertebrados, que é a transformação de padrões estáticos de entrada em padrões espaço-temporais (dinâmicos) de saída. Um dos estudos sugeriu uma maneira como os padrões oscilatórios gerados pelo sistema podem ser lidos e avaliados por leitores de saída, isto é, usando leitores que acessem a saída de forma oscilatória em sincronia com as oscilações do sistema. 
- o sistema baseado no bulbo olfatório foi aplicado em diferentes situações com o intuito de classificar padrões e obteve resultados bastante satisfatórios, mesmo na presença de ruídos ou padrões incompletos. Além disso, a combinação de técnicas para melhorar a classificação ou para preparar melhor os dados de entrada foram usadas com sucesso.

Como desdobramentos dessa tese podemos elencar alguns trabalhos futuros a saber:

- o Nemos pode ser trabalhado em três frentes:

- o desenvolvimento de novos modelos, de uma documentação e de tutoriais apropriados para divulgação e incentivo ao uso da ferramenta por parte de outros pesquisadores.

- o refinamento e otimização do código para que o desempenho do mesmo se torne mais competitivo. Além disso, é possível a adaptação do código para que o Nemos seja executado em clusters, algo muito comum na área de simulação.

- a interoperabilidade com outros sistemas e, principalmente, com descritores de modelos e simulação como, por exemplo, o NeuroML [Gleeson et al. 2010].

- o sistema computacional inspirado no bulbo olfatório pode ser explorado em alguns tópicos:

- a exploração de outros tipos de conectividade, bem como de outros parâmetros que nesta tese ficaram fixos, como, por exemplo, os parâmetros da sinapse dinâmica.

- a introdução de modelos de plasticidade sináptica de longa duração no modelo, e a avaliação de como tal introdução altera o desempenho do sistema no reconhecimento de padrões.

- a alteração da arquitetura do bulbo, com a adição de novos modelos de células e uma forma de modelar os glomérulos e o epitélio olfatório, que não foram considerados neste modelo. 
- a continuidade dos testes do sistema computacional desenvolvido usando dados de outros domínios de conhecimento. 


\section{REFERÊNCIAS BIBLIOGRÁFICAS}

[Adlassnig et al. 1985]ADLASSNIG, K.-P. et al. CADIAG: Approaches to computerassisted medical diagnosis. Comput.Biol.Med., Pergamon Press, v. 15, n. 5, 1985.

[Araneda, Firestein e Kini 2000]ARANEDA, R. C.; FIRESTEIN, S.; KINI, A. D. The molecular receptive range of an odorant receptor. Nature Neuroscience, v. 3, p. $1248-1255,2000$.

[Auer, Burgsteiner e Maass 2002]AUER, P.; BURGSTEINER, H.; MAASS, W. Reducing communication for distributed learning in neural networks. In: DORRONSORO, J. (Ed.). Artificial Neural Networks - ICANN 2002. [S.l.]: Springer Berlin / Heidelberg, 2002. (Lecture Notes in Computer Science, v. 2415), p. 133-133.

[Auer, Burgsteiner e Maass 2008]AUER, P.; BURGSTEINER, H.; MAASS, W. A learning rule for very simple universal approximators consisting of a single layer of perceptrons. Neural Networks, v. 21, n. 5, p. 786 - 795, 2008. ISSN 0893-6080. Disponível em: <http://www.sciencedirect.com/science/article/B6T08-4RGFCYSB/2/6b2cd2b61a38807d1ac548da01b5f041>.

[Barnett et al. 1987]BARNETT, G. et al. Dxplain: an evolving diagnostic decisionsupport system. Journal of the American Medical Association, v. 258, p. 67-74, 1987.

[Bishop 1995]BISHOP, C. Neural Networks for Pattern Recognition. [S.l.]: Oxford University Press, 1995.

[Blake e Merz 1998]BLAKE, C. L.; MERZ, C. J. UCI Repository of machine learning databases. 1998. 
[Bower e Beeman 1998]BOWER, J. M.; BEEMAN, D. he Book of GENESIS: Exploring Realistic Neural Models with the GEneral NEural SImulation System. [S.l.]: Springer-Verlag, 1998.

[Brette e Gerstner 2005]BRETTE，R.; GERSTNER，W. Adaptive exponential integrate-and-fire model as an effective description of neuronal activity. $J \mathrm{Neu}$ rophysiol, v. 94, n. 5, p. 3637-42, Nov 2005.

[Buck 1996]BUCK, L. Information coding in the vertebrate olfactory system. Annual Review of Neuroscience, v. 19, p. 517-544, 1996.

[Buck e Axel 1991]BUCK, L.; AXEL, R. A novel multigene family may encode odorant receptors: a molecular basis for odor recognition. Cell, v. 65, p. 175-187, 1991.

[Buonomano e Merzenich 1999]BUONOMANO, D. V.; MERZENICH, M. A neural network modell of temporal code generation and position invariant pattern recognition. Neural Computation, v. 11, n. 1, p. 103-116, 1999.

[Carnevale e Hines 2006]CARNEVALE, N.; HINES, M. The NEURON Book. [S.1.]: Cambridge University Press, 2006.

[David, Krivine e Simmons 1993]DAVID, J.; KRIVINE, J.; SIMMONS, R. Second generation expert systems: A step forward in knowledge engineering. In: DAVID, J.-M.; KRIVINE, J.-P.; SIMMONS, R. (Ed.). Second Generation Expert Systems. Berlin: Springer-Verlag, 1993. p. 405-427.

[Davison, Feng e Brown 2003]DAVISON, A. P.; FENG, J.; BROWN, D. Dendrodendritic inhibition and simulated odor responses in a detailed olfactory bulb network model. Journal of Neurophysiology, v. 90, p. 1921-1935, 2003.

[Dayan e Abbott 2001]DAYAN, P.; ABBOTT, L. Theoretical Neuroscience: Computational and Mathematical Modeling of Neural Systems. [S.1.]: MIT Press, 2001.

[Detrano et al. 1989]DETRANO, R. et al. International application of a new probability algorithm for the diagnosis of coronary artery disease. The American Jour- 
nal of Cardiology, v. 64, n. 5, p. 304 - 310, 1989. ISSN 0002-9149. Disponível em: <http://www.sciencedirect.com/science/article/pii/0002914989905249>.

[Diesmann, Gewaltig e Aertsen 1999]DIESMANN, M.; GEWALTIG, M.; AERTSEN, A. Stable propagation of synchronous spiking in cortical neural networks. Nature, v. 402, p. 529-533, 1999.

[Dreyfus e Dreyfus 1986]DREYFUS, H.; DREYFUS, S. Why expert systems do not exhibit expertise. IEEE Expert, p. 86-90, 1986.

[Dryer e Graziadei 1994]DRYER, L.; GRAZIADEI, P. P. Mitral cell dendrites: a comparative approach. Anat Embryol (Berl), Department of Biological Sciences B-221, Florida State University, Tallahassee 32306., v. 189, n. 2, p. 91-106, 1994. ISSN 0340-2061 (Print).

[Duda e Hart 1973]DUDA, R. O.; HART, P. E. Pattern Classification and Scene Analysis. John Wiley \& Sons Inc, 1973. Hardcover. ISBN 0471223611. Disponível em: <http://www.amazon.com/exec/obidos/redirect?tag=citeulike0720\&path $=$ ASIN $/ 0471223611>$.

[Duda e Hart 2000]DUDA, R. O.; HART, P. E. Pattern Classification. [S.l.]: John Wiley and Sons, 2000.

[Egger, Svoboda e Mainen 2005]EGGER, V.; SVOBODA, K.; MAINEN, Z. F. Dendrodendritic synaptic signals in olfactory bulb granule cells: local spine boost and global low-threshold spike. J Neurosci, Cold Spring Harbor Laboratory, Cold Spring Harbor, New York 11724, USA. veronica.egger@lrz.uni-muenchen.de, v. 25, n. 14, p. 3521-3530, 2005. ISSN 1529-2401 (Electronic).

[Ferrández e Mira 2009]FERRÁNDEZ， J.; MIRA， J. Non-conventional computing paradigms. Natural Computing, Springer Netherlands, v. 8, p. 643-644, 2009. ISSN 1567-7818. 10.1007/s11047-009-9139-7. Disponível em: <http://dx.doi.org/10.1007/s11047-009-9139-7>.

[Fisher 1936]FISHER, R. A. The use of multiple measurements in taxonomic problems. Annals Eugen., v. 7, p. 179-188, 1936. 
[FitzHugh 1955]FITZHUGH, R. Mathematical models of threshold phenomena in the nerve membrane. Bull, v. 17, p. 257-278, 1955.

[FitzHugh 1961]FITZHUGH, R. Impulses and physiological states in theoretical models of nerve membrane. Biophysical Journal, v. 1, p. 445-466, 1961. ISSN 00063495 .

[Friedrich 2002]FRIEDRICH, R. W. Real time odor representations. Trends in Neurosciences, v. 25, n. 10, p. 487-489, 2002.

[Fujii et al. 1996]FUJII, H. et al. Dynamical cell assembly hypothesis-theoretical possibility of spatio-temporal coding in the cortex. Neural Networks, v. 9, n. 8, p. 1303-1350, 1996.

[Galán, Ermentrout e Urban 2006]GALÁN, R. F.; ERMENTROUT, G. B.; URBAN, N. N. Reliability, discriminality and stochastic synchronization of olfactory neurons. Sensors and Actuators B, n. 116, p. 168-173, 2006.

[Geiger e Jonas 2000]GEIGER, J.; JONAS, P. Dynamic control of presynaptic ca inflow by fast-inactivating $\mathrm{k}$ channels in hippocampal mossy fiber boutons. Neuron, v. 28 , p. $927-939,2000$.

[Gerstner e Kistler 2002]GERSTNER, S.; KISTLER, R. Spking Neuron Models. Single Neurons, Populations and Plasticity. [S.l.]: Cambridge University Press, 2002 .

[Gerstner 1995]GERSTNER, W. Time structure of the activity in neural network models. Physical Review E, v. 51, p. 738-758, jan 1995.

[Gewaltig e Diesmann 2007]GEWALTIG, M.-O.; DIESMANN, M. Nest (neural simulation tool). Scholarpedia, v. 2, n. 4, p. 1430, 2007.

[Gleeson et al. 2010]GLEESON, P. et al. Neuroml: A language for describing data driven models of neurons and networks with a high degree of biological detail. PLoS Comput Biol, Public Library of Science, v. 6, n. 6, p. e1000815, 062010.

[Gross 2005]GROSS, R. Face databases. In: S.LI, A. (Ed.). Handbook of Face Recognition. New York: Springer, 2005. 
[Haberly 2001]HABERLY, L. Parallel-distributed processing in olfactory cortex: new insights from morphological and physiological analysis of neuronal circuitry. Chemical Senses, v. 26, p. 551-576, 2001.

[Haykin 1998]HAYKIN, S. Neural Networks. [S.l.]: Macmillan, 1998.

[Heyward et al. 2001]HEYWARD, P. et al. Membrane bistability in olfactory bulb mitral cells. The Journal of Neuroscience, v. 21, n. 14, p. 5311-5320, 2001.

[Hodgkin e Huxley 1952]HODGKIN, A. L.; HUXLEY, A. F. A quantitative description of membrane current and its application to conduction and excitation in nerve. J. Physiol., v. 116, p. 500-544, 1952.

[Huerta et al. 2004]HUERTA, R. et al. Learning classification in the olfactory system of insects. Neural Computation, v. 16, n. 8, p. 1601-1640, 2004.

[Izhikevich 2000]IZHIKEVICH, E. M. Neural excitability, spiking, and bursting. International Journal of Bifurcation and Chaos, v. 10, p. 1171-1266, 2000.

[Izhikevich 2003]IZHIKEVICH, E. M. Simple model of spiking neurons. IEEE Transactions on Neural Networks, v. 14, p. 1569-1572, 2003.

[Izhikevich 2004]IZHIKEVICH, E. M. Which model to use for cortical spiking neurons? IEEE Transactions on Neural Networks, n. 15, p. 1063 - 1070, 2004.

[Izhikevich 2007]IZHIKEVICH, E. M. Dynamical Systems in Neuroscience: Dynamical Systems in Neuroscience: The Geometry of Excitability and Bursting. [S.1.]: The MIT Press, 2007.

[Jaeger 2002]JAEGER, H. Short term memory in echo state networks. [S.l.], 2002. Disponível em: <http://www.faculty.jacobsuniversity.de/hjaeger/pubs/STMEchoStatesTechRep.pdf $>$.

[Jolliffe 2002]JOLLIFFE, I. T. Principal Component Analysis. [S.1.]: SpringerVerlag, 2002.

[Kandel, Schwartz e Jessell 2000]KANDEL, E.; SCHWARTZ, J.; JESSELL, T. Principles of Neural Science. 4. ed. [S.l.]: McGrawHill/ Appleton \& Lange, 2000. 
[Kay, Sugimori e Llinas 1998]KAY, A. R.; SUGIMORI, M.; LLINAS, R. Kinetic and stochastic properties of a persis- tent sodium current in mature guinea pig cerebellar purkinje cells. J. Neurophysiology, v. 80, p. 1167-1179, 1998.

[Knüsel et al. 2004]KNÜSEL, P. et al. Decoding a temporal population code. Neural Computation, v. 16, n. 10, p. 2079-2100, 2004.

[Koch e Segev 1999]KOCH, C.; SEGEV, I. Methods in Neuronal Modeling: From Ions to Networks. 2. ed. [S.I.]: MIT Press, 1999.

[Korngreen e Sakmann 1998]KORNGREEN, A.; SAKMANN, B. Voltage-gated k+ channels in layer 5 neocortical pyrami- dal neurones from young rats: subtypes and gradients. Journal of Physiology, v. 525, n. 3, p. 621-239, 1998.

[Korsching 2002]KORSCHING, S. Olfactory maps and odor images. Current Opinion in Neurobiology, v. 12, n. 4, p. 387-392, 2002.

[Kratskin e Belluzzi 2005]KRATSKIN, I. L. .; BELLUZZI, O. Handbook of olfaction and gustation. In: Second edition, revised and expanded. [S.l.]: Marcel Dekker, 2005. cap. Anatomy and Neurochemistry of the Olfactory Bulb.

[Laurent 1997]LAURENT, G. Olfactory processing: maps, time and codes. Current Opinion in Neurobiology, v. 7, p. 547-553, 1997.

[Laurent et al. 2001]LAURENT, G. et al. Odor encoding as an active, dynamical process: Experiments, computation, and theory. Annual Review of Neuroscience, v. 24, p. 263-297, 2001.

[Little et al. 2009]LITTLE, M. A. et al. Suitability of dysphonia measurements for telemonitoring of parkinson's disease. IEEE Transactions on Biomedical Engineering, v. 56, n. 4, p. 1015-1022, 2009.

[Lytton 2002]LYTTON, W. W. From Computer to Brain. [S.l.]: Springer-Verlag, 2002.

[Maass, Natschläger e Markram 2002]MAASS, W.; NATSCHLÄGER, T.; MARKRAM, H. Real-time computing without stable states: A new framework for neural 
computation based on perturbations. Neural Computation, v. 14, n. 11, p. 25312560, 2002.

[Maass, Natschläger e Markran 2004]MAASS, W.; NATSCHLÄGER, T.; MARKRAN, H. Computational neuroscience: A comprehensive approach. In:

[S.1.]: Chapman \& Hall, 2004. cap. Computational models for generic cortical microcircuits, p. 575-605.

[Maass e Ruf 1996]MAASS, W.; RUF, B. The computational power of spiking neurons depends on the shape of the postsynaptic potentials. In: ECCCTR: Electronic Colloquium on Computational Complexity, technical reports. [S.l.: s.n.], 1996.

[Malnic et al. 1999]MALNIC, B. et al. Combinatorial receptor codes for odors. Cell, v. 96, p. 713-723, 1999.

[Markram, Wang e Tsodyks 1998]MARKRAM, H.; WANG, Y.; TSODYKS, M. Differential signaling via the same axon of neocortical pyramidal neurons. In: Proceedings of the National Academy of Sciences (USA). [S.l.: s.n.], 1998. v. 95, p. $5323-5328$

[Marr 1982]MARR, D. Vision. [S.l.: s.n.], 1982.

[Meunier e Bouchon 2000]MEUNIER, B.; BOUCHON, C. Nonlinear biomedical signal processing: Fuzzy logic, neural networks and new algorithms. In: [S.l.]: IEEE Press, 2000. v. 1, cap. Uncertainty management in medical applications, p. $1-26$.

[Migliore e Shepherd 2008]MIGLIORE, M.; SHEPHERD, G. M. Dendritic action potentials connect distributed dendrodendritic microcircuits. J Comput Neurosci, Department of Neurobiology, Yale University School of Medicine, New Haven, CT, USA. michele.migliore@pa.ibf.cnr.it, v. 24, n. 2, p. 207-221, 2008. ISSN 0929-5313 (Print).

[Miller e Geissbuhler 1999]MILLER, R.; GEISSBUHLER, A. Clinical decision support systems: Theory and practice. In: . [S.1.]: Springer-Verlag, 1999. cap. Clinical diagnostic decision support systems -an overview, p. 3-34. 
[Miller et al. 1986]MILLER, R. et al. The internist1/quick medical reference project: status report. Western Journal of Medicine, v. 145, p. 818-822, 1986.

[Mitchell 1998]MITCHELL, T. An Introduction to Genetic Algorithms. [S.1.]: MIT Press, 1998.

[Mori, Nagao e Yoshihara 1999]MORI, K.; NAGAO, H.; YOSHIHARA, Y. The olfactory bulb: coding and processing of odor molecule information. Science, v. 286, n. 5440, p. $711-5$, Oct 1999.

[Musen, Shahar e Shortliffe 2001]MUSEN, M.; SHAHAR, Y.; SHORTLIFFE, E. Medical informatics: Computer applications in health care and biomedicine. In: 2. ed. [S.1.]: Springer-Verlag, 2001. cap. Clinical decision-support systems, p. $573-609$.

[Nagumo, Arimoto e Yoshizawa 1962]NAGUMO, J.; ARIMOTO, S.; YOSHIZAWA, S. An active pulse transmission line simulating nerve axon. In: Proc. IRE. [S.l.: s.n.], 1962. v. 50, p. 2061-2070.

[Parri e Crunelli 1999]PARRI, H. R.; CRUNELLI, V. Sodium current in rat and cat thalamocortical neurons: Role of a non-inactivating component in tonic and burst firing. The Journal of Neuro-science, v. 18, n. 3, p. 854-867, Fevereiro 1999.

[Pecevski, Natschläger e Schuch 2009]PECEVSKI, D.; NATSCHLÄGER, T.; SCHUCH, K. Pcsim: a parallel simulation environment for neural circuits fully integrated with python. Frontiers in Neuroinformatics, v. 3, n. 0, 2009. ISSN 1662-5196.

[Principe, CurtLefebvre e Euliano 2000]PRINCIPE, J.; CURTLEFEBVRE, W.; EULIANO, N. Neural and Adaptive Systems: Fundamentals Through Simulations. [S.l.]: Wiley, 2000.

[Principe, Euliano e Garani 2002]PRINCIPE, J.; EULIANO, N.; GARANI, S. Principles and networks for selforganization in spacetime. Neural Networks, v. 15, p. 1069-1083, 2002. 
[Quinlan 1986]QUINLAN, R. Induction of decision trees. Machine Learning, v. 1, p. 81-106, 1986.

[Rubin e Katz 1999]RUBIN, B.; KATZ, L. Optical imaging of odorant representations in the mammalian olfactory bulb. Neuron, v. 23, p. 499-511, 1999.

[Schoppa e Westbrook 1999]SCHOPPA, N. E.; WESTBROOK, G. L. Regulation of synaptic timing in the olfactory bulb by an a-type potassium current. Nat Neurosci, Vollum Institute, Oregon Health Sciences University, 3181 SW Sam Jackson Park Road, Portland, Oregon 97201, USA. schoppan@ohsu.edu, v. 2, n. 12, p. 11061113, 1999. ISSN 1097-6256 (Print).

[Shepherd 2004]SHEPHERD, G. M. The synaptic organization of the brain. 5th ed. ed. Oxford: Oxford University Press, 2004. ISBN 0195159551 (alk. paper).

[Shepherd et al. 2007]SHEPHERD, G. M. et al. The olfactory granule cell: from classical enigma to central role in olfactory processing. Brain Res Rev, v. 55, n. 2, p. 373-82, Oct 2007.

[Silva 2000]SILVA, R. LEPIDUS: Sistema Especialista em Medicina Geral. Tese (Doutorado) - FFCLRP USP, 2000.

[Souza e Roque 2004]SOUZA, F. S. de; ROQUE, A. A biophysical model of vertebrate olfactory epithelium and bulb exhibiting gap junction dependent odor-evoked spatiotemporal patterns of activity. Biosystems, v. 73, n. 1, p. 25-43, 2004.

[Spors e Grinvald 2002]SPORS, H.; GRINVALD, A. Spatio-temporal dynamics of odor representations in the mammalian olfactory bulb. Neuron, v. 34, p. 301-315, 2002 .

[Stopfer, Jayaraman e Laurent 2003]STOPFER, M.; JAYARAMAN, V.; LAURENT, G. Intensity versus identity coding in an olfactory system. Neuron, v. 39, p. $301-315,2003$.

[Strogatz 1994]STROGATZ, S. H. Nonlinear dynamics and Chaos : with applications to physics, biology, chemistry, and engineering. [S.1.]: Addison-Wesley Pub., 1994. ISBN 0201543443. 
[Szolovits 1982]SZOLOVITS, P. Artificial Intelligence in Medicine. Boulder, Colorado: Westview Press, Inc., 1982.

[Tsodyks, Pawelzik e Markram 1998]TSODYKS, $\quad$ M.; $\quad$ PAWELZIK, $\quad$ K.; MARKRAM, H. Neural networks with dynamic synapses. Neural Computation, v. 10, n. 4, p. 821-835, 1998. Disponível em: $<$ http://www.mitpressjournals.org/doi/abs/10.1162/089976698300017502>.

[Tsuda 2001]TSUDA, I. Toward an interpretation of dynamic neural activity in terms of chaotic dynamical systems. Behavioral and Brain Sciences, v. 24, p. 793-847, 2001.

[Wilson e Stevenson 2003]WILSON, D.; STEVENSON, R. Olfactory perceptual learning: the critical role of memory in odor discrimination. Neuroscience and Behavioral Reviews, v. 27, p. 307-328, 2003.

[Wolberg e Mangasarian 1990]WOLBERG, W. H.; MANGASARIAN, O. L. Multisurface Method of Pattern Separation for Medical Diagnosis Applied to Breast Cytology. Proceedings of the National Academy of Sciences, U.S.A., v. 87, p. 91939196, 1990.

[Wold, Esbensen e Geladi 1987]WOLD, S.; ESBENSEN, K.; GELADI, P. Principal component analysis. Chemometrics and Intelligent Laboratory Systems, v. 2, n. 1-3, p. 37 - 52, 1987. ISSN 0169-7439. Disponível em: <http://www.sciencedirect.com/science/article/pii/0169743987800849>.

[Zadeh 1965]ZADEH, L. A. Fuzzy sets. Information and Control, v. 8, p. 338-353, 1965.

[Zelles et al. 2006]ZELLES, T. et al. Branch-specific ca2+ influx from natdependent dendritic spikes in olfactory granule cells. Journal of Neuroscience, v. 1, n. 26 , p. $30-40,2006$.

[Zhang 1992]ZHANG, J. Selecting typical instances in instance-based learning. In: Proceedings of the ninth international workshop on $\mathrm{Ma}$ chine learning. San Francisco, CA, USA: Morgan Kaufmann Publishers 
Inc., 1992. (ML92), p. 470-479. ISBN 1-5586-247-X. Disponível em: $<$ http://portal.acm.org/citation.cfm?id=141975.142091>. 


\section{APÊNDICE}

\section{Código do Modelo do Bulbo No NEMOS}

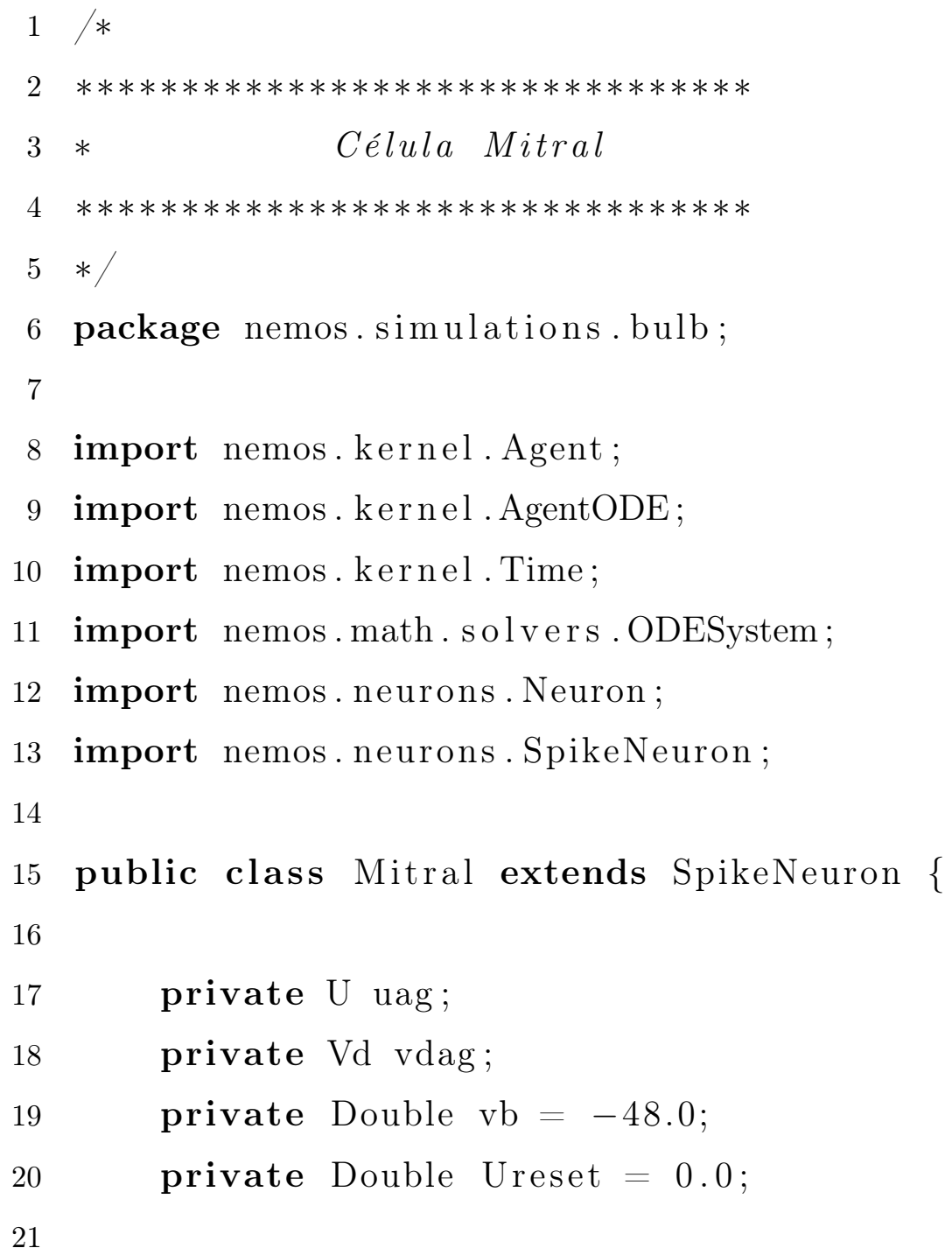




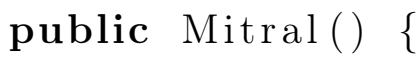




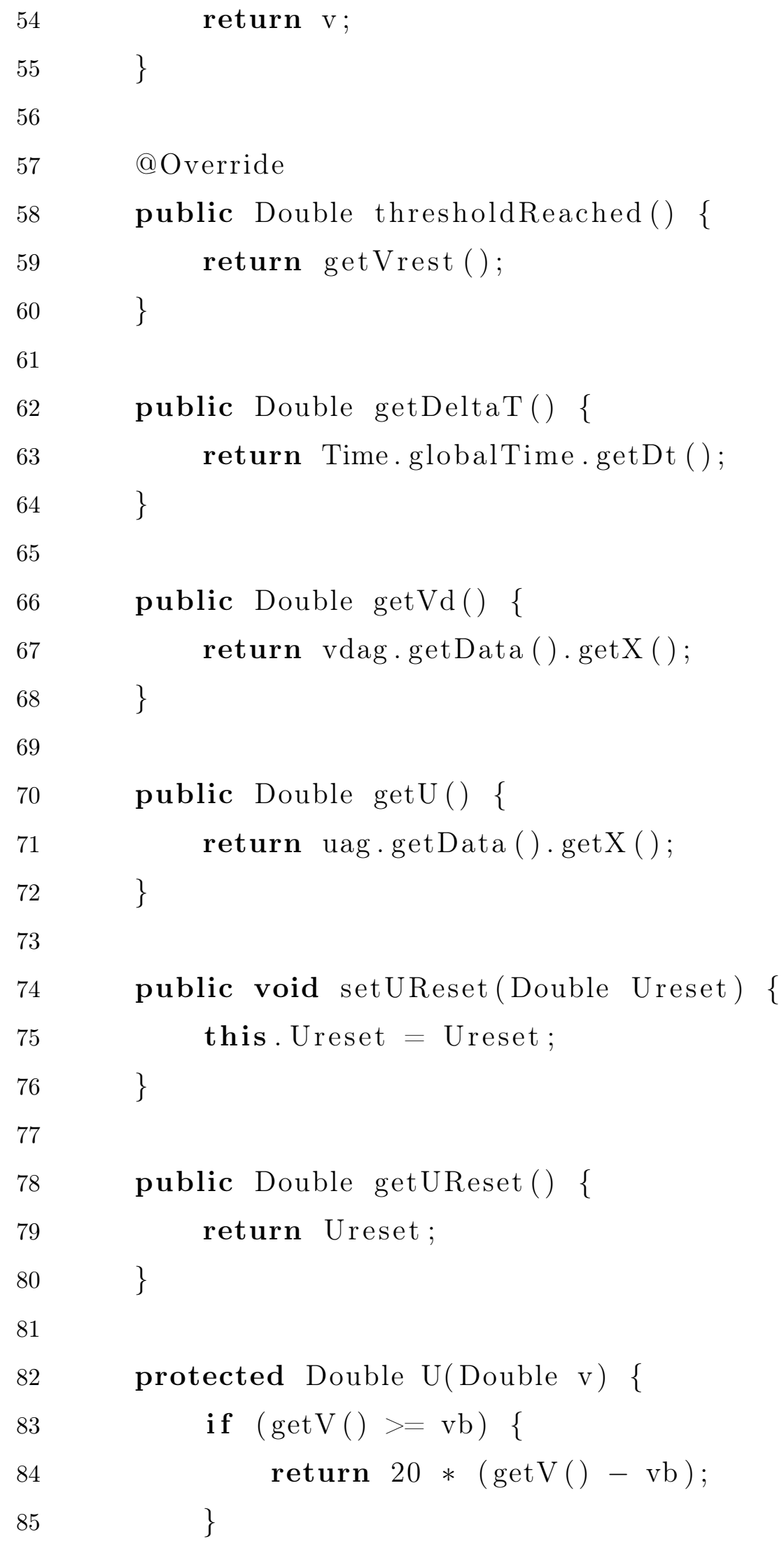


90

98

108

109

110

111

112

113

114

115

116

117 return Ureset;

\}

class Vd extends AgentODE \{

public $\operatorname{Vd}() \quad\{$

super ( ) ;

\}

@ Override

protected void initODE () \{

\}

public Double fX(ODESystem odesys) \{ return $0.125 *(\operatorname{get} \mathrm{V}()-\operatorname{get} \mathrm{Data}() \cdot \operatorname{get} \mathrm{X}())$;

\}

public void preprocess () \{

\}

\}

class U extends AgentODE \{

super ( ) ;

\}

@ Override

protected void initODE () \{

\}

public Double fX(ODESystem odesys) \{ 
141

142

143

144

145

146

147

148

149

return $0.4 *(\mathrm{U}(\operatorname{get} \mathrm{V}())-\operatorname{get} \mathrm{Data}() \cdot \operatorname{get} \mathrm{X}())$; \} public void preprocess ()\{ \} \}

public void setCurrentTime(Double t) \{ setAgentTime ( $\mathrm{t})$;

\}

@ Override public void reset () \{ super.reset ( ) ; vdag. getData (). setX (getVrest ( )); uag. getData ( ). setX (0.0);

\}

\}

$*$

Célula Granular

$*$

package nemos.simulations.bulb;

import nemos.math. solvers. ODESystem;

import nemos.neurons. Neuron;

import nemos. neurons. SimpleNeuron;

public class Granule extends SimpleNeuron \{ private final Double $\mathrm{A}=4.722 \mathrm{e}-08 *$ Math pow $(200,3)-$ $7.883 \mathrm{e}-06 *$ Math. pow $(200,2)+0.0004552 * 200-0.007633$; 
150

151

160

179

180

181

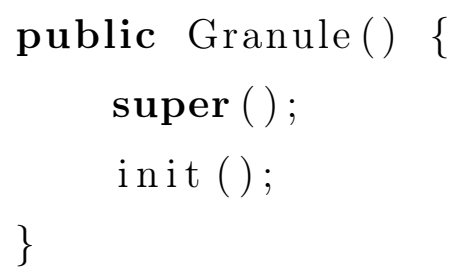

public Granule(Double vr, Double vt, Double ta, Double a, Double b, Double d, Double k, Double vpeak) \{ $\operatorname{super}(\mathrm{vr}, \mathrm{vt}, \mathrm{ta}, \mathrm{a}, \mathrm{b}, \mathrm{d}, \mathrm{k}, \operatorname{vpeak})$; \}

public Granule(Double vr, Double vt, Double ta) \{ super (vr, vt, ta);

\}

public void init () \{

super.init ();

setType (Neuron. INHIBITORY);

set Capacitance ( 100.0$)$;

setVrest $(-65.0)$;

setVthreshold (51.0);

setVt $(-43.0)$;

$\operatorname{set} \mathrm{C}(-70.0)$;

$\operatorname{set} \mathrm{D}(20.0)$;

$\operatorname{setK}(0.195)$;

$\operatorname{set} B(0.7)$;

$\operatorname{set} \mathrm{A}(0.0001)$;

setName(Granule. class getSimpleName () + getID ());

\}

public Double dxdt(ODESystem odesys) \{

Double $\mathrm{I}=$ calcAllCurrent () ; 
Double $\mathrm{a}=0.03$;

$$
\text { if }(\mathrm{I}>30 \& \& \quad \mathrm{I}<200)
$$

$\mathrm{a}=4.722 \mathrm{e}-08 *$ Math. pow $(\mathrm{I}, 3)-7.883 \mathrm{e}-06 *$ Math.pow $(\mathrm{I}, \quad 2)$

$$
+0.0004552 * \mathrm{I}-0.007633 \text {; }
$$

else

$$
\mathrm{a}=\mathrm{I}<=30 \quad ? \quad 0.03: \mathrm{A} \text {; }
$$

$\operatorname{set} \mathrm{A}(\mathrm{a})$;

return super.dxdt(odesys);

\}

\section{\}}

(1)

Configuração das Células Mitrais

$* * * * * * * * * * * * * * * * * * * * * * * * * * * * * * * * * * * * * * * * * * *$

*/

package nemos.simulations.bulb.config;

import java.util. List;

import nemos.config. ConfigForEach;

import nemos.simulations. bulb. Bulb;

import nemos.simulations.bulb. Mitral;

import nemos.math. RandomGen;

import nemos. neurons. Neuron;

public class ConfigMitrais extends ConfigForEach \{

@ Override

public void configParameters (Object obj, List lst) \{

12 RandomGen rnd $=$ Bulb. randBulb;

Mitral mitral $=($ Mitral $)$ obj; 
214

$244 *$

245 package nemos.simulations.bulb.config;

if $($ rnd.nextDouble ()$<0.4)\{$ mitral. setUReset $(-10.0)$;

\} mitral .setType ( Neuron.EXCITATORY); \}

Configuração das Células Granulares $*$

package nemos.simulations.bulb.config;

import java.util. List;

import nemos.config. ConfigForEach;

import nemos.neurons. Neuron;

import nemos.simulations.bulb. Granule;

$$
\text { @Override }
$$
Granule granular $=$ (Granule) obj; granular . set Type ( Neuron. INHIBITORY);

\}

* Conexão entre Mitral e Granulares

public class ConfigGranulares extends ConfigForEach \{

public void configParameters(Object obj, List lst) \{ 
246

import java.util. LinkedList;

248 import java.util. List;

249 import nemos.math. Coordinate;

250 import nemos. simulations. bulb. Bulb;

251 import nemos.math. RandomGen;

252 import nemos. networks. NeuralNetwork;

253 import nemos.networks. NeuronPool;

254 import nemos. networks. connections. Connection Rule;

255 import nemos.neurons. Neuron;

256 import nemos. synapses. Synapse;

public class ConnectionM2G2M extends ConnectionRule \{ private Integer qtSynapses $=0$;

261 private Integer radialDistance $=0$;

$$
\text { public ConnectionM2G2M() \{ }
$$$$
\text { \} }
$$

public ConnectionM2G2M(int radialDistance, int qtSynapses) \{ this radialDistance $=$ radialDistance;

$$
\text { this.qtSynapses = qtSynapses; }
$$

\}

public List $<$ Synapse $>$ connect (NeuralNetwork netOri, NeuralNetwork netDest) \{

NeuronPool mitralsPool $=($ NeuronPool $)$ netOri;

NeuronPool granuliPool $=($ NeuronPool $)$ netDest;

Neuron mitral, granule;

Coordinate point;

List $<$ Synapse $>$ syList $=$ new LinkedList $<$ Synapse $>()$;

Synapse sy $=$ null ; 
278

279

280

281

282

283

284

285

286

287

288

289

290

291

292

293

294

295

296

297

298

299

300

301

302

303

304

305

306

307

308

309 for (Object mobj : mitralsPool.getList ()) \{ mitral $=($ Neuron $)$ mobj;

for (int $\mathrm{i}=0 ; \mathrm{i}<\operatorname{getQtSynapses}() ; \mathrm{i}++)\{$ point $=$ choosePoint ( mitralsPool.get AbsolutePosition (mitral), granuliPool.getAbsoluteCoordSize ( )); granule $=\operatorname{chooseCell}($ granuliPool, point $)$; sy $=$ makeConnection(mitral, granule);

if $($ sy $!=$ null $)$ syList . add ( sy);

\}

\}

return syList;

protected Coordinate choosePoint(Coordinate coord, Coordinate coordS RandomGen rnd $=$ Bulb.randBulb;

int $\mathrm{xinit}=\operatorname{coord} \cdot \operatorname{get} \mathrm{X}()-$ getRadialDistance ()$>0$ ?

coord $\cdot \operatorname{get} X()-\operatorname{get} R$ adialDistance ()$: 0$;

int yinit $=$ coord.getY ()$-\operatorname{get} R$ adialDistance ()$>0$ ?

$\operatorname{coord} \operatorname{get} Y()-\operatorname{get} R a d i a l D i s t a n c e(): 0$;

int $\mathrm{xfinal}=\operatorname{coord} \cdot \operatorname{get} \mathrm{X}()+\operatorname{getRadialDistance}()<$

coordSize.getX () ?

coord $\cdot \operatorname{get} X()+\operatorname{get} R a d i a l D i s t a n c e(): \operatorname{coordSize} \cdot \operatorname{get} X()$; int $y f i n a l=$ coord get $Y()+$ getRadialDistance ()$<$

coordSize.getY() ?

coord.getY ()$+\operatorname{get} R a d i a l D i s t a n c e():$ coordSize.getY () ;

int $\mathrm{x}=$ rnd.nextInt $(\mathrm{xfinal}-\mathrm{xinit})+$ xinit +1 ;

int $y=$ rnd.nextInt (yfinal - yinit $)+$ yinit +1 ; 
return new Coordinate $(\mathrm{x}, \mathrm{y}, 1)$; \}

protected Neuron chooseCell(NeuronPool pool, Coordinate point) \{ if $($ point $\cdot \operatorname{get} X()>$ pool.getAbsoluteCoordSize ()$\cdot \operatorname{get} X())\{$ point.setX ( pool.getAbsoluteCoordSize ().getX ( )); \} if (point.getY ()$>$ pool.getAbsoluteCoordSize ()$\cdot \operatorname{get}())\{$ point.setY ( pool.getAbsoluteCoordSize ().getY ( )); \} return pool.getNeuron(point);

\}

protected Synapse makeConnection(Neuron ori, Neuron dest) \{ List $<$ Synapse $>$ sydest $=$ dest $\cdot$ getSynapses () ;

for (Synapse sy : sydest) \{ if (sy.getSpikeSource ()$=$ ori) \{ return null;

\}

\}

Synapse $\mathrm{s}=$ getSynapseFactory (). createSynapse(ori, dest); dest.addSynapse (s, ori );

return $\mathrm{s}$;

\}

public Integer getQtSynapses() \{ return qtSynapses;

\}

public void setQtSynapses(Integer qtSynapses) \{ this.qtSynapses = qtSynapses; 
342

370

\section{public Integer getRadialDistance() \{} return radialDistance;

\}

public void setRadialDistance(Integer radialDistance) \{ this. radialDistance $=$ radialDistance; \}

\section{\}}

/*

* Conexão entre Granulares

* /

package nemos.simulations.bulb.config;

import java.util. LinkedList;

import java.util. List;

import nemos.math. Coordinate;

import nemos.networks. NeuralNetwork;

import nemos. networks. NeuronPool;

import nemos.neurons. Neuron;

import nemos.synapses. Synapse;

public class ConnectionG2G extends ConnectionM2G2M \{ super (radialDistance, qtSynapses); 
374

375
@ Override

public List $<$ Synapse $>$ connect (NeuralNetwork netOri, NeuralNetwork netDest) \{ NeuronPool granulePoolOri $=($ NeuronPool $)$ netOri; NeuronPool granulePoolDest $=($ NeuronPool $)$ netDest; Neuron granuleOri, granuleDest;

Coordinate point;

List $<$ Synapse $>$ syList $=$ new LinkedList $<$ Synapse $>()$; Synapse sy $=\mathbf{n u l l}$;

for (Object gobj : granulePoolOri.getList ()) \{ granuleOri $=($ Neuron $)$ gobj; for (int $\mathrm{i}=0 ; \mathrm{i}<\operatorname{getQtSynapses}() ; \mathrm{i}++)\{$ point $=$ choosePoint ( granulePoolOri.get AbsolutePosition (granuleOri), granulePoolDest . get AbsoluteCoordSize ( ) ); granuleDest $=\operatorname{chooseCell}($ granulePoolDest, point $)$; sy $=$ makeConnection(granuleOri, granuleDest $)$; syList . add ( sy);

\}

\}

return syList;

\}

\section{\}}

/*

* Sinapses Dendodendríticas

$* * *$

*/

package nemos.simulations.bulb.config; 
import nemos.simulations.bulb. Bulb;

import nemos.math. RandomGen;

import nemos. networks. connections. SynapseFactory;

import nemos.neurons. Neuron;

import nemos.synapses. AlphaMgSynapse;

import nemos.synapses. AlphaSynapse;

import nemos.synapses . dynamics. DynamicsM;

import nemos.synapses. Synapse;

public class SyFactoryDendodendritic implements SynapseFactory \{ private boolean dynamics = false;

$$
\text { public SyFactoryDendodendritic () }\{
$$$$
\text { \} }
$$

public SyFactoryDendodendritic(boolean dynamics) \{ this.dynamics $=$ dynamics;

\}

public Synapse createSynapse(Neuron neuronA, Neuron neuronB) \{ return createSynapse (neuronA, neuronB);

\}

private Synapse createSynapse(Neuron neuronA, Neuron neuronB) \{ RandomGen rnd $=$ Bulb.randBulb;

AlphaSynapse ampa $=$ new AlphaSynapse (); ampa.setName ("ampa_-_" + neuronA.getName ()$+"$ " $"+$ neuronB $\cdot \operatorname{getName}())$; ampa.setGmax (rnd . nextGaussian (1.0, 0.05$)$ ); ampa.setTau1 (rnd.nextGaussian (5.5, 1.2)); ampa.setTau2 (1.0); 
ampa.setE (0.0);

ampa.setDelay (rnd . nextGaussian (1.8, 0.3$)$ );

ampa.setSpikeSource (neuronA);

neuronB . addSynapse (ampa);

ampa. setWeight (rnd. nextGaussian (Bulb. wscale $* 1.5$, Bulb. wscale $* 0.5$

AlphaMgSynapse nmda = new AlphaMgSynapse ();

nmda. setName ("nmda___" +

neuronA.getName ()$+"$ " $"+$ neuronB $\cdot \operatorname{getName}())$;

nmda.setGmax (rnd . nextGaussian (0.593, 0.05$)$ );

nmda. setTau1 (rnd.nextGaussian (343.0, 48.0));

nmda. set Tau2 (2.0);

nmda. setE ( 0.0$)$;

nmda. setDelay (rnd. nextGaussian (1.8, 0.3$))$;

nmda. $\operatorname{set} \operatorname{Mg}(1.0)$;

nmda. setSpikeSource (neuronA);

neuronB . addSynapse (nmda);

nmda. setWeight (rnd . nextGaussian (

Bulb. wscale $* 1.0$, Bulb. wscale $* 0.2))$;

AlphaSynapse gaba $=$ new AlphaSynapse ();

gaba.setName ("gaba_-_" +

neuronB.getName ()$+"$ " $"+\operatorname{neuronA} \cdot \operatorname{getName}())$;

gaba.setGmax (rnd.nextGaussian (0.6, 0.2$))$;

gaba.setTau1 (rnd.nextGaussian (18.0, 1.0));

gaba.setTau2 (4.0);

gaba.setE ( -80.0$)$;

gaba.setDelay ( 0.6$)$;

gaba.setSpikeSource (neuronB);

neuronA . addSynapse (gaba);

gaba.setWeight (rnd. nextGaussian(

Bulb. wscale $* 1.5$, Bulb. wscale $* 0.5))$; 
470

471

472

473

474

475

476

477

478

479

480

481

482

483

484

485

486

487

488

489

490

491

492

493

494

495

496

497

498

499

500

$501\}$ return gaba;

\}

public void addDynamics(Synapse sy) \{

DynamicsM dy;

Neuron preNeuron $=($ Neuron $)$ sy $\cdot$ getSpikeSource () ;

Neuron posNeuron $=$ sy $\cdot \operatorname{getPosNeuron}()$;

$\mathrm{dy}=$ new DynamicsM () ;

if (preNeuron.isExcitatory () \&\& posNeuron.isInhibitory ()) \{ dy. setU (1.0);

dy . setD (Math . abs (Bulb . randBulb . nextGaussian (125, 60)));

dy.setF (Math.abs (Bulb.randBulb.nextGaussian (1200, 600)));

\} else if (preNeuron. is Inhibitory () \&\& posNeuron.isExcitatory ()$)$ dy. setU (1.0);

dy. setD (Math.abs (Bulb . randBulb . nextGaussian (144, 72 )));

dy. setF (Math.abs (Bulb.randBulb.nextGaussian (60, 30)));

\} else if (preNeuron.isInhibitory () \&\& posNeuron.isInhibitory ( )) dy. setU (1.0);

dy . setD (Math . abs (Bulb . randBulb . nextGaussian (144, 72 )));

dy. setF (Math.abs (Bulb.randBulb.nextGaussian (60, 30)));

\}

sy. setDynamics (dy); 
502

/*

* Sinapses Inibitórias Granulares

$*$

package nemos.simulations.bulb.config;

import nemos.simulations.bulb. Bulb;

import nemos.math. RandomGen;

import nemos.networks. connections. SynapseFactory;

import nemos.neurons. Neuron;

import nemos.synapses. AlphaSynapse;

import nemos.synapses. Synapse;

\section{public class SyFactoryG2G implements SynapseFactory \{}

public Synapse createSynapse(Neuron neuronA, Neuron neuronB) \{ AlphaSynapse gaba $=$ new AlphaSynapse (); gaba.setName ("gaba" + neuronA.getName () + "_" + neuronB $\cdot \operatorname{getName}())$; gaba.setGmax (Bulb.randBulb .nextGaussian (0.6, 0.2)); gaba.setTau1 (Bulb.randBulb.nextGaussian (18.0, 1.0)); gaba.set Tau2( 4.0$)$; gaba.setE $(-70.0)$; gaba.setDelay (0.6); gaba.setSpikeSource (neuronB); neuronA . addSynapse (gaba); gaba. setWeight (Bulb . randBulb . nextGaussian( Bulb. wscale $* 5.0$, Bulb. wscale $* 1.5))$; return gaba; \}

西


534

$* * * * * * * * * * * * * * * * * * * * * * * * * * * * * * * * * * * * * * * * * * *$

Bulbo Olfatório

$*$

package nemos.simulations.bulb;

import java.util. LinkedList;

import java.util. List;

import nemos.math. Coordinate;

import nemos. managers. ModelManager;

import nemos.data. SpikeData;

import nemos. kernel. Time;

import nemos.config. Configuration;

import nemos.kernel.persistence. Persist;

import nemos.simulations.bulb. config. ConfigGranulares;

import nemos.simulations.bulb.config. ConfigMitrais;

import nemos.simulations. bulb.config. ConnectionG2G;

import nemos.simulations.bulb. config. ConnectionM2G2M;

import nemos.simulations.bulb.config. SyFactoryDendodendritic;

import nemos.simulations.bulb. config. SyFactoryG2G;

import nemos.math. RandomGen;

import nemos.networks. NeuralMicrocircuit;

import nemos. networks. NeuronPool;

import nemos.networks. connections. ConnectionRule;

import nemos.networks. connections. SynapseFactory;

import nemos. neurons. Neuron;

import nemos.synapses.dynamics. DynamicsM;

import nemos.synapses. Synapse;

import nemos.tools. SpikeTools; 
566

593

594

595

596

597

*@author lucasfigueira

*/

public class Bulb extends NeuralMicrocircuit \{

public static RandomGen randBulb = new RandomGen();

public static Double wscale $=1.0$;

private int numMitrais $=10 * 10$;

private int numGranulares $=20 * 20$;

private Configuration configGranuli = new ConfigGranulares ();

private Configuration configMitrals = new ConfigMitrais ();

private ConnectionRule connectionM2G2M =

new ConnectionM2G2M $(9,60)$;

private ConnectionRule connectionG2G = new ConnectionG2G $(4,12)$;

private SynapseFactory syDendodendritic =

new SyFactoryDendodendritic ();

private SynapseFactory syG2G = new SyFactoryG2G();

private String modelMitral = "nemos.simulations.bulb. Mitral"; private String modelGranule = "nemos.simulations.bulb. Granule";

public Bulb(String name) \{

super (name);

589
58

public int getNumMitrals () \{

return numMitrais;

\}


598

599

600

601

602

603

604

605

606

607

608

609

610

611

612

613

614

615

616

617

618

619

620

621

622

623

624

625

626

627

628

629

public void setNumMitrals (int numMitrals) \{

this.numMitrais = numMitrals;

\}

public int getNumGranuli() \{

return numGranulares;

\}

public void setNumGranuli(int numGanuli) \{

this.numGranulares $=$ numGanuli;

\}

public Configuration getConfigGranuli() \{

return configGranuli;

\}

public void setConfigGranuli(Configuration configGranuli) \{ this. configGranuli = configGranuli;

\}

public Configuration getConfigMitrals () \{

return configMitrals;

\}

public void setConfigMitrals (Configuration configMitrals) \{ this.configMitrals = configMitrals;

\}

public ConnectionRule getConnectionM2G2M() \{

return connection $2 \mathrm{G} 2 \mathrm{M}$;

\} 
653

654

655

656

657

658

659

660

661

public void setConnectionM2G2M(ConnectionRule connectionM2G2M) \{ this . connectionM2G2M = connectionM2G2M; \}

public ConnectionRule getConnectionG2G() \{ return connection $\mathrm{G} 2 \mathrm{G}$;

\}

public void setConnection $\mathrm{G} 2 \mathrm{G}$ (ConnectionRule connectionG2G) \{ this . connection $22 \mathrm{G}=$ connection $\mathrm{G} 2 \mathrm{G}$;

\}

public SynapseFactory getSyDendodendritic() \{ return syDendodendritic;

\}

public void setSyDendodendritic (SynapseFactory syDendodendritic) \{ this.syDendodendritic $=$ syDendodendritic;

\}

public SynapseFactory getSyG2G() \{ return syG2G;

\}

public void setSyG2G(SynapseFactory syG2G) \{ this. syG2G = syG2G;

\}

public void configAndConnect () \{

// criar células mitrais

List mitrais $=$ ModelManager.createModel (modelMitral, numMitrais, " mitrals" ); 
663

List granulares $=$ ModelManager. createModel (modelGranule,

666 numGranulares , "granuli " );

668

NeuronPool mitrais $\mathrm{P}=$ NeuronPool.createNeuronPool(mitrais new Coordinate(sqrmitral, sqrmitral, 1), new Coordinate $(0,0,0)$, space, space, 1$)$;

684

685

mitraisP . setName("Mitral_Layer");

NeuronPool granulares $\mathrm{P}=$ NeuronPool.createNeuronPool(granulares, new Coordinate (sqrgranule, sqrgranule, 1), new Coordinate $(0,0,1)$, $1,1,1)$

692

693

connectionM2G2M . setSynapseFactory (syDendodendritic); connectionM2G2M . connect (mitraisP , granularesP) ; connection $\mathrm{G} 2 \mathrm{G}$. set SynapseFactory (syG2G); connectionG2G. connect (granularesP , granularesP );

addPool (mitraisP ); 
698 return ModelManager. createModel(modelMitral, numMitrais);

protected List createGranuli() \{ return ModelManager.createModel(modelGranule, numGranulares); \} return modelMitral;

$$
\}
$$

public void setModelMitral(String modelMitral) \{ this. modelMitral $=$ modelMitral;

$$
\}
$$

$$
\text { public String getModelGranule () \{ }
$$
return modelGranule;

\}

public void setModelGranule(String modelGranule) \{ this . modelGranule = modelGranule;

\}

public void saveStatesPSP(String patt) \{ List $<$ SpikeData $>$ state $=$ getMicrocircuitStateSpikes ( ); SpikeTools.saveSpikesToAlphaFile(getName ()$+$ patt + ".dat", 
state, $1.0,30.0$

Time.globalTime.getInitialTime (),

Time.globalTime.getFinalTime(), Time.globalTime.

public void saveStates (String patt) \{

List $<$ SpikeData $>$ state $=$ getMicrocircuitStateSpikes (); SpikeTools.saveSpikesCircuitToSpikesCircuitBin (getName() + patt \}

public void saveTimeStates(String patt) \{ List $<$ SpikeData $>$ state $=$ getMicrocircuitStateSpikes ( ); SpikeTools.saveSpikesCircuitToFile(getName ()$+$ patt + ". dat", state, Time.globalTime.getInitialTime (), Time.globalTime.getFinalTime (), Time.globalTime. public void loadBulb(String fname) \{ List $1 \mathrm{t}=$ Persist.load (fname);

setName ( ( String) lt . get (0)); setNumMitrals ( ( Integer) lt . get (1)); setNumGranuli (( Integer ) lt . get (2)); setConfigGranuli (( Configuration) lt . get (3)); setConfigMitrals (( Configuration) lt .get (4)); setConnectionM2G2M ( ( ConnectionRule) lt .get (5)); setConnectionG2G (( ConnectionRule) lt . get (6)); setSyDendodendritic (( SynapseFactory) lt . get ( 7 )); setSyG2G (( SynapseFactory ) lt . get ( 8)); setModelMitral ( ( String) lt.get (9)); setModelGranule (( String) lt . get (10)); 
760

761

762

763

780

781

782

$783\}$
setDynamics (( Boolean)lt . get (11));

randBulb $=($ RandomGen $) l t \cdot \operatorname{get}(12)$;

randBulb.reset ();

public void saveBulb(String fname) \{

List ltcomp $=$ new LinkedList ();

ltcomp .add (getName ());

ltcomp .add (new Integer (numMitrais));

ltcomp.add(new Integer (numGranulares));

ltcomp .add (configGranuli );

ltcomp .add (configMitrals);

ltcomp a add (connection M2G2M);

ltcomp . add (connection G2G);

ltcomp . add (syDendodendritic);

ltcomp . add (syG2G);

ltcomp .add (modelMitral);

ltcomp . add (modelGranule);

ltcomp .add (new Boolean(dynamics));

ltcomp .add (Bulb .randBulb);

Persist.save(ltcomp, fname);

$82\}$

$$
\}
$$

西

